Universidad de Lima

Facultad de Ingeniería y Arquitectura

Carrera de Ingeniería Industrial

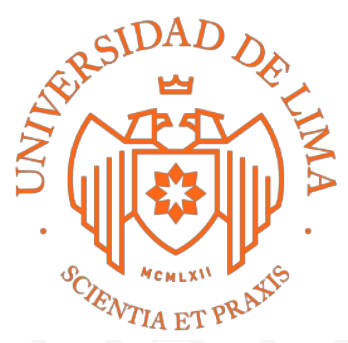

\title{
ESTUDIO DE PREFACTIBILIDAD PARA LA INSTALACIÓN DE UN BAR
}

\section{AUTOMATIZADO}

Trabajo de investigación para optar el Título Profesional de Ingeniero Industrial

\author{
Brian Bruce Guin Urmeneta \\ Código 20142431 \\ Carlos Eduardo Herbozo Vidal
}

Código 20142432

Asesor

Luis Moy Vargas

Lima - Perú

Junio de 2019 


\section{ESTUDIO DE PREFACTIBILIDAD PARA LA INSTALACIÓN DE UN BAR}

AUTOMATIZADO 


\section{TABLA DE CONTENIDO}

RESUMEN EJECUTIVO ...............................................................1

EXECUTIVE SUMMARY ....................................................................2

CAPÍTULO I: ASPECTOS GENERALES ..............................................3

1.1. Problemática de la Investigación..................................................... 3

1.2. Objetivos de la investigación .....................................................

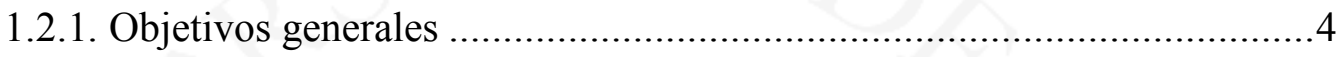

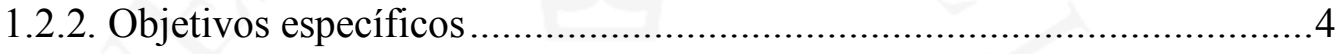

1.3. Justificación del tema ....................................................................

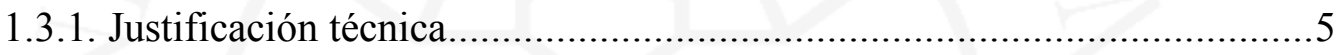

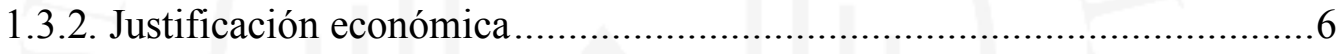

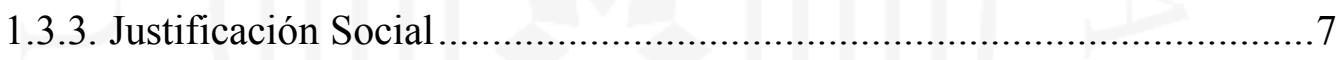

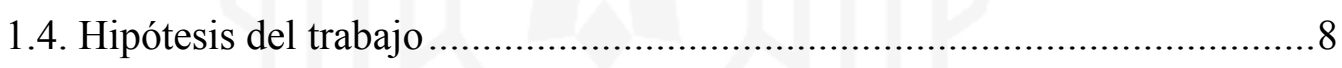

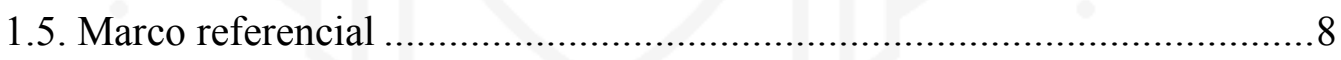

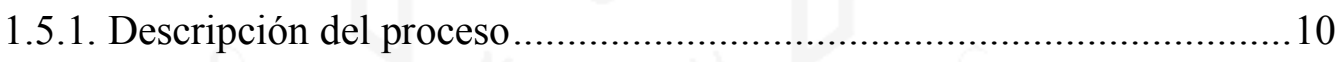

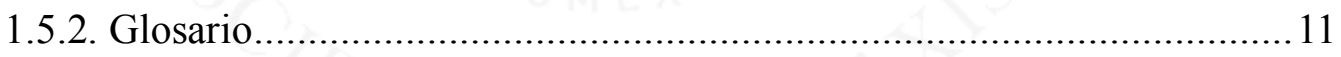

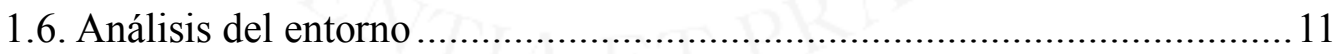

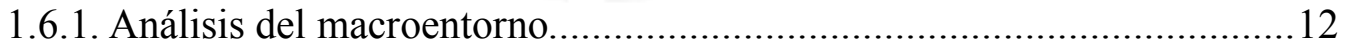

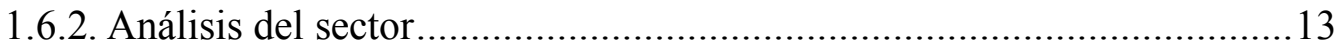

CAPÍTULO II: ESTUDIO DE MERCADO .......................................18

2.1. Aspectos generales del estudio de mercado ....................................... 18

2.1.1. Definición comercial del servicio.................................................. 18

2.1.2. Principales beneficios del servicio .............................................. 18

2.1.3. Macrolocalización del servicio..................................................24 
2.1.5. Determinación de la metodología que se empleará en la investigación de mercado .30

2.2. Análisis de la demanda .30

2.2.1. Data histórica del consumidor y sus patrones de consumo 30

2.2.2. Demanda potencial .33

2.3. Análisis de la oferta 34

2.3.1. Análisis de la competencia..... 35

2.3.1. Beneficios ofertados por los competidores directos 35

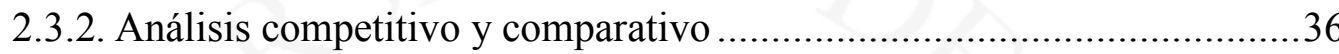

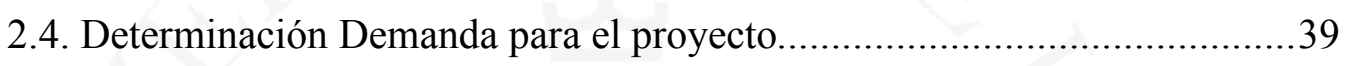

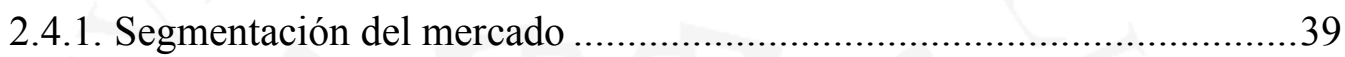

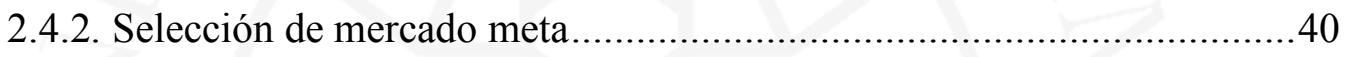

2.4.3. Demanda mediante fuentes primarias............................................... 40

2.4.4. Determinación de la participación de mercado para el proyecto ............42

2.5. Definición de estrategia de comercialización .......................................44

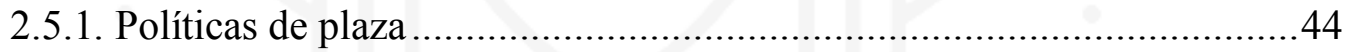

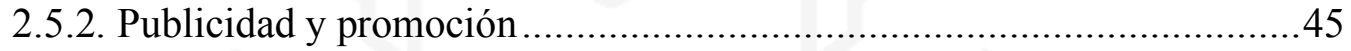

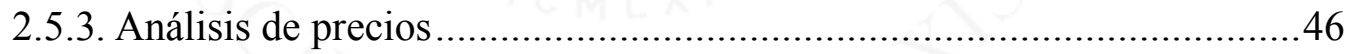

CAPÍTULO III: LOCALIZACIÓN DEL SERVICIO.............................49

3.1. Identificación y análisis detallado de los factores de microlocalización....49

3.2. Identificación y descripción de las alternativas de localización .................53

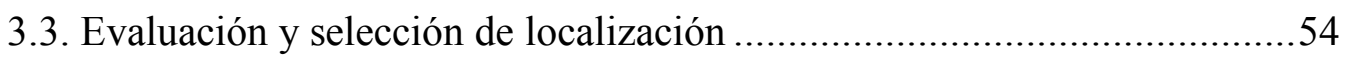

CAPÍTULO IV: DIMENSIONAMIENTO DEL SERVICIO .................57

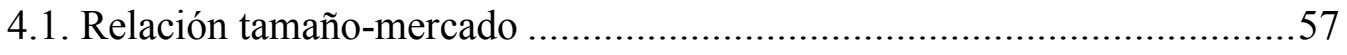

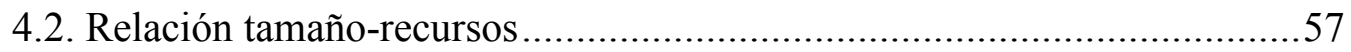

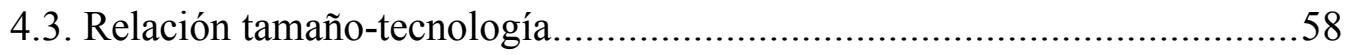


4.4. Relación tamaño-punto de equilibrio .60

4.5. Selección de la dimensión del servicio .61

CAPÍTULO V: INGENIERÍA DEL PROYECTO ..................................62

5.1. Proceso para la realización del servicio.................................................62

5.1.1. Descripción del proceso del servicio ................................................62

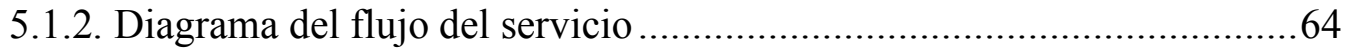

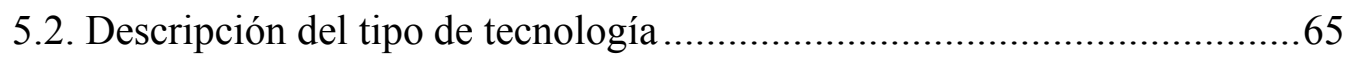

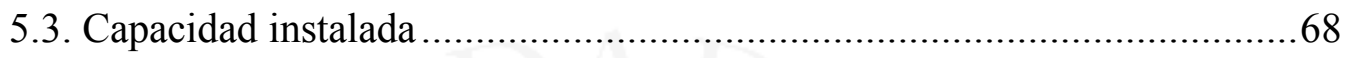

5.3.1. Identificación y descripción de los factores que intervienen en brindar el servicio .68

5.3.2. Determinación del factor limitante de la capacidad ............................70

5.3.3. Determinación del número de recursos del factor limitante ..................70 70

5.3.4. Determinación del número de recursos de los demás factores ...............73

5.3.5. Cálculo de la capacidad de atención.................................................. 73

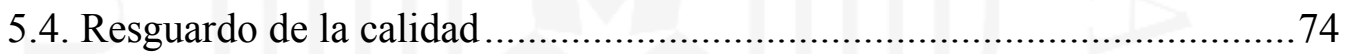

5.4.1. Calidad del proceso y del servicio...................................................... 74

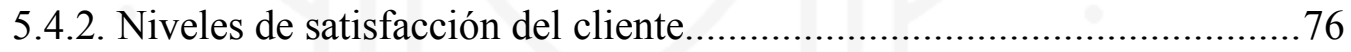

5.4.3. Medidas de resguardo de la calidad.................................................... 77

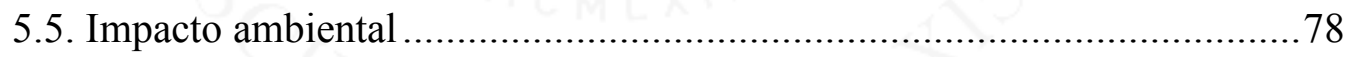

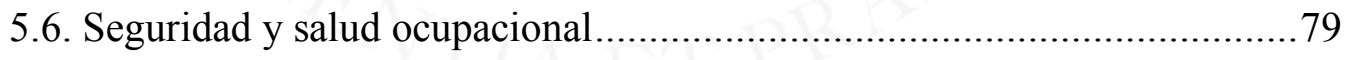

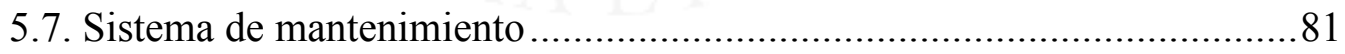

5.8. Programación de operaciones del negocio.......................................... 82

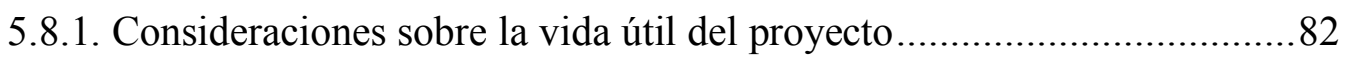

5.8.2. Programa de operaciones durante la vida útil del proyecto ................... 82

5.9. Requerimiento de Materiales, Personas y Servicios .............................. 84

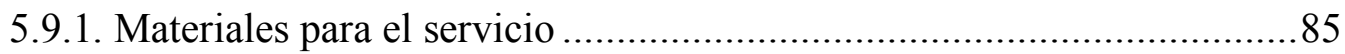

5.9.2. Determinación del requerimiento de personal de atención al cliente......87 
5.9.3. Servicios de terceros

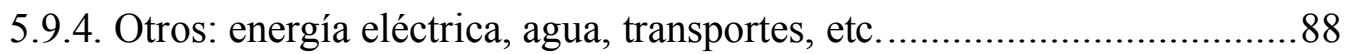

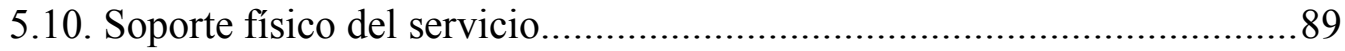

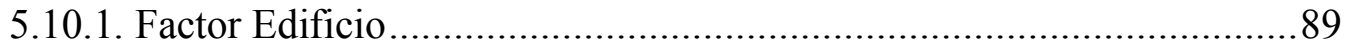

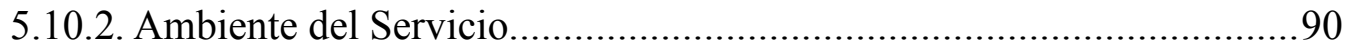

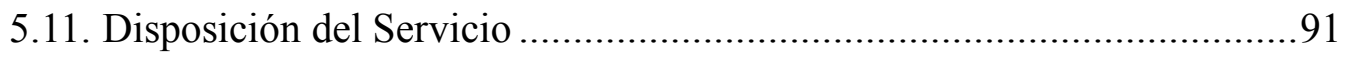

5.11.1. Disposición General................................................................... 91

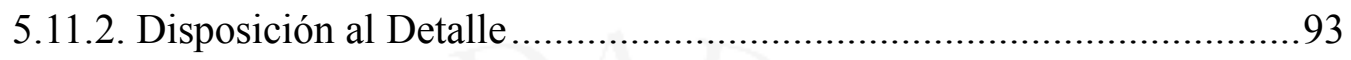

5.12. Cronograma de implementación del proyecto .....................................94

CAPÍTULO VI: ORGANIZACIÓN ADMINISTRATIVA ....................96

6.1. Formación de la organización empresarial ........................................96

6.2. Requerimiento de personal directivo, administrativo y de servicios..........98

6.3. Esquema de la estructura organizacional y funciones generales de los principales puestos

CAPÍTULO VII: ASPECTOS ECONÓMICOS 103

7.1. Inversiones 103

7.1.1. Estimación de las inversiones de largo plazo (tangibles e intangibles). 103

7.1.2. Estimación de las inversiones de corto plazo (capital de trabajo).........104

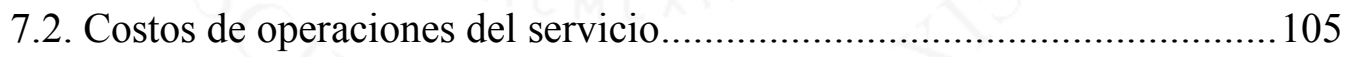

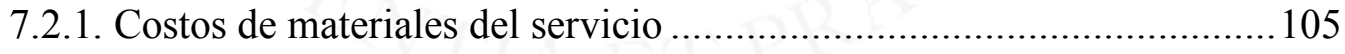

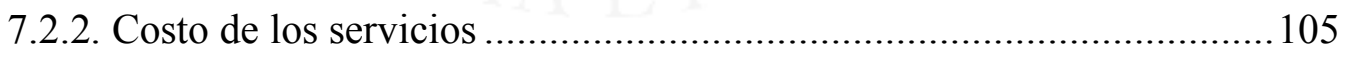

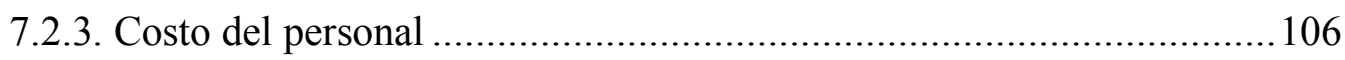

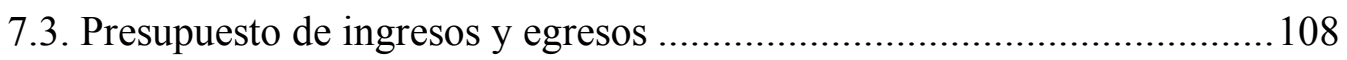

7.3.1. Presupuesto de ingreso por ventas............................................... 108

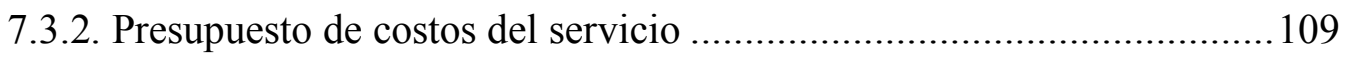

7.3.3. Presupuesto operativo de gastos generales ......................................... 109

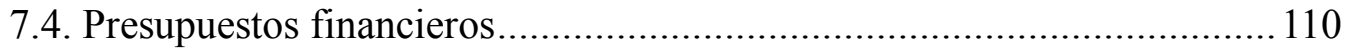


7.4.1. Presupuesto de servicio de deuda 110

7.4.2. Presupuesto de estado de resultados

7.4.3. Presupuesto de estado de situación financiera

7.5. Flujo de fondos netos...................................................................... 113

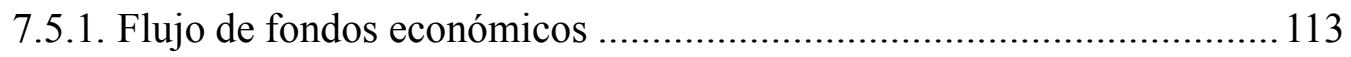

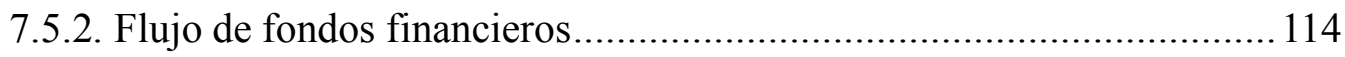

CAPÍTULO VIII: EVALUACIÓN ECONÓMICA Y FINANCIERA.. 116

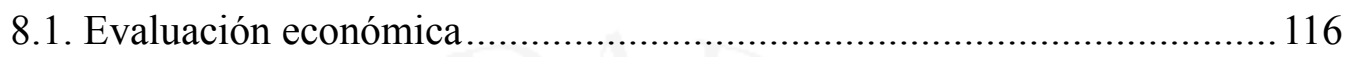

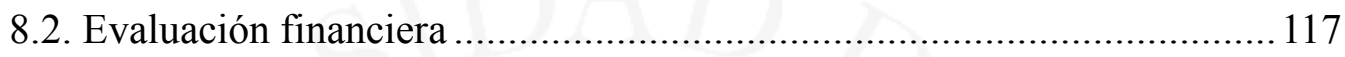

8.3. Análisis de los resultados económicos y financieros del proyecto............ 118

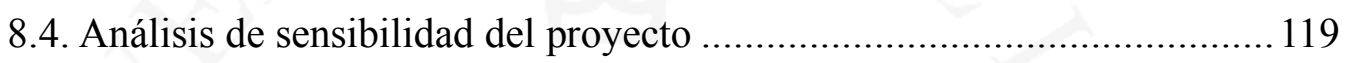

CAPÍTULO IX: EVALUACIÓN SOCIAL .....................................121

9.1. Identificación de las zonas y comunidades de influencia del proyecto.... 121

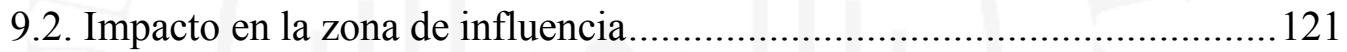

9.3. Impacto social del proyecto …........................................................... 122

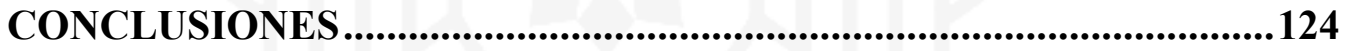

RECOMENDACIONES .....................................................................125

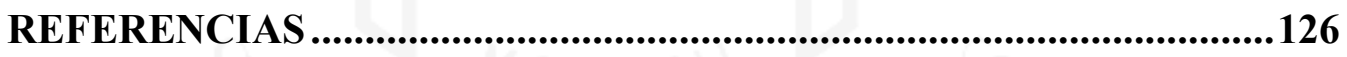

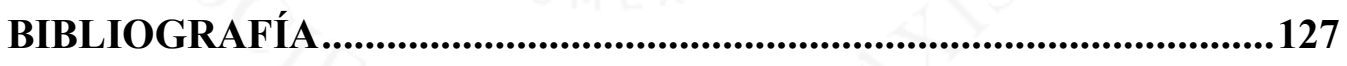

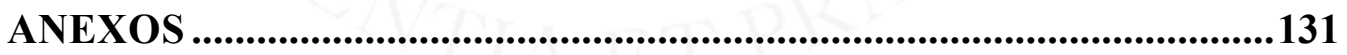




\section{ÍNDICE DE TABLAS}

Tabla 2.1 Modelo canvas del bar automatizado

Tabla 2.2 Consumo anual de bebidas alcohólicas per cápita mayor de edad en litros. .31

Tabla 2.3 Selección de ecuación de regresión 31

Tabla 2.4 Demanda proyectada anual de bebidas alcohólicas per cápita mayor de edad en litros .32

Tabla 2.5 Demanda anual en millones de litros, histórica y proyectada .33

Tabla 2.6 Demanda anual de bebidas alcohólicas on-trade per cápita, en litros34

Tabla 2.7 Matriz de enfrentamiento para análisis del perfil competitivo ..........37

Tabla 2.8 Matriz de perfil competitivo .37

Tabla 2.9 Resumen de pasos para la determinación de la demanda anual en soles

Tabla 2.10 Cálculo de la población alcanzada a través de redes sociales .46

Tabla 3.1 Matriz de enfrentamiento de factores de localización ......................54

Tabla 3.2 Resultado de análisis para el factor "Costo"....................................55

Tabla 3.3 Resultado de análisis para el factor "Cercanía a otros bares" ...........55

Tabla 3.4 Resultado de análisis para el factor "Área total" .............................55

Tabla 3.5 Resultado de análisis del factor "Licencias Municipales" ................55

Tabla 3.6 Resultados del procedimiento de jerarquía analítica (AHP) .............56

Tabla 4.1 Proyección de relación "Tamaño - Mercado"...................................57

Tabla 4.2 Proyección de los gastos fijos del negocio....................................60

Tabla 4.3 Margen de contribución y proporción a las ventas por producto ......61

Tabla 4.4 Determinación del punto de equilibrio............................................61

Tabla 5.1 Demanda en visitas por año......................................................... 71

Tabla 5.2 Cálculo de cantidad de módulos de preparación de bebidas .............71

Tabla 5.3 Cálculo de trabajadores en cocina ................................................ 72

Tabla 5.4 Cálculo del número de anfitriones ............................................... 72

Tabla 5.5 Capacidad de atención por actividad ............................................ 73

Tabla 5.6 Capacidad de atención del servicio............................................. 73

Tabla 5.7 Cuadro de especificaciones de calidad para bebidas ...................... 75 
Tabla 5.8 Cuadro de especificaciones de calidad para piqueos .......................76

Tabla 5.9 Matriz de aspectos e impactos ambientales.....................................78

Tabla 5.10 Análisis preliminar de riesgos.................................................. 80

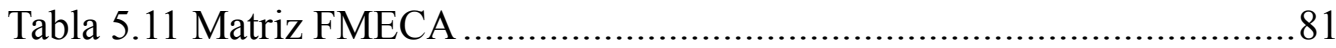

Tabla 5.12 Horarios de trabajo para el bar automatizado..............................84

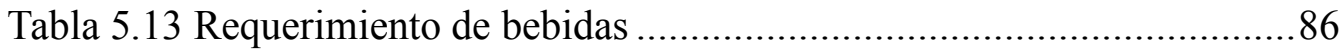

Tabla 5.14 Numeración de las áreas del servicio.........................................93

Tabla 7.1 Inversiones de largo plazo (Activo Fijo)....................................... 103

Tabla 7.2 Inversiones de corto plazo (Capital de Trabajo) ............................ 104

Tabla 7.3 Presupuesto de compras de materiales.......................................... 105

Tabla 7.4 Presupuesto de consumo de materiales .......................................... 105

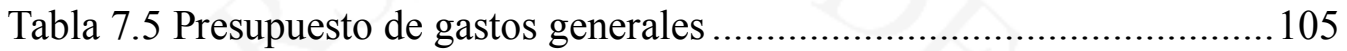

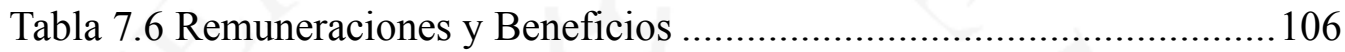

Tabla 7.7 Remuneraciones y beneficios (Continuación)............................... 107

Tabla 7.8 Presupuesto de mano de obra directa (MOD) ................................ 107

Tabla 7.9 Presupuesto de mano de obra indirecta (MOI) ............................. 108

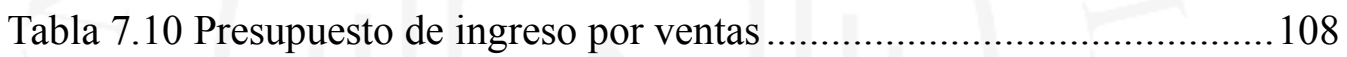

Tabla 7.11 Presupuesto de depreciación operativa .......................................109

Tabla 7.12 Presupuesto de pago de alquileres ........................................... 109

Tabla 7.13 Presupuesto de costo de ventas.................................................. 109

Tabla 7.14 Presupuesto de gastos administrativos ........................................ 109

Tabla 7.15 Presupuesto de gastos operativos............................................... 110

Tabla 7.16 Inversión requerida para un Bar Automatizado ........................... 110

Tabla 7.17 Presupuesto de servicio de deuda ............................................. 110

Tabla 7.18 Presupuesto de proyección del estado de resultados..................... 111

Tabla 7.19 Presupuesto de flujo de efectivo de corto plazo .......................... 112

Tabla 7.20 Presupuesto de estado de situación financiera proyectado........... 113

Tabla 7.21 Flujo de fondos económicos ................................................... 114

Tabla 7.22 Presupuesto del flujo de fondos financieros ............................... 115

Tabla 8.1 Evaluación económica del proyecto ........................................... 116

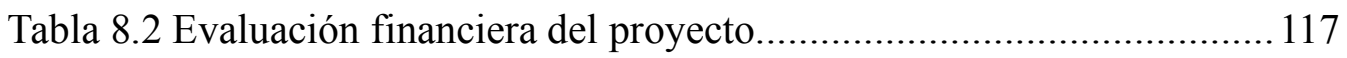

Tabla 9.1 Evaluación social del proyecto ................................................ 122

Tabla 9.2 Productividad de la mano de obra................................................ 123 


\section{ÍNDICE DE FIGURAS}

Figura 1.1 PBI per cápita en soles (Perú) ................................................

Figura 1.2 Ventas anuales de bebidas alcohólicas en millones de soles (Perú)...7

Figura 1.3 Diagrama de las 5 fuerzas del sector ......................................... 14

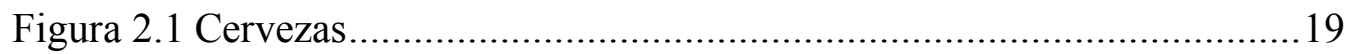

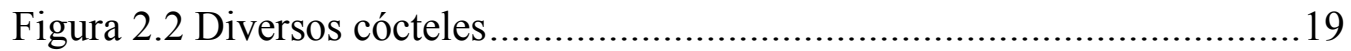

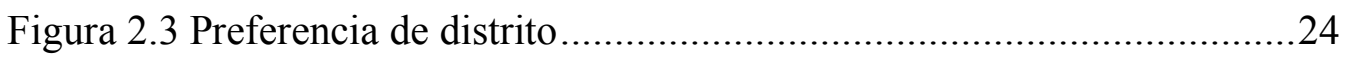

Figura 2.4 Regresión polinómica del consumo de bebidas alcohólicas .............32

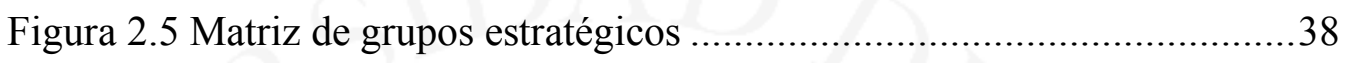

Figura 2.6 Mapa de bares, tabernas, discotecas y juguerías en Miraflores .......43

Figura 2.7 Elección de vía de publicidad y promoción.....................................45

Figura 2.8 Elección de precio para un cóctel personalizado ...........................47

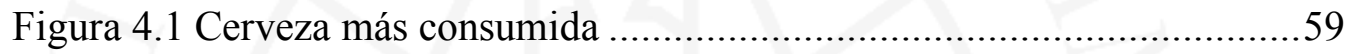

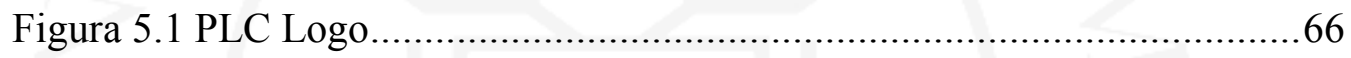

Figura 5.2 Desplegado de costos de tarifa BT5-A ..................................... 88

Diagrama 5.1 Diagrama trirelacional del bar automatizado..........................64

Diagrama 5.2 Esquema de servicio del bar automatizado...........................65

Diagrama 5.3 Diagrama de Gantt para la implementación del proyecto ..........94

Diagrama 6.1 Organigrama del bar automatizado ......................................99

Mapa 3.1 Distribución de bares y pubs en la zona aledaña al parque Kennedy 50 Mapa 3.2 Determinación del centro de gravedad de bares y pubs cercanos al parque Kennedy .51 


\section{ÍNDICE DE ANEXOS}

Anexo 1: Modelo de encuestas .............................................................. 132

Anexo 2: Presupuesto de requerimientos de materiales.............................. 137

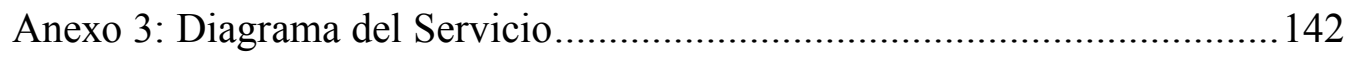

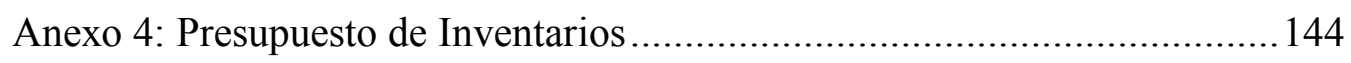

Anexo 5: Resultados de Encuestas............................................................. 147

Anexo 6: Herramientas de planeamiento y control de operaciones................. 154 


\section{RESUMEN EJECUTIVO}

El objetivo del presente trabajo es determinar la viabilidad técnica, económica y financiera del proyecto de instalación de un bar automatizado en la ciudad de lima. Para ello, se utilizaron las diferentes herramientas de ingeniería disponibles para la concepción, diseño, gestión y evaluación de un proyecto. En el primer capítulo, se trata de la problemática general, y de los motivos por los cuales surge la idea de automatizar un servicio de esta índole.

En los capítulos posteriores, se utilizan las técnicas de estudio de mercado para determinar si existe un mercado potencial, y cuantificar la demanda real del servicio. Para ello se utilizan técnicas como las encuestas y entrevistas con personal experto. Posteriormente, una vez definida la demanda, se procede a determinar la localización que permita optimizar las operaciones del servicio.

En los siguientes capítulos se procede a realizar la ingeniería del proyecto, desde la determinación del tamaño y la capacidad, hasta el análisis de necesidades de mantenimiento, outsourcing y seguridad. Así mismo, se procede con la generación de la disposición del espacio, y los cuatro ambientes que conforman el servicio principal. En el capítulo siguiente, se analizan los requerimientos de personal, ya sea operativo $u$ administrativo y las funciones que debe cumplir en la empresa.

Finalmente, en el capítulo VII, se realiza el análisis de los resultados proyectados del negocio, y se determina si la idea es económica y financieramente rentable. Para el caso del Bar automatizado, se obtuvo que, tanto en un escenario económico como en uno financiero, el negocio resulta rentable para los accionistas, por lo que se llega a la conclusión que también es viable. Lamentablemente, el análisis de sensibilidad demostró que los resultados son demasiado sensibles a un ligero cambio en la demanda del mercado, por lo que, como en cualquier servicio, es necesario mantener los más altos estándares de calidad en cuanto a atención directa al cliente. 


\section{EXECUTIVE SUMMARY}

Determining the technical, economic and financial viability of the installation of an Automated Bar in Lima, Peru is the main objective of this paper; multiple industrial engineering tools will be used throughout the investigation in order to do this. Furthermore, this paper will cover the entirety of the project's planning and evaluation process; this includes the bar's creation, design, management and even the economic and financial evaluation, to name a few steps that will be taken towards the goal of determining the project's viability. The first chapter talks about the initial motivation for the project, a problem that is waiting to be solved by the modernization of an industry that has yet to reach its maximum potential: the bar industry.

In the consequent chapters, market analysis techniques are used to determine the degree of interest that the automated bar would have and are later used to quantify the proposed service's real demand and even quantitatively choose a location to place the business in. Some of the aforementioned techniques include representative surveys, multiple expert opinions which help ground hypotheses into conservative expectations and election methods such as the Condorcet method.

In the following chapters, the size and capacity of the service is determined, maintenance needs, security efforts and outsourcing requirements are identified. Likewise, the locale's layout is defined, including the 4 different environments that make up the bar's unique value proposition. Additionally, operational and administrative personnel requirements are analyzed and their respective functions are set.

Finally, financial and economic viability analyses are held in the last chapter. The results turn up to be very promising, as the bar is expected to be not only viable but also profitable for the investors and stakeholders. However, the sensitivity analysis showed that the business' results are vastly leveraged by the market's demand, which means that keeping the quality standards high is an absolute must in this business, a goal we intend to achieve through the automatization of the bartending process. 


\section{CAPÍTULO I: ASPECTOS GENERALES}

\subsection{Problemática de la Investigación}

La innovación y el desarrollo constante que ocurre en el mundo es un hecho innegable; nuevas invenciones y mejoras en técnicas y tecnologías ya existentes ocurren con una frecuencia que incrementa exponencialmente. Descripciones y teorías sobre estas tendencias no son raras y únicas; es más, son abundantes y aceptadas por la comunidad. Notables ejemplos de estas teorías son: la específica "Ley de Moore"1, o la más general "Ley de rendimientos acelerados de Kurzweil""2.

Consecuentemente, vivimos en un mundo que evoluciona constantemente y es por eso que es sumamente importante que todas las personas, negocios, y países dediquen gran parte de sus esfuerzos en innovar para no quedarse atrás de la competencia.

Las innovaciones se pueden dar en cualquier aspecto de la vida, grande o pequeño. La siguiente investigación es ejemplo de una innovación en un aspecto bastante preciso de la vida: los bares. La razón por la cual el tema del estudio será sobre un bar es porque es un tipo de servicio que no ha tenido ningún cambio sustancial desde hace bastante tiempo; por lo menos no el Perú.

En el mundo, sin embargo, los bares han estado cambiando recientemente gracias a nuevas tendencias tecnológicas como "The Internet of Things": ofreciendo mejoras como brazos robóticos que emulan movimientos y acrobacias de los más experimentados bartenders o como técnicas de detección de clientes frecuentes usadas para servirles sus bebidas favoritas incluso antes de que lleguen a la barra.

La motivación principal para la siguiente investigación es la rotunda diferencia entre la sofisticación de los bares peruanos y la de los bares del resto del mundo. Especialmente porque el Perú es un país que tiene las bebidas alcohólicas muy

\footnotetext{
${ }^{1}$ Ley que describe la duplicación del número de transistores usados en circuitos integrados cada año desde la invención de estos últimos.

${ }^{2}$ Ley que describe el desarrollo exponencial de la tecnología en el tiempo.
} 
incorporadas en su cultura, la industria de las bebidas alcohólicas y la misma economía peruana ha estado en un constante crecimiento desde hace varios años.

Por todas las razones anteriormente expuestas, simplemente no tiene sentido no tratar de innovar dentro de este sector para tratar de mantenernos al tanto de las nuevas tendencias mundiales. La siguiente investigación nacen dos interrogantes presentadas al considerar todos los factores previamente mencionados: ¿Existen las condiciones del mercado necesarias para instalar y operar un bar automatizado en Lima, Perú? ¿Y Será económicamente y financieramente viable? Para poder responder dichas preguntas, se tendrán que determinar: el lugar óptimo dentro de Lima para ubicar el bar, la tecnología a utilizar, la disposición del local, la demanda que tendrá el servicio, etc. Todos estos temas se tratarán a lo largo de la investigación.

\subsection{Objetivos de la investigación}

\subsubsection{Objetivos generales}

La innovación constante puede llegar a alterar, crear o refinar las costumbres de poblaciones enteras. Sin embargo, son estas mismas personas las que decidirán si es que cierta innovación tendrá impacto en sus futuras costumbres ya que si la innovación es de su agrado, la acogerán y si no lo es, la descartarán. Es por esto que, tomando el punto de vista de un empresario, si es que se quiere instalar un servicio u ofrecer un producto innovador, es vital hacer investigaciones previas para poder determinar si es que dicha innovación será acogida por el público o no y como consecuencia, si es que el proyecto será viable financiera y económicamente.

Como consecuencia, el objetivo general de la siguiente investigación será: Determinar la viabilidad económica y financiera de instalar y operar un bar automatizado en Lima, Perú. La razón por la cual este será el objetivo general es porque al cumplir este objetivo se podrá saber si es que el proyecto de instalar un bar automatizado será realizable.

\subsubsection{Objetivos específicos}

A manera de facilitar el cumplimiento del objetivo general se plantearán múltiples objetivos específicos. 
Primero objetivo específico: Establecer los aspectos generales del servicio y determinar si el entorno es favorable para su instalación.

Segundo objetivo específico: Determinar la demanda potencial del bar automatizado y el mejor método para maximizarla.

Tercer objetivo específico: Determinar el mejor distrito para instalar y operar un bar automatizado en Lima, Perú (entre Barranco, Miraflores y San Isidro).

Cuarto objetivo específico: Averiguar el diseño, disposición y servicios secundarios óptimos que deberá tener el bar automatizado para conseguir la aceptación y preferencia del público peruano en lugar del bar tradicional.

Quinto objetivo específico: Estudiar la tecnología necesaria para la instalación y operación de un bar automatizado en Lima, Perú.

Sexto objetivo específico: Establecer la mejor estructura organizacional de la empresa.

Séptimo objetivo específico: Optimizar la estructura de costos que se tendrá que implementar para incrementar la viabilidad económica y financiera del bar automatizado.

Octavo objetivo específico: Determinar la viabilidad económica y financiera del servicio.

Noveno objetivo específico: Determinar si la instalación de un bar automatizado es socialmente responsable, además de ser económicamente viable.

Todos estos objetivos específicos ayudarán a guiar la investigación al hacerla más estructurada y organizada. Cuando los objetivos específicos se hayan completado, se facilitará la determinación de la viabilidad de la implementación del bar automatizado en Lima, Perú.

\subsection{Justificación del tema}

\subsubsection{Justificación técnica}

La tecnología de transporte de líquidos no es nada nueva, ha sido usada por sinfín de industrias desde hace cientos de años. Ejemplos de estas industrias son: industria cervecera, industria láctea, etc. Industrias embotelladoras en general. 
Esto quiere decir que un bar muy fácilmente podría adaptar esta tecnología, reduciéndola en escala, para así crear un tipo de bar innovador donde se le hace un bypass directo al bartender.

La maquinaria para utilizar está disponible en el Perú ya que es la misma tecnología que se utiliza en industrias en donde se necesiten mezclar líquidos de manera precisa como por ejemplo la industria cervecera, la de gaseosas, la láctea, etc.

Ya que el objetivo es poder suministrar diferentes insumos líquidos de manera precisa, la maquinaria necesaria podría incluir sensores de nivel, de presión y de temperatura. Tanto como diferentes actuadores que puedan controlar la cantidad de líquido suministrado; existen varios actuadores capaces de realizar esta tarea: electroválvulas On-Off, electro-válvulas servoaccionadas, etc. Algunos son más complicados y costos que otros, es por eso que más adelante se decidirá la tecnología exacta que convenga utilizar para implementar el proyecto.

\subsubsection{Justificación económica}

El PBI y PBI per cápita peruano ha estado experimentando un creciendo constante desde hace más de 10 años, como se puede apreciar en la Figura 1.1 a continuación. Este crecimiento hace que Perú sea un país muy atractivo para la implementación de servicios innovadores. Esto se debe a que, con mayor poder adquisitivo, las personas suelen estar dispuestas para probar servicios y productos novedosos en el país. Un claro ejemplo es el caso de Krispy Kreme: doughnuts bastante más caras que Dunkin’ Donuts pero de calidad superior. La marca es novedosa en el Perú, esta es una de las razones por la cual está teniendo una respuesta tan buena del público.

Además, el sector de bebidas alcohólicas en el Perú también ha estado creciendo constantemente desde hace varios años y las tendencias muestran que seguirá creciendo en el futuro, desde ventas anuales de S/12 013200 en el año 2011 hasta S/ 17594800 en el año 2016; este crecimiento se presenta de forma gráfica a continuación en la Figura 1.1. Dichas razones incrementan el atractivo de implementar un bar en Perú ya que es un lugar donde abundan las bebidas alcohólicas. 
Figura 1.1

PBI per cápita en soles (Perú)

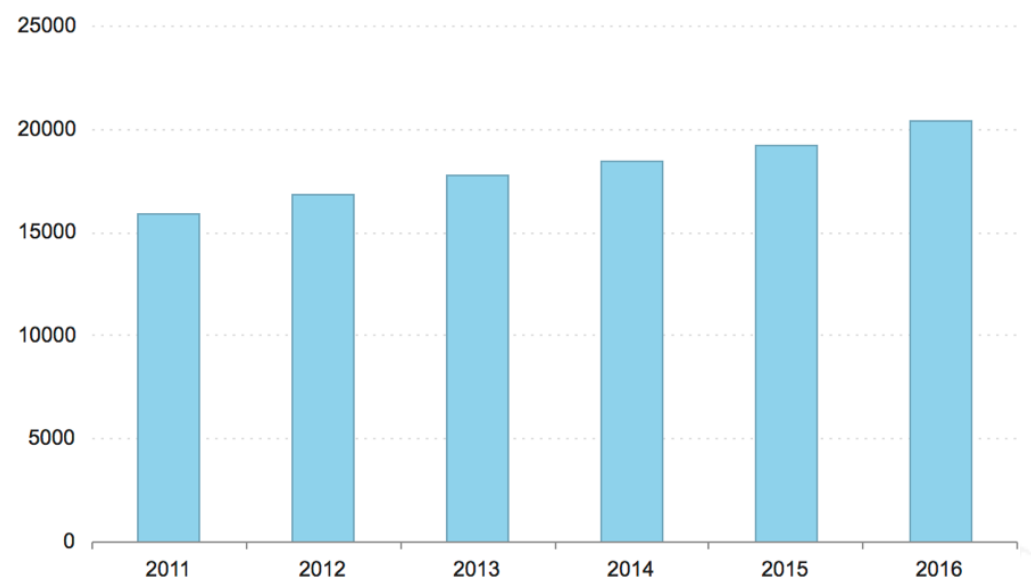

Fuente: Euromonitor (2017)

Figura 1.2

Ventas anuales de bebidas alcohólicas en millones de soles (Perú)

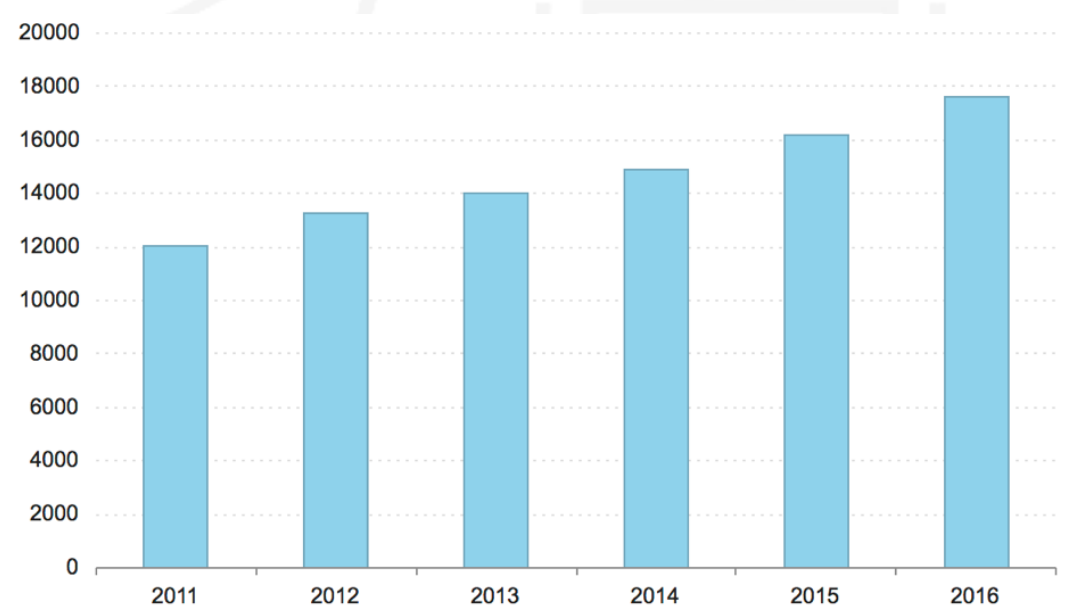

Fuente: Euromonitor (2017)

\subsubsection{Justificación Social}

Es posible que la estructura tradicional de el bar cambie por completo al evitar las barras con bartender. El error humano se eliminaría: las bebidas podrán ser homogéneas o personalizadas con gran precisión, el tiempo de espera para obtener la bebida que pidió el cliente se reduciría drásticamente, etc.

Es importante recalcar la importancia del incremento en seguridad al implementar 
un bar automatizado. Como se mencionó previamente, tener un bar automatizado eliminaría el error humano, esto quiere decir que sobornar al bartender para que dope alguna bebida sería imposible. Además, los clientes siempre tendrían la seguridad de que su bebida no ha sido comprometida ya que ninguna persona aparte del consumidor toca la bebida ni el vaso/copa antes de ser entregada para su consumo. Esto ayudará a combatir el peligro de las conocidas "peperas", mujeres criminales que colocan "pepas" en las bebidas de hombres incautos para luego seducirlos y robarles dinero y objetos de valor.

También es posible que esta nueva tecnología no revolucione a la industria completamente ya sea gracias a la calidad añadida por tener a otro humano sirviendo las bebidas o por alguna otra razón; lo que no se puede negar es que introduciendo este nuevo modelo de bar, se le estaría dando más opciones a los consumidores y eso tiene mucho valor para la sociedad.

Adicionalmente, la implementación del bar automático ayudaría a la sociedad peruana mediante la creación de empleos, si bien no en la barra, en otros trabajos con otras responsabilidades como ayudar en la caja para enseñarles a los nuevos clientes como funciona el autoservicio, bouncers y personas de seguridad, limpieza, entretenedores, etc.

\subsection{Hipótesis del trabajo}

Es factible y viable financiera, económica, social y tecnológicamente, instalar y operar un bar automatizado en Lima, Perú.

\subsection{Marco referencial}

\section{Referencia 1: Automated Beverage Dispenser - Honors Research Projects}

Istocka, Sonya

Primavera 2015

Esta primera referencia propone un sistema dispensador automatizado de bebidas, que identifica al consumidor con ayuda de su smartphone y sirve su bebida favorita incluso antes de que llegue al bar. Se utilizará dicha investigación como modelo para definir los diferentes requisitos tecnológicos para la implementación del bar 
automatizado, con la diferencia que no tendrá que servir las bebidas antes que el cliente llegue al bar y estará más enfocado en la personalización de la bebida.

\section{Referencia 2: The Internet of Drinks - Lab-based Research for the Taste of It}

Lewandowski M., Schmidt K., Kielhorn C., Uckelmann D. 2012

De manera similar, esta referencia investiga diferentes maneras de integrar tecnologías RFID e Internet of Things a aplicaciones con bebidas. Por lo tanto, se utilizará como modelo de los requisitos tecnológicos de un bar que pueda servir bebidas automáticamente luego de un proceso de personalización por parte del cliente.

Referencia 3: Aplicación de métodos de localización para un restaurant-bar temático en la isla de Tenerife - Tesis Profesional

María del Carmen Martínez Morán, Vanessa Pedraza Armenta 2004

Esta tercera referencia trata con los diferentes métodos de localización para decidir la ubicación de un restaurant-bar temático. Se utilizará como referencia de posibles métodos a emplear para la etapa de localización del servicio. Es una referencia relevante ya que el servicio presentado en esta tesis se encuentra en el mismo sector que el servicio propuesto.

Referencia 4: Choosing Among Alternative Service Delivery Modes: An Investigation of Customer Trial of Self-Service Technologies

Matthew L. Meuter, Mary Jo Bitner, Amy L. Ostrom, Stephen W. Brown 2005

La cuarta referencia trata sobre pruebas de tecnologías de autoservicio en clientes y la manera en la que las empresas las emplean para entender las nuevas necesidades de las personas y así definir las mejores propuestas de valor posibles para el cliente moderno. Esta referencia servirá para analizar el aumento de los autoservicios en los 
negocios y sirve como justificación para la implementación de los módulos de autoservicio en el bar.

\section{Referencia 5: Self-Service Shopping Grows in Popularity, According to Cisco Study - Cisco Technology News (Article) \\ Cisco (Cisco® Customer Experience Report) \\ 2013}

Finalmente, esta ultima referencia sirve como evidencia que el autoservicio, como negocio, está creciendo en popularidad. A pesar de ser un modelo de negocio relativamente nuevo para el Perú, es uno que se beneficiará grandemente por este crecimiento en popularidad.

\subsubsection{Descripción del proceso}

El bar será automatizado de la siguiente manera:

- El cliente podrá seleccionar la bebida que desee gracias a una interfaz táctil de comunicación, pudiendo personalizar las proporciones de los insumos y la cantidad total de bebida a preparar.

- La interfaz solicitará el pago con tarjeta de crédito, efectivo o con el celular.

- Una vez pagada la bebida, el bar procederá a servirla abriendo las diferentes válvulas de los insumos guardados en los dispensadores en cascada por el tiempo necesario y se cerrarán las válvulas cuando la cantidad de cada insumo haya sido suministrada.

- Se esperará a que el cliente retire el vaso/copa.

- Si se quiere servir una bebida con los mismos insumos, se podrá servir inmediatamente.

- Si se quiere servir una bebida con insumos completamente diferentes, primero se deberá suministrar un corto chorro de agua o aire a presión para limpiar la pequeña tubería de mezcla. Después de este paso, el bar estará listo para servir otra bebida. 
Servicios adicionales del bar incluirán:

- Música, a veces en vivo.

- Juegos de mesa como: "Monopolio", cuatro en raya, "Uno", "Cards Against Humanity" y ajedrez

- Juegos de video (exclusivamente para jugar en grupo)

Diferentes ambientes adicionales que acomoden a diversos tipos de grupos.

\subsubsection{Glosario}

A continuación, se presentan definiciones de los términos de mayor importancia en el bar propuesto. Estos términos se refieren tanto al proceso de un bar normal, como a la parte automatizada del servicio.

Sensor: Instrumento que detecta un tipo específico de señal y lo traduce a pulsos eléctricos que sirven de mensaje para comunicarse con el controlador especializado.

Electroválvula: Tipo de actuador, encargado de controlar el flujo de un líquido o un gas. Dispensador en Cascada: Tanque para almacenar un fluido, será de vidrio o acrílico.

Servomotor: Tipo de motor de alta precisión, especializado en rotaciones pequeñas medidas en grados o velocidades de giro precisas y relativamente lentas.

Barra: Mostrador del bar, sobre el cual los bartenders preparan y entregan el pedido al cliente.

Bartender/barman: Persona encargada de atender la barra; mezclar cocteles, servir tragos cortos, cerveza, agua, etc. para los clientes.

Bartending: El proceso de mezcla, preparación y servicio en la barra del bar.

\subsection{Análisis del entorno}

Ya definido el distrito donde el bar estará ubicado, se puede analizar si es que el entorno que este distrito conlleva será el apropiado para establecer es servicio propuesto. El análisis utilizará diferentes herramientas como el análisis PEST, el análisis de las fuerzas del mercado de Porter y la Matriz de Evaluación de Factores Externos en ese orden. 


\subsubsection{Análisis del macroentorno}

A continuación, se desarrollará un análisis PEST para poder entender mejor el entorno de Miraflores y poder determinar si es que será viable localizar el bar en este distrito.

\section{Factores Políticos}

- Aumento de facilidad para conseguir prestamos

- Prórroga de pago de IGV por 3 meses para MYPES

- Promoción de actividades culturales para fomentar el turismo con PromPerú

\section{Factores Económicos}

- PBI per cápita en aumento desde hace más de 10 años

- Población económicamente activa: 43,557 personas

- Ingreso familiar per cápita: S/ 953.4

- Aumento de salario mínimo a S/ 850 en el año 2016 aumenta el poder de adquisición del peruano/miraflorino

\section{Factores Sociales}

- $62 \%$ de la población miraflorina está conformada por jóvenes adultos y adultos (18-59 años)

- Aumento de interés en servicios ágiles con tiempos de atención cada vez más rápidos debido a la costumbre de la velocidad del mundo digital

- $93 \%$ de peruanos usan redes sociales para buscar información de interés, esto ayuda a la exposición de las empresas hacia potenciales clientes de forma económica y de poco esfuerzo

- Aumento en la utilización de electrodomésticos inteligentes de preparación de bebidas como cafeteras Nestle Dolce Gusto, Nespresso, etc.

- Popularización de la tendencia "Maker", donde las personas comunes muestran mayor interés por proyectos tecnológico, negocios independientes automatizados o tecnológicos y negocios novedosos 


\section{Factores Tecnológicos}

- Avances tecnológicos cada vez mas frecuentes y aumento en la disponibilidad de las nuevas tecnologías en el Perú como la tecnología Internet of Things, donde objetos comunes se conectan entre si y con procesadores convirtiéndolos en una red.

- Aumento en disponibilidad de microcontroladores baratos y versátiles como Arduino o Raspberry Pi que facilitan la creación de productos y servicios novedosos.

Tras este análisis se puede concluir que la situación de Miraflores y del Perú en sí, es favorable para la implementación de nuevos negocios, proyectos y de nuevas inversiones. Este atractivo es especialmente fuerte para negocios centrados en la tecnología y la digitalización, lo cual es sumamente conveniente para el servicio propuesto gracias a que sería el bar mas tecnológico de Lima al momento de su implementación.

\subsubsection{Análisis del sector}

Para poder determinar la viabilidad del servicio de bar automatizado dentro del sector comercial de bebidas alcohólicas, se hará un análisis de las 5 fuerzas del sector basada en la teoría de Michael Porter. A continuación, se presentará un diagrama de las 5 fuerzas, representando la intensidad de las fuerzas como tamaños: 
Figura 1.3

Diagrama de las 5 fuerzas del sector

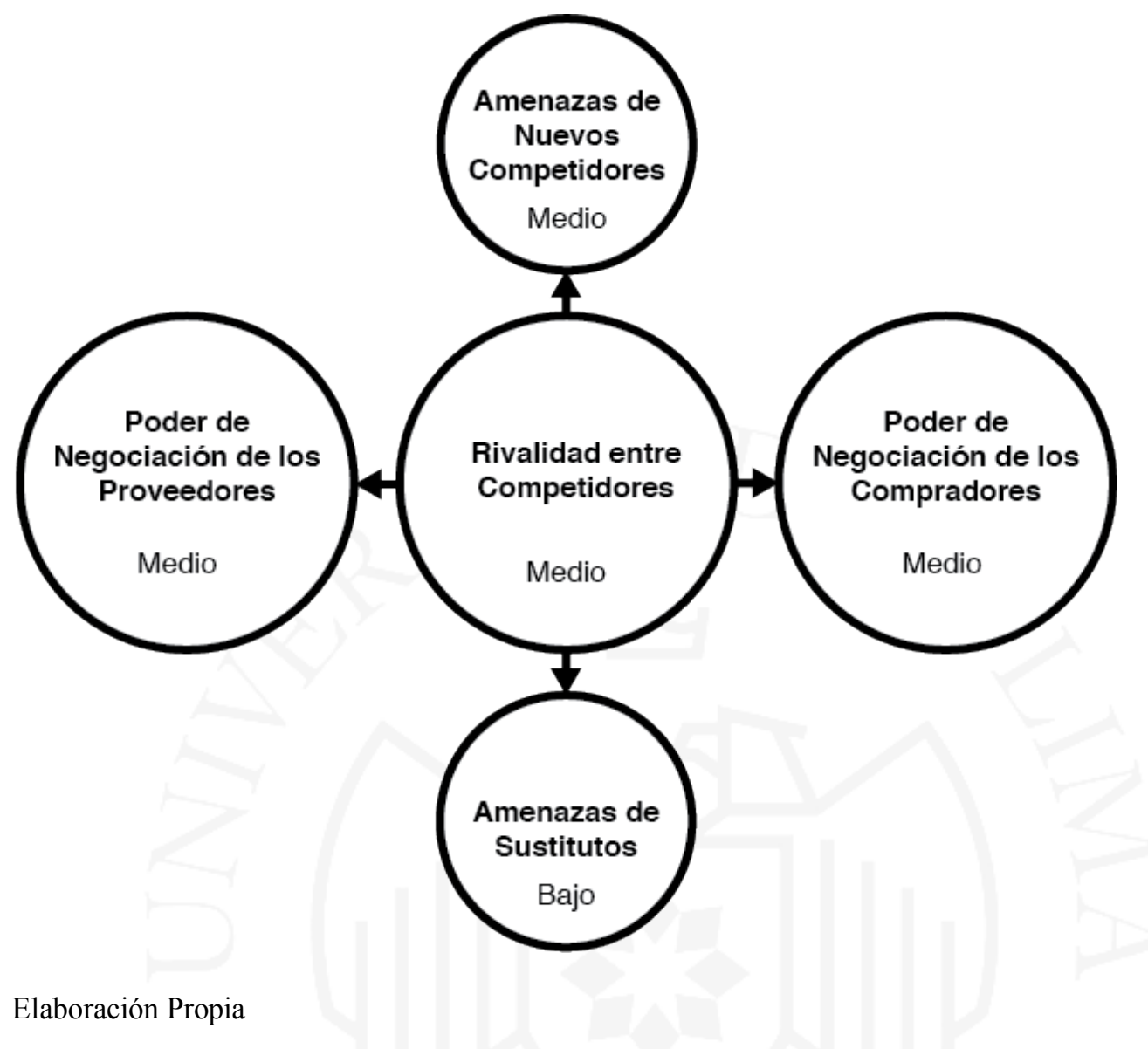

\section{Rivalidad entre competidores}

La rivalidad entre competidores se clasificó como media debido al elevado número de bares en los distritos de San Isidro, Barranco y Miraflores, especialmente los dos últimos. Sin embargo, si bien el servicio básico (es decir el consumo de bebidas alcohólicas) es el mismo en todos los locales, el bar automatizado posee elementos diferenciadores como los 4 ambientes distintos y la presencia de elementos de servucción automática que ayudarán a sobrepasar esta rivalidad entre competidores.

\section{Amenaza de nuevos competidores}

La amenaza de nuevos participantes se ha considerado como media ya que instalar un bar nuevo no tiene mayor complicación: los insumos pueden comprarse con facilidad y el personal necesario para el servicio no es ni escaso ni muy costoso. 
Sin embargo, los nuevos participantes no podrán copiar el mayor diferenciador de nuestro servicio, la automatización y capacidad de personalización que se le da al cliente debido a que la tecnología de servucción automática (mediante tanques y válvulas servo-accionadas), será patentada por la empresa.

Al patentar esta nueva forma de atender al cliente, ningún competidor podrá adoptar esta particular propuesta de valor por el tiempo que dure el patente. Esto significa que la intensidad media de amenaza de nuevos competidores se mantendrá a lo largo de la vigencia de la patente, después de la cual la intensidad subirá a alta (como lo suele ser para un bar promedio).

Finalmente, la razón por la que se decidió clasificar la intensidad como media y no como baja es que el patente que se tendrá en cuanto a la tecnología de servucción automática solo cubrirá esa tecnología especifica. Esto significa que competidores podrán desarrollar tecnología diferente para ofrecer una experiencia de servucción automática como lo son los brazos robóticos. Sin embargo, se ha evaluado cada tipo de tecnología de servucción automática y se determinó que la que se utilizará en bar automatizado es la mejor propuesta, por lo que la propuesta de valor seguirá siendo superior a la posible competencia incluso si intentasen adoptar la servucción automática.

\section{Poder de negociación de los proveedores}

Se clasificó el poder de negociación de los proveedores como medio debido a que es extremadamente importante que el servicio siempre tenga los insumos necesarios para poder brindarle al cliente la mejor experiencia posible; esto quiere decir que existe una gran dependencia del servicio hacia los proveedores. No obstante, hay una gran cantidad de proveedores disponibles, causando que el poder de negociación de cada uno disminuya.

\section{Amenazas de los sustitutos}

Solo existen dos diferentes servicios donde las personas pueden consumir bebidas alcohólicas en cantidades más grandes: las discotecas y los bares. Esto quiere decir que los únicos sustitutos de servicios proveedores de bebidas alcohólicas son las discotecas. 
Otros servicios que ofrecen bebidas alcohólicas son los restaurantes con "Happy Hours" $\mathrm{y}$ algunos pequeños locales en centros comerciales que preparan cocteles.

A pesar de que las discotecas son sustitutos de los bares en cuanto al producto que ofrecen, las discotecas tienen características muy diferentes a los bares en cuanto al servicio y como consecuencia tienen públicos con diferentes objetivos. Por lo general, las discotecas son frecuentadas por personas que quieren bailar y tomar mientras que la comunicación verbal no es lo prioritario. Por otro lado, los bares son frecuentados por personas que también quieren consumir bebidas alcohólicas, pero que quieren un amiente ligeramente más calmado, en el que prima la comunicación verbal y el baile no es muy frecuente. Esto quiere decir que las discotecas no compiten con los bares por el mismo mercado y que, por lo tanto, la poca presencia de competencia directa (tanto en producto como servicio) hace que la amenaza de los sustitutos sea baja.

\section{Poder de negociación de los compradores}

El poder de negociación de los compradores fue clasificado como medio ya que, como se mencionó anteriormente, existe una gran cantidad de bares en los tres distritos a analizar. Sin embargo, la falta de sustitutos y la alta diferenciación del bar automatizado, limita el poder de negociación de los compradores, ya que si desean experimentar el servicio automatizado solo podrán acudir a nuestro bar.

Sin embargo, el poder de negociación de los compradores no se clasificó como bajo ya que el producto principal del bar automatizado sigue siendo las bebidas alcohólicas. Los clientes potenciales podrán ir a cualquier otro bar para conseguir bebidas alcohólicas, lo que significa que el bar automatizado tendrá que tener cuidado de mantener precios competitivos en el mercado y en lugar de competir por precios, buscar ganar a los clientes con una mejor propuesta de valor como lo es el servicio automatizado.

Tras este análisis se puede concluir que el sector de las bebidas alcohólicas en Miraflores es muy atractivo para la implementación de un bar automatizado ya que si bien existen varios bares ya establecidos, el nivel de diferenciación presente en el bar automático es sumamente elevado. Esto significa que la propuesta de valor, como se tratará después, sería mayor que la de la competencia. Adicionalmente, el mercado de los bares es muy vulnerable a nuevos bares con innovadoras propuestas de valor ya que como 
se mencionó en la introducción de la problemática en el primer capítulo: el núcleo de la propuesta de valor del bar promedio está obsoleto ya que no ha cambiado hace varias décadas. 


\section{CAPÍTULO II: ESTUDIO DE MERCADO}

\subsection{Aspectos generales del estudio de mercado}

\subsubsection{Definición comercial del servicio}

En el capítulo anterior se presentó la idea de un bar cuyo objetivo principal era ofrecer a los clientes diferentes tipos de bebidas alcohólicas, tanto simples como elaboradas, de manera instantánea con ayuda de la automatización del proceso de bartending.

Sin embargo, este diferenciador no altera la definición comercial del servicio ya que este sigue siendo un bar en el núcleo; por lo tanto, el giro de la empresa será "Empresa de actividades de servicio de bebidas" y el CIIU será “5630”.

\subsubsection{Principales beneficios del servicio}

\section{Producto básico}

Primero, es necesario definir el servicio en cada uno de los diferentes niveles del producto basados en la teoría de los "tres niveles del producto" de Philip Kotler, introducida en el libro "Principios de Marketing”. Los tres niveles son: básico, real y aumentado.

\section{Nivel de servicio: Básico}

El servicio básico del bar será ofrecer bebidas alcohólicas, desde simples cervezas o tragos cortos hasta elaborados cocteles.

\section{Nivel de servicio: Real}

Se le dará al cliente una gran variedad de opciones en cuanto al menú de bebidas disponibles. Las bebidas alcohólicas que se ofrecerán incluyen:

- Fermentados como las cervezas tipo ale, cervezas tipo lager, vinos, champán, etc. (Figura 2.1.)

- Destilados como el pisco, tequila, vodka, ron, whisky, etc. 
- Licores y cremas como baileys, licor de café, licor de hierbas, etc

Figura 2.1

\section{Cervezas}

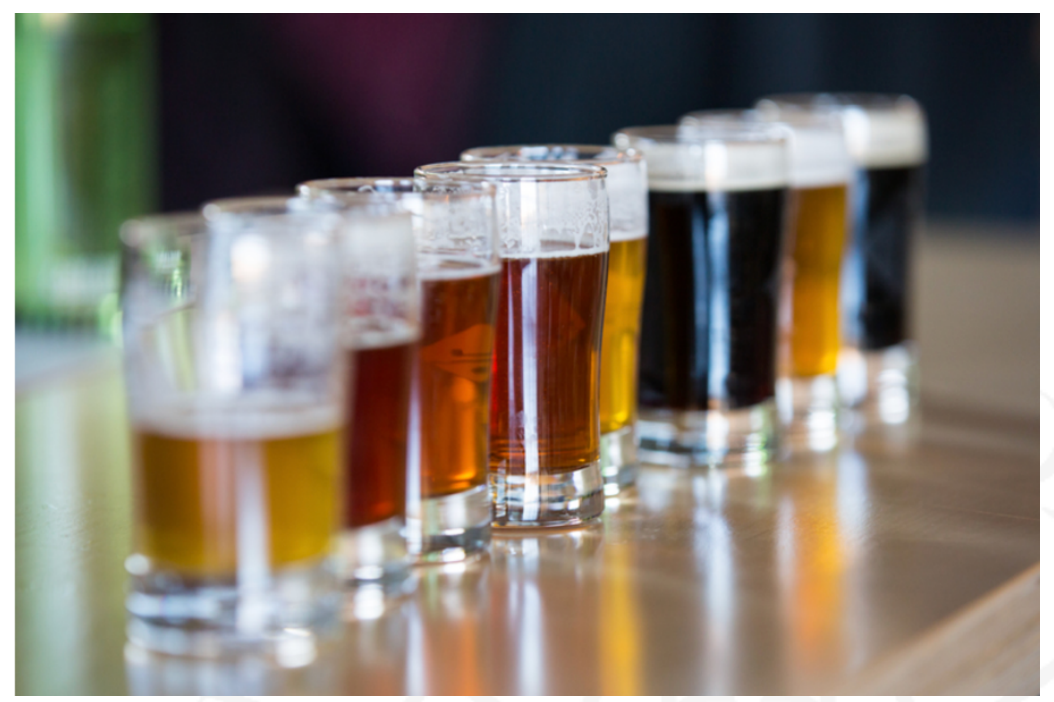

Fuente: Temperence Beer (2016)

También se ofrecerán ingredientes adicionales para la creación de diversos cocteles: jugo de naranja, granadina, gaseosas, hielo, jugo de tomate, limón, etc. Las bebidas alcohólicas mezcladas de diferentes maneras y en diferentes proporciones permitirán preparar múltiples cocteles elaborados como: pisco sour, chilcano, bloody mary, daiquiri, martini, cosmopolitan, tequila sunrise, mojito, piña colada, etc. como se muestra en la Figura 2.2. a continuación:

\section{Figura 2.2}

Diversos cócteles
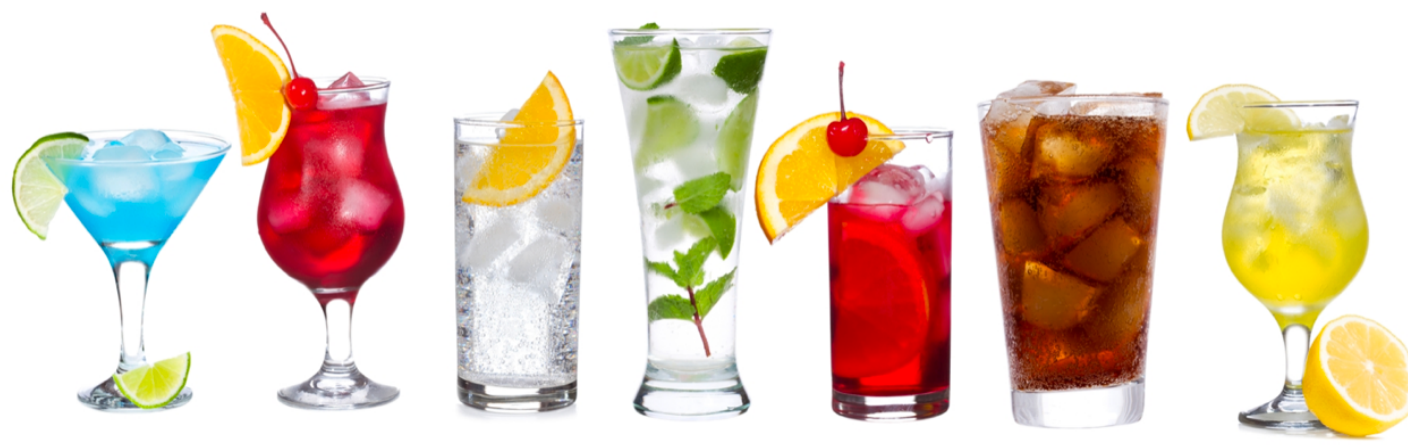

Fuente: Kneipen Klaus (2016) 
Sin embargo, el aspecto más importante del nivel "real" del bar será su automatización: los bartenders serán remplazados por dispensadores en cascada, cada uno lleno con un insumo diferente (bebidas alcohólicas e ingredientes adicionales). Estos dispensadores serán conectados por tuberías hasta llegar a una única salida de forma que se podrán servir bebidas alcohólicas y cocteles ya listos directo a la copa o al vaso del cliente.

Además, se le dará al cliente la opción de personalizar su bebida, ofreciéndoles la receta "de la casa" con las proporciones básicas como primera instancia junto con una opción con menor nivel de alcohol y otra con mayor nivel de alcohol. Estas tres opciones serán formuladas por especialistas para asegurar que la combinación de ingredientes y sus respectivas proporciones sean óptimas para asegurarle al cliente el mejor sabor posible.

Adicionalmente, habrá una opción para habilitar al cliente a elegir las proporciones de los insumos de la bebida que haya elegido; esto le dará a los clientes control completo sobre su bebida ya que la podrán alterar a su gusto. Sin embargo, esta opción vendrá con una advertencia ya que no se puede asegurar que las proporciones elegidas por el cliente resultarán en una bebida agradable dado que se le dará control completo al cliente.

\section{Nivel de servicio: Aumentado}

El servicio aumentado del bar se podrá notar a lo largo de toda la estadía del cliente y también se extenderá a la post-venta y la pre-venta.

Fuera del bar se le ofrecerá al cliente instrucciones simples y rápidas para el efectivo uso del bar automatizado a través de la página web oficial del bar y de fanpages en las redes sociales más relevantes en el Perú (Facebook, Instagram, Twitter y Snapchat), enseñándoles todas las posibilidades que se le estará dando. Dichos fanpages también podrán ser usadas como portales de comunicación con la empresa, tanto para preguntas como para quejas y sugerencias. 


\section{Servicios complementarios}

De acuerdo con el modelo molecular, los servicios complementarios a ofrecer se clasifican en 2 grupos principales: de facilitación y de mejora, cada uno está dividido en 4 subgrupos.

\section{Servicios de facilitación}

\section{Información}

Debido a que el concepto de un Bar Automatizado es relativamente nuevo, será necesario informar a los clientes a cerca del funcionamiento del establecimiento. Este servicio complementario será más notorio durante los primeros meses de funcionamiento del establecimiento.

Sin embargo, ya que siempre existen clientes nuevos, siempre existirá la necesidad de brindar este servicio, aunque sea en menor medida. La información entregada explicará principalmente el funcionamiento del bar, las diferentes áreas que existen dentro del establecimiento, y los procedimientos de facturación y pago.

\section{Toma de pedidos}

Este servicio complementario es el más importante, ya que es lo que distingue al negocio de aquellos que se desenvuelven en el mismo rubro. Como se ha mencionado anteriormente, la toma de pedidos referida a bebidas alcohólicas será personalizable y totalmente automatizada, por lo que se realizará de manera rápida, eficiente y será posible que todos los clientes consuman sus tragos favoritos preparados exactamente como deseen.

\section{Facturación}

Al momento de ingresar al establecimiento, el cliente deberá entregar su DNI, no solo para que se pueda comprobar que es mayor de edad, sino también para que se le pueda otorgar una pequeña tarjeta que estará enlazada con su persona. Todos los pedidos del cliente se almacenarán en una base de datos junto al código de la tarjeta; esto permitirá 
que se realice una facturación correcta al momento de pagar, evitando problemas y manteniendo satisfecho al cliente.

Del mismo modo, si el cliente se encuentra en compañía de un grupo de amistades, es posible que se realice la facturación de manera separada, de manera conjunta e incluso de manera que se obtenga un promedio simple de la cuenta grupal. Esto le facilitará el trabajo tedioso de decidir la distribución de la cuenta a los clientes.

Así mismo, será posible que los clientes se suscriban al servicio, obteniendo una tarjeta única que no deberá ser devuelta. Esta tarjeta almacenará todos sus consumos y se le realizará el cobro después de un periodo fijado previamente con el cliente (semanal, mensual, bimensual, etc.).

\section{Pago}

El proceso de pago se puede realizar de dos formas: por caja o con ayuda de los meseros. Una vez que el cliente haya terminado su estadía podrá acercarse a cualquier caja a cancelar el monto que debe; dicho monto estará registrado en la tarjeta que se le entregó a su llegada.

El cliente deberá ingresar la tarjeta y cancelar el monto respectivo con tarjeta de crédito o efectivo. Alternativamente, el cliente podrá pedirle la cuenta al mesero para cancelar la tarjeta con un POS de la misma forma en la que lo haría en el cajero pero de manera asistida.

\section{Servicios de mejora}

\section{Consulta}

A pesar de la información brindada al momento de ingresar al local, adicionalmente, habrán trabajadores responsables de resolver cualquier duda que pueda tener el cliente durante el proceso de pedido. Esto se debe a que siempre habrán clientes que requieran orientación adicional a los numerosos instructivos propagados por redes sociales que demuestren la fácil interacción con el bar. Además, el cliente podrá pedir recomendaciones al personal de consulta y las respuestas se darán de manera que respondan personalmente a las necesidades del cliente. 


\section{Hospitalidad}

Los servicios de hospitalidad se pueden apreciar en las diferentes áreas que existen en el local. Con el propósito de promover las interacciones y conexiones interpersonales entre los clientes, mejorando así su experiencia, se ofrecerán múltiples ambientes especializados: una sala de videojuegos grupales y casuales orientada a clientes más digitales; otra sala para fumadores; y un ambiente con mesas de billar y tableros de dardos para los clientes que quieran divertirse de una manera más activa y competitiva. Finalmente, el ambiente principal ofrecerá una amplia variedad de juegos de mesa como: Uno, 4 en raya, Cards Against Humanity, Ajedrez, Monopolio, etc.

Estos servicios complementarios asegurarán que todos los clientes tengan la posibilidad de interactuar con personas que tengan intereses similares, tanto con amigos conocidos como con amigables desconocidos. Por otro lado, se buscará que el local se encuentre siempre limpio, en todas sus áreas; ya sean las 4 áreas principales, los servicios higiénicos, la barra, etc.

\section{Cuidado}

En cuanto a servicios de cuidado, se contará con personal de seguridad para evitar cualquier problema dentro del establecimiento. Por otro lado, no se proveerá el servicio de estacionamiento ni Valet Parking, ya que al ser un servicio especializado en la comercialización de bebidas alcohólicas, no es socialmente responsable el promover manejar bajo la influencia de sustancias como el alcohol.

El bar también contará con cámaras de seguridad para siempre cuidar el bienestar y seguridad tanto del cliente como de sus pertenencias. Más aún, el bar contará con mobiliario ergonómico para cuidar la salud del cliente, asegurando que estén físicamente cómodos durante su estadía.

\section{Excepciones}

En caso existiese algún pedido especial por parte de los clientes, como lo puede ser la alergia a alimentos al momento de pedir piqueos o reclamos con respecto a alguna de las bebidas entregadas, el personal estará siempre dispuesto a responder de manera cordial y resolver los problemas con los que el cliente se haya podido encontrar. 


\subsubsection{Macrolocalización del servicio}

En el primer capítulo se decidió que el bar iba a estar localizado en Lima Metropolitana, esto quiere decir que la marcolocalización será a nivel de distritos. Se han elegido tres posibles distritos en los cuales se podría localizar el servicio: Barranco, Miraflores y San Isidro. Esto se debe a que estos tres distritos ya tienen una gran cantidad de bares instalados, lo que significa que la industria de bebidas alcohólicas ya está bien establecida y por lo tanto será más fácil atraer clientes debido a que ya estarán deambulando cerca del bar.

Otro beneficio de establecerse en uno de estos distritos es que el costo de reaprovisionar insumos se podrá reducir ya que los proveedores ya están habituados a suplir cualquiera de estas zonas, y además se podrán hacer tratos con otros bares para consolidar las ordenes a los proveedores para reducir costos por economías de escala.

Para determinar el mejor distrito para localizar el bar se hicieron encuestas (de las que se hablará más adelante, pero cuyo resultado se encuentra en el anexo $\mathrm{n}^{\circ}$ 5). Las respuestas de estas encuestas fueron representativas de los diferentes grupos de clientes que podrían atender al bar y era por eso que se le dio tanto peso a sus opiniones. Se eligió Miraflores como el mejor distrito para localizar el bar ya que como se puede ver en la Figura 2.3, más del 50\% de las encuestas preferían a este distrito por sobre los demás:

Figura 2.3

Preferencia de distrito

¿Dónde te gustaría que estuviese ubicado el Bar?
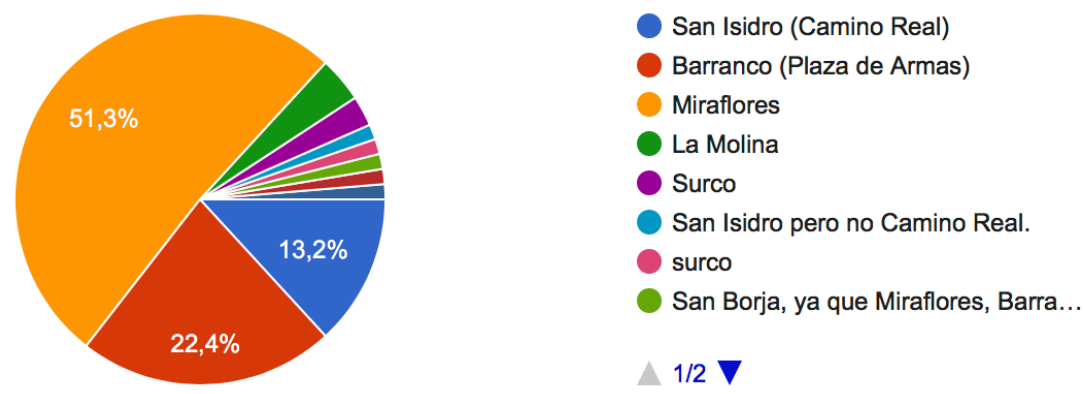

Elaboración propia 
Es conveniente instalar el bar en el distrito de Miraflores ya que la industria de bebidas alcohólicas está ya desarrollada, con clientes frecuentes en busca de nuevos y mejores bares. Pero también porque este distrito tiene una mayor cantidad de zonas aptas para este tipo de establecimiento, lo que significa que habrá mayor posibilidad de elección en la microlocalización

De igual manera, al realizar la encuesta se preguntó por la preferencia de zonas dentro del distrito, para poder determinar en qué parte de Miraflores resulta más conveniente la instalación del Bar. Se preseleccionaron las siguientes tres zonas para determinar la mejor macrolocalización:

\section{Parque Kennedy}

La zona alrededor de este parque es muy popular tanto para un sinfín de trabajadores sino también para una cantidad igual de grande de turistas y extranjeros viviendo temporalmente en Miraflores.

Habiendo dicho esto, se puede asumir que habrá una gran cantidad de clientes potenciales gracias a trabajadores buscando un bar para el after-office y también de clientes flotantes gracias a el gran número de bares ubicados en las calles cercanas al Parque Kennedy.

\section{Ovalo Gutiérrez}

Este óvalo es sumamente recorrido a lo largo de todo el día y es esto que lo hace un sitio atractivo para establecer el bar propuesto. No solo hay un gran tráfico sino que este es un lugar con mucho potencial gracias a que hay muchos diferentes negocios cerca y que hay pocos bares por la zona y es por eso que los pocos bares no tienen la necesitad de competir por cubrir la demanda.

\section{Larcomar}

Esta última opción es atractiva ya que también está ubicado en un lugar muy frecuentado tanto por turistas como por locales; teniendo cerca de lugares públicos como el parque del amor, así como la zona de parapentes. 
Al igual que el Ovalo Gutiérrez, esta alternativa es atractiva ya que no existe mucha competencia directa ubicada en el mismo Larcomar. Este factor, en combinación con todo el tráfico generado diariamente por dicho mall, convierte a esta alternativa en una muy buena propuesta de localización.

Finalmente, los resultados de la encuesta indicaron que los clientes potenciales prefieren la zona aledaña al parque Kennedy, por lo que es ésta el área en que se realizará el análisis de microlocalización.

\subsubsection{Modelo de negocio}

Definir el modelo de negocio de manera detallada tiene grandes beneficios para la empresa ya que ayuda a expandir y concretar todas las ideas de lo que realmente será el negocio una vez que esté en operación.

Con el objetivo de detallar el modelo de negocio de manera organizada, fácil de entender y posteriormente interiorizar, se utilizará el modelo de negocios Canvas inventado por Alexander Osterwalder. Con ayuda de este modelo se investigarán los elementos clave del servicio, los cuales deberán trabajar en harmonía para asegurar el funcionamiento óptimo del bar. A continuación, se detallan todos los elementos del modelo Canvas:

\section{Segmentos de clientes}

Debido a que el bar propuesto ofrecerá un ambiente óptimo para entablar largas conversaciones acompañadas por bebidas alcohólicas y diferentes servicios complementarios que servirán de rompe-hielos, la segmentación será predominantemente psicográfica. El bar será dirigido a personas sociables con inclinación a los ambientes públicos y las bebidas alcohólicas, con interés en negocios novedosos y nuevas tendencias siempre y cuando sean mayores de 18 años. Adicionalmente, se apuntará al sector socioeconómico A y B y se estima que la mayoría del público tendrá entre 25 y 40 años de edad. 


\section{Propuesta de valor}

Venta de una amplia variedad de bebidas alcohólicas y no alcohólicas de calidad preparadas al instante sin tiempo de espera y con posibilidad de completa personalización. Oferta de servicios complementarios y múltiples ambientes para acomodar a diversos tipos de personas con diferentes intereses.

\section{Canales de distribución y comunicación}

La distribución se realizará directamente y exclusivamente en el mismo local de manera rápida y eficaz, con alto grado de personalización. Mientras que los canales de comunicación que más se utilizarán son las redes sociales debido a que, como se mencionó anteriormente, son las vías de comunicación más utilizadas hoy en día. Las redes sociales a utilizar serán: Facebook, Instagram, Twitter y Snapchat.

\section{Relación con el cliente}

Se tendrá especial cuidado de que la relación con los clientes sea siempre lo mejor posible. Esta relación será controlada a través del uso de un software de CRM y fomentado a través de la buena comunicación con el cliente y todos los servicios que se les brindaran.

\section{Fuente de ingresos}

La fuente principal de ingresos del bar automatizado será la venta de bebidas alcohólicas, sean cocteles, tragos cortos o cerveza. El sistema de cobre consistirá de POS para pagar con tarjetas de crédito o débito y de una caja registradora en el caso de que algún cliente desee pagar con efectivo. Conforme se vaya normalizando el uso de las cryptomonedas, también se añadirá soporte para poder aceptarlas como método de pago.

\section{Actividades clave}

La actividad más importante y emblemática del bar será la preparación automatizada de la bebida solicitada. Sin embargo existen otras actividades clave para el buen funcionamiento del servicio, como por ejemplo el cuidado, manejo y préstamo de 
los juegos de mesa; las presentaciones musicales, sean bandas en vivo, DJs o la simple elección del playlist; actualizar constantemente el contenido en las diferentes redes sociales para mantener el negocio en el "feed" y, por lo tanto, en la mente del cliente; etc.

\section{Recursos clave}

Sin lugar a dudas, los recursos de mayor importancia son los insumos de las bebidas ya sean los diferentes licores y tragos o los aditivos; estos deben ser de la mejor calidad posible. Otros recursos clave serían los sensores, actuadores, fuentes de alimentación, microprocesadores, etc. Básicamente, todos los componentes necesarios para la automatización del proceso de preparación y servido de los pedidos.

\section{Relaciones clave}

Se deberán formar relaciones estratégicas con los proveedores de tragos, cervezas y aditivos tanto como con influenciadores de redes sociales ya que la campaña de marketing se concentrará grandemente en las redes sociales.

\section{Estructura de costos}

Los costos principales del bar están ligados al uso de la materia prima para la elaboración de los tragos. Otros costos notables incluirán el costo de mantenimiento del sistema automatizado, el costo de energía y agua, y el costo por transacción conlleva el uso de las pasarelas de pago para tarjetas de crédito. Asimismo, otro componente importante de la estructura de costos es la inversión inicial para implementar el bar: el terreno, la construcción del local, la maquinaria, etc.

A continuación, se muestra el lienzo Canvas resumiendo la información que se acaba de desplegar: 
Tabla 2.1

Modelo canvas del bar automatizado

\begin{tabular}{|c|c|c|c|c|c|}
\hline $\begin{array}{l}\text { Relaciones } \\
\text { clave } \\
\text {-Relaciones } \\
\text { estratégicas con } \\
\text { proveedores } \\
\text {-Relaciones con } \\
\text { influenciadores } \\
\text { en redes sociales }\end{array}$ & $\begin{array}{l}\text { Actividades clave } \\
\text {-Preparación } \\
\text { automática de bebidas } \\
\text {-Préstamo de juegos } \\
\text { de mesa } \\
\text {-Presentaciones } \\
\text { musicales } \\
\text {-Actualizado } \\
\text { constante de redes } \\
\text { sociales } \\
\text { Recursos } \\
\text { clave } \quad \text {-Insumos } \\
\text { microprocesadores } \\
\text { actuadores, fuentes de } \\
\text { alimentación cocteles } \\
\text {-Sensores, } \\
\text { - }\end{array}$ & $\begin{array}{l}\text { Propuest } \\
\text { valor } \\
\text {-Amplia } \\
\text { de bebida } \\
\text {-Bebidas } \\
\text {-Al inst } \\
\text { tiempo de } \\
\text {-Posibilid } \\
\text { completa } \\
\text { personali } \\
\text {-Múltiple } \\
\text { complem } \\
\text {-Gran va } \\
\text { ambiente } \\
\text { acomodar } \\
\text { tipo de cl }\end{array}$ & $\begin{array}{l}\text { de } \\
\text { variedad } \\
\text { de calidad } \\
\text { espera sin } \\
\text { ade } \\
\text { servicios } \\
\text { ación } \\
\text { iedarios de } \\
\text { a todo } \\
\text { ente }\end{array}$ & $\begin{array}{l}\text { Canales } \\
\text {-Canal de } \\
\text { distribución } \\
\text { directo, exclusivo } \\
\text { - } \\
\text { Comunicación a } \\
\text { través de redes } \\
\text { sociales }\end{array}$ & $\begin{array}{l}\text { Segmentos de } \\
\text { mercado } \\
\text {-Clientes } \\
\text { mayores de } 20 \\
\text { - } 54 \text { años } \\
\text {-Sector socio } \\
\text { económico A } \\
\text { y B } \\
\text {-Vivan } \\
\text { Lima } \\
\text {-Sociables con } \\
\text { inclinación a } \\
\text { ambientes } \\
\text { públicos y } \\
\text { bebidas } \\
\text { alcohólicas }\end{array}$ \\
\hline $\begin{array}{l}\text { Estructura de co } \\
\text {-Costo de insumo } \\
\text {-Coto de manteni } \\
\text {-Costo de energía } \\
\text {-Costo por transa } \\
\text {-Inversión inici } \\
\text { maquinaria, etc. }\end{array}$ & $\begin{array}{l}\text { para cocteles y bebidas } \\
\text { iento del equipo automa } \\
\text { agua }\end{array}$ & $\begin{array}{l}\text { general } \\
\text { zado }\end{array}$ & $\begin{array}{l}\text {-Cobro p } \\
\text {-Por tarje } \\
\text {-Se de } \\
\text { cryptomo }\end{array}$ & $\begin{array}{l}\text { la venta de bebidas a } \\
\text { de crédito o efectivo } \\
\text { das conforme aumer }\end{array}$ & $\begin{array}{l}\text { I contado } \\
\text { soporte } \\
\text { te su uso }\end{array}$ \\
\hline
\end{tabular}

Elaboración propia 


\subsubsection{Determinación de la metodología que se empleará en la investigación de mercado}

Ahora que ya se estudió la situación del entorno y la magnitud de las diferentes fuerzas del mercado y se ha concluido que un bar automatizado podría competir en el mercado sin grandes problemas, debemos analizar la demanda.

La demanda de bebidas alcohólicas será analizada de diferentes maneras: primero se estudiará los patrones de consumo históricos para luego realizar una proyección de la demanda. Adicionalmente, se calculará la demanda potencial para determinar si hay posibilidad de crecimiento en porcentaje del mercado.

Más adelante se buscará afinar la demanda para hallar la demanda que realmente será abarcada por el bar automatizado propuesto. Esto se hará mediante el uso y análisis de encuestas; las cuales también servirán para informarnos sobre preferencias de localización, precio, patrones de consumo adicionales, preferencias de canal de promoción, etc. Con esta información luego podremos fijar el precio óptimo para los tragos del bar, afinar la disposición del local basándonos en las preferencias del cliente, etc.

\subsection{Análisis de la demanda}

A continuación, se estimará la demanda del servicio propuesto mediante el análisis de los patrones históricos de consumo, la estacionalidad del producto y la demanda potencial basada en la demanda de un país similar, pero con mayor desarrollo en el sector de las bebidas alcohólicas.

\subsubsection{Data histórica del consumidor y sus patrones de consumo}

Se analizará la data histórica de consumo de bebidas alcohólicas en el Perú proveniente de Euromonitor actualizado al 2016: 
Tabla 2.2

Consumo anual de bebidas alcohólicas per cápita mayor de edad en litros

\begin{tabular}{l|llllll} 
AÑO & $\mathbf{2 0 1 1}$ & $\mathbf{2 0 1 2}$ & $\mathbf{2 0 1 3}$ & $\mathbf{2 0 1 4}$ & $\mathbf{2 0 1 5}$ & $\mathbf{2 0 1 6}$ \\
\hline LITROS & 69,4 & 72,3 & 70,5 & 71,1 & 71,2 & 71,6 \\
& & & & & & \\
Fuente: Euromonitor $(2017)$ & & & & & \\
Elaboración propia
\end{tabular}

Como se puede ver en la Tabla 2.2, el consumo de bebidas alcohólicas per cápita mayor de edad en litros al año ha incrementado a lo largo de estos últimos 6 años. Estos datos nos permiten hacer múltiples regresiones para luego elegir la línea de tendencia más representativa y así poder calcular la proyección de la demanda.

En la siguiente tabla se muestra la comparación entre posibles regresiones, de acuerdo a su coeficiente de determinación.

Tabla 2.3

Selección de ecuación de regresión

\begin{tabular}{l|cc} 
Regresión & Ecuación & Coeficiente de Determinación \\
\hline Polinómica & $\mathrm{y}=0.005 \mathrm{x}^{3}-30.44 \mathrm{x}^{2}+61386 \mathrm{x}-4 \mathrm{E}+07$ & $\mathrm{R}^{2}=0.9894$ \\
Lineal & $\mathrm{y}=0.4365 \mathrm{x}+69.101$ & $\mathrm{R}^{2}=0.9617$ \\
Exponencial & $\mathrm{y}=69.11 \mathrm{e}^{0.0062 \mathrm{x}}$ & $\mathrm{R}^{2}=0.9605$ \\
Logarítmica & $\mathrm{y}=1.1993 \ln (\mathrm{x})+69.348$ & $\mathrm{R}^{2}=0.9813$
\end{tabular}

Elaboración propia

Se escogió la ecuación polinómica de tercer grado como la más apropiada para el estudio dado que tiene un mayor $\mathrm{R}$ cuadrado.

En la figura 2.4 se puede apreciar la línea de tendencia que se ajusta al crecimiento del consumo anual de bebidas alcohólicas per cápita en el Perú. Esta ecuación se utilizará para realizar la proyección de la demanda. 
Figura 2.4

Regresión polinómica del consumo de bebidas alcohólicas

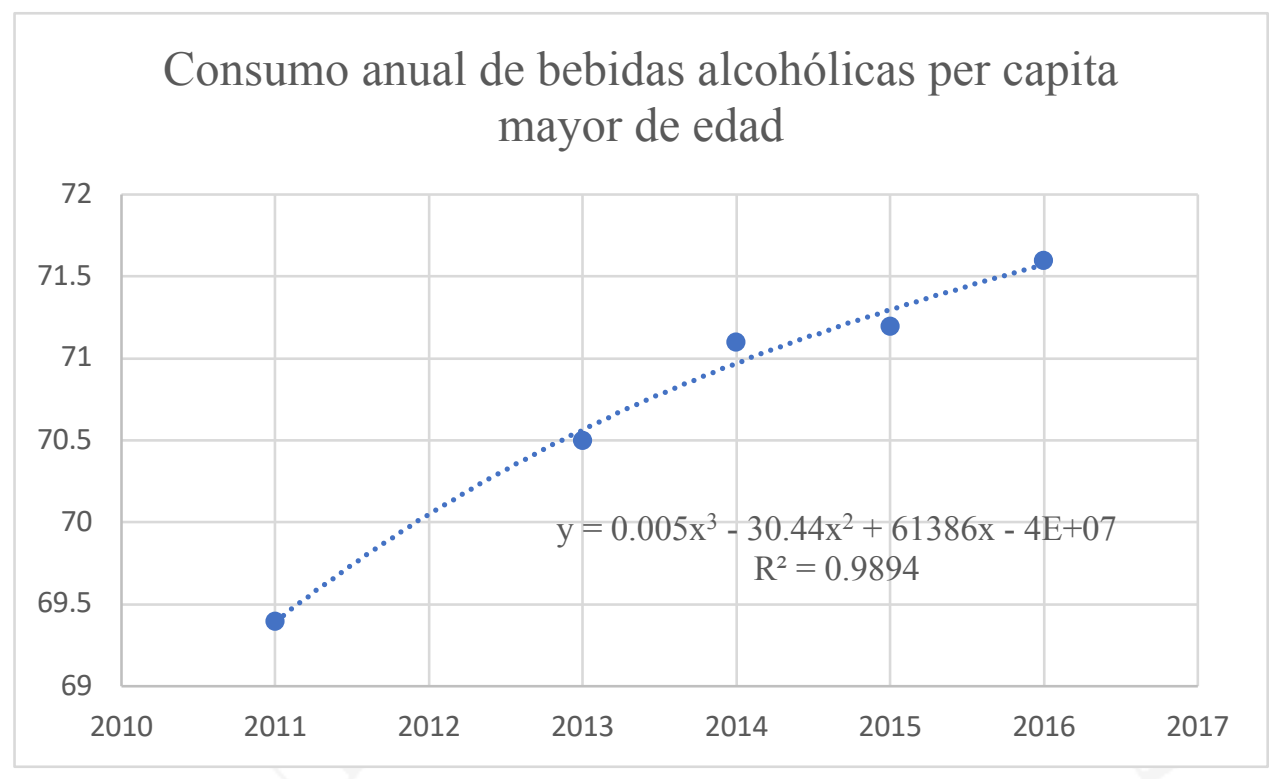

Elaboración propia

La regresión que más se ajustó a los datos fue la polinómica de grado 3; cabe resaltar que el año 2012 se consideró como una anomalía y no se consideró en la regresión. La fórmula de la línea de tendencia polinómica nos permite proyectar la demanda hacia el futuro como se puede ver en la Tabla 2.4. a continuación:

Tabla 2.4

Demanda proyectada anual de bebidas alcohólicas per cápita mayor de edad en litros

\begin{tabular}{c|cccccc} 
AÑN & $\mathbf{2 0 1 7}$ & $\mathbf{2 0 1 8}$ & $\mathbf{2 0 1 9}$ & $\mathbf{2 0 2 0}$ & $\mathbf{2 0 2 1}$ & $\mathbf{2 0 2 2}$ \\
\hline LITROS & 71.8 & 72.1 & 72.4 & 72.8 & 73.2 & 73.8
\end{tabular}

Elaboración propia

Como se puede ver en la tabla anterior, la tendencia es que la demanda siga un crecimiento estable. Aunque el crecimiento anual no parezca muy grande, hay que considerar que los datos hablan del consumo anual en litros de bebidas alcohólicas por persona mayor de edad. Esto quiere decir que en el año 2022, se estima que cada persona mayor de edad consumirá 73.8 litros de bebidas alcohólicas, lo cual en realidad es una cantidad considerable. 
De manera similar, se puede hacer el mismo análisis para el consumo anual de bebidas alcohólicas en litros. A continuación, se presenta una tabla con los datos de Euromonitor junto con las proyecciones de la demanda se presentan a continuación en la Tabla 2.5.

Tabla 2.5

Demanda anual en millones de litros, histórica y proyectada

\begin{tabular}{l|lllllllllllllll} 
AÑO & 2011 & 2012 & $\mathbf{2 0 1 3}$ & $\mathbf{2 0 1 4}$ & $\mathbf{2 0 1 5}$ & $\mathbf{2 0 1 6}$ & $\mathbf{2 0 1 7}$ & $\mathbf{2 0 1 8}$ & $\mathbf{2 0 1 9}$ & $\mathbf{2 0 2 0}$ & $\mathbf{2 0 2 1}$ & $\mathbf{2 0 2 2}$ \\
\hline MILLON & 1348 & 1433 & 1424 & 1464 & 1491 & 1527 & 1558 & 1589 & 1621 & 1653 & 1686 & 1721 \\
LITROS & & & & & & & & & & & & & & &
\end{tabular}

Fuente: Euromonitor (2017)

Elaboración propia

Como se puede ver en la tabla anterior, se estima que la demanda anual de bebidas alcohólicas en el año 2022 sea 1721000000 litros, lo cual es una muy buena señal para la viabilidad de la propuesta ya que se puede notar la prosperidad de la industria de bebidas alcohólicas.

\subsubsection{Demanda potencial}

Ocurre un error una vez que se calcula la demanda potencial del país de la forma anterior y la razón es que se asume que la demanda seguirá la misma tendencia que ha estado siguiendo estos últimos seis años. Cuando en realidad este método no toma en consideración que hay otros países que presentan un mayor desarrollo de mercado al cual el mercado peruano podría llegar en algún punto en el futuro. Un buen ejemplo es Chile, que aunque tiene menor consumo anual de bebidas alcohólicas que Perú, tiene un crecimiento mucho más notorio en cuanto al consumo anual per cápita de bebidas alcohólicas, lo cual quiere decir que el chileno promedio es mejor comprador de bebidas alcohólicas que el peruano promedio.

Es importante recalcar que para este cálculo solo se tomará la demanda de bebidas alcohólicas on-trade, que significa que se vende en lugares como bares, pubs y 
restaurantes mas no en supermercados y bodegas. Se hará el cálculo solamente con ventas de tipo on-trade ya que de esta manera se podrá calcular de forma mucho más precisa la demanda potencial, debido a que el bar automatizado solo forma parte de este tipo de ventas. Estos datos se pueden ver en la tabla a continuación:

Tabla 2.6

Demanda anual de bebidas alcohólicas on-trade per cápita, en litros

\begin{tabular}{c|cccccc}
\multicolumn{1}{c}{ AÑO } & $\mathbf{2 0 1 1}$ & $\mathbf{2 0 1 2}$ & $\mathbf{2 0 1 3}$ & $\mathbf{2 0 1 4}$ & $\mathbf{2 0 1 5}$ & $\mathbf{2 0 1 6}$ \\
\hline PERÚ & 7.7 & 8.1 & 8.1 & 8.3 & 8.5 & 8.9 \\
CHILE & 10.2 & 10.0 & 10.1 & 10.3 & 10.2 & 10.9
\end{tabular}

Fuente: Euromonitor (2017)

Se tomará el mercado de bebidas alcohólicas de Chile como medida de lo que el mercado de bebidas alcohólicas peruano se podrá convertir conforme el sector vaya madurando. Utilizando la demanda per cápita de Chile en combinación con la población peruana se puede calcular la demanda potencial con la siguiente fórmula:

Demanda Potencial $=\mathrm{CPC}_{\text {Chile }} \times$ Población $_{\text {Perú }}$

Para el cálculo de la demanda potencial se utilizaron los datos del año 2016, donde el CPC de Chile se puede ver en la tabla anterior y la población del Perú fue de 31488 625 habitantes. Consecuentemente, se calcula que la demanda potencial de bebidas alcohólicas on-trade en Perú es de 343226 012,5 litros al año.

\subsection{Análisis de la oferta}

A continuación, se analizará la oferta ya existente en el mercado de las bebidas alcohólicas para poder determinar las fortalezas y debilidades de la competencia, así como para hallar la cuota real del mercado que se busca cubrir. Para ello se analizarán tan solo a las principales empresas del mercado de bebidas alcohólicas tanto como los beneficios que ofrecen. Seguidamente, se realizará un análisis de perfil competitivo y de grupos estratégicos. 


\subsubsection{Análisis de la competencia}

Existen dos tipos principales de bares: para conversar y para bailar; es por eso que este análisis hará distinción entre estos dos tipos diferentes de bares como herramienta de organización y de selección ya que solo uno de estos tipos clasifica como competencia directa.

Bares para conversar: Estos bares se caracterizan por brindar un ambiente acogedor para incentivar las conversaciones entre clientes: la música no es muy fuerte, hay diferentes ambientes, hay una gran cantidad de lugares para sentarse, etc. Dentro de esta categoría existen:

- Barbarian

- La Cachina

- Huaringas

- Nuevo Mundo Draft Bar

- La Destilería

- La Emolientería

Bares para bailar: Este tipo de bar se caracteriza por brindar un ambiente activo y divertido para incentivar a los clientes a bailar: la música es fuerte, movida y bailable; son más espaciosos que los bares de conversar para permitir que los clientes bailen; no hay tantos lugares ambientados para sentarse; etc. Sin embargo, no existen tantos bares de este tipo en Miraflores; aunque estos abundan en Barranco. Dentro de esta categoría existen:

- Cocodrilo Verde

- Rouge Bar

\subsubsection{Beneficios ofertados por los competidores directos}

Se han seleccionado únicamente a los bares para conversar como nuestros competidores directos; los beneficios que ofrecen a sus clientes suelen ser similares y serán descritos a continuación.

Como se ha mencionado anteriormente, este tipo de bares cuidan mucho el ambiente del local para asegurarse de mantener al cliente cómodo para así lograr que se 
desenvuelva socialmente sin ninguna incomodidad externa. Para lograr esto la buena decoración del local es primordial; conjuntamente, la música es cuidadosamente elegida para mantener al cliente entretenido y para mantener un nivel de sonido mínimo consistente, sea con música en vivo o con sets musicales predefinidos.

Uno de los beneficios más comunes entre estos bares es la venta de piqueos suplementarios a las bebidas ya que debe haber un balance entre oferta de bebidas y de comida. Otro beneficio que ofrece la mayoría de bares en Miraflores son los diferentes ambientes, estos sirven para darle mayor privacidad a los clientes al mismo tiempo que también pueden servir para mantener cómodos a diferentes tipos de clientes.

Adicionalmente, muchos bares ofrecen actividades adicionales como préstamo de juegos de mesa, deportes de espacio reducido como billar o dardos, juegos para tomar como cachito o beer-pong, etc.

\subsubsection{Análisis competitivo y comparativo}

Una vez determinada la oferta existente se pueden analizar las virtudes de cada competidor para luego decidir cuál es el más fuerte y por ende, a cuál se le tendrá que prestar mayor atención. Se utilizarán dos matrices para este análisis: la matriz de perfil competitivo para determinar el competidor más peligroso y la matriz de grupos estratégicos para determinar la competencia más parecida a nuestra propuesta. A continuación, se presentan los factores elegidos para llevar a cabo la comparación de los diferentes competidores actuales:

- Participación de mercado

- Competitividad de precio

- Variedad de bebidas

- Calidad de tragos

Se ha elaborado un ranking de factores para otorgarle pesos ponderados a los diferentes factores: 
Tabla 2.7

Matriz de enfrentamiento para análisis del perfil competitivo

\begin{tabular}{|c|c|c|c|c|c|c|c|}
\hline & & A & B & $\mathrm{C}$ & $\mathrm{D}$ & Peso & Ponderación \\
\hline Participación de Mercado & A & & 1 & 1 & 1 & 3 & 0.4286 \\
\hline Competitividad de precio & B & 0 & & 1 & 0 & 1 & 0.1429 \\
\hline Variedad de bebidas & $\mathrm{C}$ & 0 & 1 & & 0 & 1 & 0.1429 \\
\hline Calidad de tragos & $\mathrm{D}$ & 0 & 1 & 1 & & 2 & 0.2857 \\
\hline \multicolumn{6}{|c|}{ Total } & 7 & 1 \\
\hline
\end{tabular}

Elaboración propia

Con los pesos ponderados de los diferentes factores de calificación se puede proceder a evaluar a los competidores mediante la matriz de perfil competitivo para eventualmente determinar al competidor más fuerte. La matriz de perfil competitivo se muestra a continuación:

Tabla 2.8

Matriz de perfil competitivo

\begin{tabular}{|c|c|c|c|c|c|c|c|c|c|c|c|c|c|c|}
\hline & & \multicolumn{2}{|c|}{ Barbarian } & \multicolumn{2}{c|}{ La Cachina } & \multicolumn{2}{c|}{ Huaringas } & \multicolumn{2}{c|}{ Nuevo Mundo Draft Bar } & \multicolumn{2}{c|}{ La Destilería } & \multicolumn{2}{c}{ La Emolientería } \\
\hline Factor & Ponderación & Calificación Puntaje & Calificación Puntaje & Calificación & Puntaje & Calificación & Puntaje & Calificación Puntaje & Calificación Puntaje \\
\hline A & 0.4286 & 5 & 2.14 & 6 & 2.57 & 3 & 1.29 & 1 & 0.43 & 3 & 1.29 & 4 & 1.71 \\
\hline B & 0.1429 & 6 & 0.86 & 4 & 0.57 & 2 & 0.29 & 5 & 0.71 & 2 & 0.29 & 4 & 0.57 \\
\hline C & 0.1429 & 3 & 0.43 & 4 & 0.57 & 3 & 0.43 & 3 & 0.43 & 6 & 0.86 & 5 & 0.71 \\
\hline D & 0.2857 & 5 & 1.43 & 3 & 0.86 & 4 & 1.14 & 3 & 0.86 & 6 & 1.71 & 1 & 0.29 \\
\hline & & & 4.86 & & 4.57 & & $\mathbf{3 . 1 4}$ & & $\mathbf{2 . 4 3}$ & & $\mathbf{4 . 1 4}$ & & $\mathbf{3 . 2 9}$ \\
\hline
\end{tabular}

Elaboración propia

Analizando los resultados se puede ver que el competidor principal será Barbarian gracias a su alta participación de mercado, buena competitividad de precio y calidad de tragos. No obstante, La Cachina Bar es el competidor con mayor participación de mercado, tornándolo en otro competidor peligroso en el ecosistema de los bares para conversar. Finalmente, La Destilería es un bar nuevo con menos de dos años; este bar está ganando tracción y es muy recomendado entre jóvenes por su excelente calidad y variedad de tragos innovadores.

A continuación, se presenta la matriz de grupos estratégicos del sector de bebidas alcohólicas, enfocado en bares para conversar: 
Figura 2.5

Matriz de grupos estratégicos

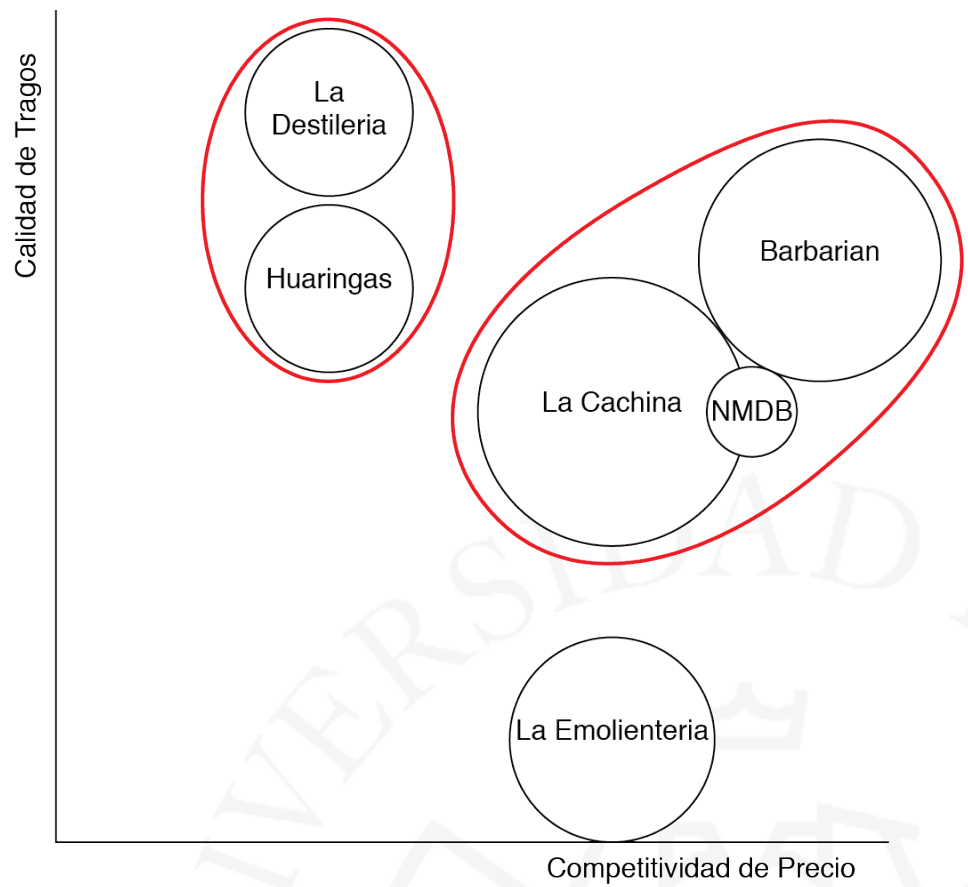

Elaboración propia

Se eligieron los ejes de competitividad de precio y calidad de trago ya que son factores muy distintos y cada uno atrae a un diferente tipo de público. El tamaño de los círculos ilustra la participación de mercado de cada bar. Mediante esta matriz se puede confirmar de manera visual y rápida lo analizado en la matriz anterior: Barbarian es una gran amenaza para el mercado, ya que ofrece tragos de buena calidad a precios muy competitivos en comparación a los otros bares.

Como se puede ver en la matriz de grupos estratégicos, los bares existentes se pueden clasificar en dos grupos predominantes: bares que ofrecen tragos de muy buena calidad a precios elevados y bares que ofrecen tragos de calidad media a precios competitivos. Esto quiere decir que la propuesta del bar automatizado podría encajar en un pequeño océano azul, ofreciendo tragos de buena calidad, pero a precios competitivos gracias al ahorro que genera la ausencia de bartender al largo plazo. 


\subsection{Determinación Demanda para el proyecto}

A continuación, se hallará la demanda exacta que tendrá el bar automatizado propuesto, para ello se hará uso de fuentes primarias de información a modo de encuestas. Sin embargo, antes de poder realizar las encuestas se tendrá que segmentar al mercado y elegir al segmento objetivo para asegurar que las preguntas de la encuesta les sean relevantes y así poder obtener información de calidad.

\subsubsection{Segmentación del mercado}

Se utilizarán tres tipos principales de segmentación de mercado: Demográfica, psicográfica y conductual. No se usará la segmentación geográfica para la elaboración de la encuesta debido a que, como se explicó en el subcapítulo 2.1.3, era importante dejar que el cliente decida el distrito en donde querría que esté ubicado el bar automatizado para así tener la seguridad de que el local estaría ubicado alrededor de la demanda. Más aún, se buscará no solo tener clientes locales, sino que se promoverá el local como un lugar turístico partidario de la innovación y creatividad en el Perú.

\section{Segmentación demográfica:}

Naturalmente, el negocio solo podrá atender a la población mayor de 18 años en concordancia con la Ley $\mathrm{N}^{0} 28681$ que prohíbe la venta de bebidas a alcohólicas a menores de edad (18 años de edad).

Por otra parte, se buscará atraer, en su mayoría, a un público de entre 25 y 35 años de edad. Esto se debe a que las personas entre estas edades son más probables de tener ingresos sustanciales, hábito de salir a divertirse a bares y discotecas y que estén cómodos alrededor de nueva tecnología o de negocios innovadores. Así mismo se seleccionará a personas de clase socioeconómica alta y media alta.

\section{Segmentación psicográfica:}

Seguidamente, se seleccionará a personas con interés en actividades de interacción social y con personalidades amigables y abiertas.

Los intereses específicos no tienen mayor importancia ya que el bar propuesto ofrecerá varios ambientes adaptados para cubrir muchos diferentes intereses, sin 
embargo, será necesario preguntar estos intereses y otros atributos que valoren en un bar para adquirir una mejor idea de lo que se le podría ofrecer a los clientes como servicios o beneficios adicionales al bar automatizado.

Nuevamente, se buscará atraer a clientes con interés en la tecnología o en negocios innovadores que usen técnicas o tecnologías nuevas para resolver diferentes problemas de maneras más efectivas. Los clientes objetivo también deberán ser creativos y deseosos de poder crear o personalizar sus bebidas.

\section{Segmentación conductual:}

Finalmente, se buscará que el público objetivo tenga una tasa de visita al servicio de por lo menos una vez al mes ya que se preferirá tener una cartera de clientes frecuentes para reducir la variación de la demanda.

Como se mencionó antes, el segmento de clientes elegido deberá tener el beneficio deseado de poder innovar ellos mismos al crear o personalizar sus propias bebidas.

\subsubsection{Selección de mercado meta}

Se definirá al mercado meta como personas mayores de 18 años con ganas de socializar y experimentar, de nivel socioeconómico alto y medio alto, interesado en la tecnología e innovación, deseosos de poder tener mayor control sobre los productos que compran o los servicios que consumen. Los clientes podrán venir de cualquier zona geográfica e incluso se incentivará la visita de clientes extranjeros a modo de turismo.

\subsubsection{Demanda mediante fuentes primarias}

La fuente primaria principal elegida para la recolección de información de este proyecto de investigación serán las encuestas, estas serán preparadas especialmente para extraer información relevante del mercado meta previamente seleccionado.

Los parámetros para las encuestas serán: Nivel de confianza de 95\% y un error máximo relativo de $8 \%$ lo cual nos permite calcular el número de respuestas necesarias 
para que la información obtenida por este medio sea representativa con el uso de la siguiente fórmula:

$$
\text { Tamaño de muestra }=\frac{p \times q \times Z^{2}}{e^{2}}
$$

Por lo tanto, se necesitarán 106 encuestas para que la información obtenida sea representativa de la población.

\section{Diseño y aplicación de encuestas}

Las preguntas realizadas en la encuesta ayudarán a determinar las mejores alternativas de plaza, promoción y precio del servicio propuesto. También permitirá saber el nivel de intensión de compra del cliente potencial junto con la intensidad de dicha intensión lo que nos permitirá tener una mejor idea sobre la demanda real que tendrá el negocio una vez abierto y en operación.

Preguntas adicionales permitirán identificar productos favoritos que no deberían faltar en la barra, atributos más valorados para saber qué factor diferenciador tendría un mayor impacto, etc. El modelo de la encuesta se presenta en los anexos.

A continuación, se presentará el análisis de los resultados de las encuestas, que se encuentran en el anexo 5 en vías a el calculo de la demanda del negocio propuesto:

Debido a que todas las personas que respondieron la encuesta fueron mayores de edad, y que esto no es representativo de la población de Lima Metropolitana, se usarán los datos del censo del año 2007 de la INEI para calcular la población de 20 a 54 años de la zona urbana de Lima Metropolitana: 3965813 personas. Sin embargo, solo el 15.1\% de Lima Metropolitana pertenece a Lima Moderna y el 85\% de Lima Moderna pertenece al sector A y B lo que nos da 509012 personas pertenecientes al sector socioeconómico A o B y residentes de Lima Moderna entre 20 y 54 años de edad.

Debido a que el $92.5 \%$ de las respuestas indicaron que sí asistían a bares por lo menos 2 veces al año, el número de clientes potenciales se reduce a 470836 personas. 
Ya que en subcapítulos anteriores se fijó la localización del bar automatizado propuesto en el distrito de Miraflores, y que el 70\% de respuestas indicó que actualmente asistían a bares en Miraflores, se podría asumir que el 70\% de las 470836 personas que asisten a bares en Lima Moderna no tendrían problema con visitar el local.

Se tomará el 70\% de las 470836 personas ya que ese fue el porcentaje de personas que actualmente asisten a bares en el distrito de Miraflores. No se tomará el 52.5\% ya que si bien el $47.5 \%$ de personas preferiría que el bar se ubique en otro lugar, el $70 \%$ de personas asistiría, aunque el bar se ubique en Miraflores. Esto nos da una cantidad de clientes potenciales de 329585 personas.

Esta cifra es nuevamente reducida debido a que el 3.7\% de los encuestados no estuvo interesado en la propuesta de negocio; esto nos deja con 317391 clientes potenciales.

Finalmente, debido a que se obtuvo una intensidad de intención de compra de $83,58 \%$ en promedio, los clientes potenciales del servicio de bar automatizado formarían un total de 264624 personas.

Cabe resaltar que no será posible atender a todos estos clientes potenciales, ya sea por falta de capacidad en los primeros años de instalación o porque simplemente habrá competidores localizados en terrenos o calles aledañas haciendo imposible la captura del $100 \%$ de demanda potencial.

\subsubsection{Determinación de la participación de mercado para el proyecto}

Como se mencionó en el último párrafo del subcapítulo anterior, será imposible captar toda la demanda potencial del mercado local miraflorino. Para obtener una cifra más realista del porcentaje de mercado que en realidad se captará una vez instalado el local, se determinará la cantidad de competidores en Miraflores. 
Figura 2.6

Mapa de bares, tabernas, discotecas y juguerías en Miraflores

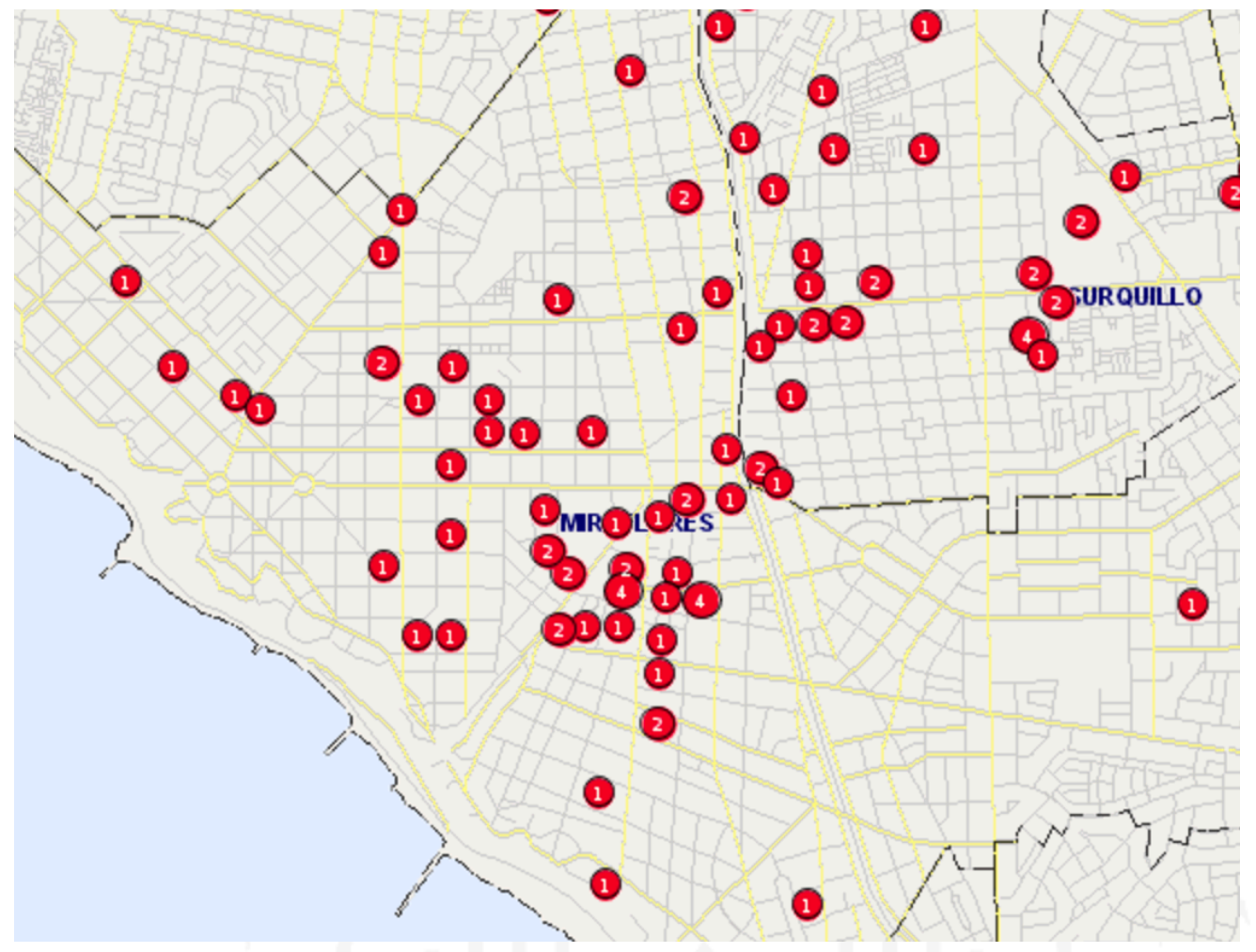

Fuente: Sistema de Información Geográfica para Emprendedores (SIGE) del INEI (2017)

Se contó un total de 60 locales competidores: entre bares, tabernas, discotecas y juguerías. Asumiendo que todos estos locales tendrán la misma participación de mercado, se puede calcular que cada local tendría una demanda de 13928 clientes, que van a bares en 22.07 veces al año en promedio y tienen un ticket promedio actual por cliente de S/ 72.47 cada vez que asisten a un bar, se obtiene que la demanda anual del negocio es S/ 7 054050.65 al año.

En la siguiente página se mostrará una tabla resumiendo los pasos para calcular la demanda anual del negocio en soles: 
Tabla 2.9

Resumen de pasos para la determinación de la demanda anual en soles

\begin{tabular}{|c|c|c|c|c|c|}
\hline Año & 2019 & 2020 & 2021 & 2022 & 2023 \\
\hline Población de Lima & 8939691.36 & 8988859.66 & 9038298.39 & 9088009.03 & 9137993.08 \\
\hline Crecimiento & $0.55 \%$ & $0.55 \%$ & $0.55 \%$ & $0.55 \%$ & $0.55 \%$ \\
\hline Lima moderna & $13.00 \%$ & $13.60 \%$ & $14.72 \%$ & $15.10 \%$ & $15.50 \%$ \\
\hline Población LM & 1162159.88 & 1222484.91 & 1330437.52 & 1372289.36 & 1416388.93 \\
\hline Porcentaje AB & $85 \%$ & $85 \%$ & $85 \%$ & $85 \%$ & $85 \%$ \\
\hline Población AB & 987835.89 & 1039112.18 & 1130871.89 & 1166445.96 & 1203930.59 \\
\hline Porcentaje de Edad & $52.20 \%$ & $52.20 \%$ & $52.20 \%$ & $52.20 \%$ & $52.20 \%$ \\
\hline Población entre 20 y 54 & 515650.34 & 542416.56 & 590315.13 & 608884.79 & 628451.77 \\
\hline Sí asisten a Bares & $92.50 \%$ & $92.50 \%$ & $92.50 \%$ & $92.50 \%$ & $92.50 \%$ \\
\hline Clientela potencial & 476976.56 & 501735.31 & 546041.49 & 563218.43 & 581317.88 \\
\hline Asistirían a Miraflores & $70 \%$ & $70 \%$ & $70 \%$ & $70 \%$ & $70 \%$ \\
\hline Clientes potenciales & 333883.59 & 351214.72 & 382229.05 & 394252.90 & 406922.52 \\
\hline Intención & $96.30 \%$ & $96.30 \%$ & $96.30 \%$ & $96.30 \%$ & $96.30 \%$ \\
\hline Clientes potenciales & 321529.90 & 338219.78 & 368086.57 & 379665.54 & 391866.39 \\
\hline Intensidad & $83.58 \%$ & $83.58 \%$ & $83.58 \%$ & $83.58 \%$ & $83.58 \%$ \\
\hline Clientes potenciales & 268734.69 & 282684.09 & 307646.76 & 317324.46 & 327521.93 \\
\hline Número de Locales & 60 & 60 & 60 & 60 & 60 \\
\hline Participación del mercado & 4478.91 & 4711.40 & 5127.45 & 5288.74 & 5458.70 \\
\hline Frecuencia de Compra & 22.07 & 22.07 & 22.07 & 22.07 & 22.07 \\
\hline Visitas potenciales & 98849.58 & 103980.63 & 113162.73 & 116722.51 & 120473.48 \\
\hline Ticket Promedio (Soles) & 72.47 & 72.47 & 72.47 & 72.47 & 72.47 \\
\hline Demanda en Soles & 7163628.85 & 7535476.29 & 8200903.17 & 8458880.63 & 8730713.21 \\
\hline Captación esperada & $30 \%$ & $50 \%$ & $75 \%$ & $80 \%$ & $100 \%$ \\
\hline Demanda real (Soles) & 2149088.65 & 3767738.15 & 6150677.38 & 6767104.51 & 8730713.21 \\
\hline
\end{tabular}

\subsection{Definición de estrategia de comercialización}

\subsubsection{Políticas de plaza}

La distribución de los productos ofrecidos, tanto las bebidas alcohólicas como los piqueos, será de forma directa y exclusiva dentro del mismo local; esto se debe a que el negocio propuesto es un servicio, lo que significa que el producto solo se puede entregar a través del bar automatizado y por ende los clientes deben acercarse al local para obtener el producto y no al contrario. 
Sin embargo, cuando se les dio a los encuestados a elegir la localización preferida del servicio, el 52.5\% respondió que prefería que esté en Miraflores. Esto quiere decir que a pesar de que la plaza es fija una vez establecida, se aseguró que el local esté en el lugar indicado con la mayor demanda flotante posible. La respuesta de la encuesta mencionada anteriormente se puede ver en la página 48, así como en el anexo $\mathrm{n}^{\circ} 5$.

\subsubsection{Publicidad y promoción}

La política de promoción será de tipo "Pull" y se enfocará grandemente en las redes sociales, esto se debe a que fue el medio de publicidad elegido por la vasta mayoría de los encuestados, como se puede ver en la Figura 2.7

Figura 2.7

Elección de vía de publicidad y promoción

\section{¿Cómo te gustaría enterarte de nuestro Bar y sus promociones?}

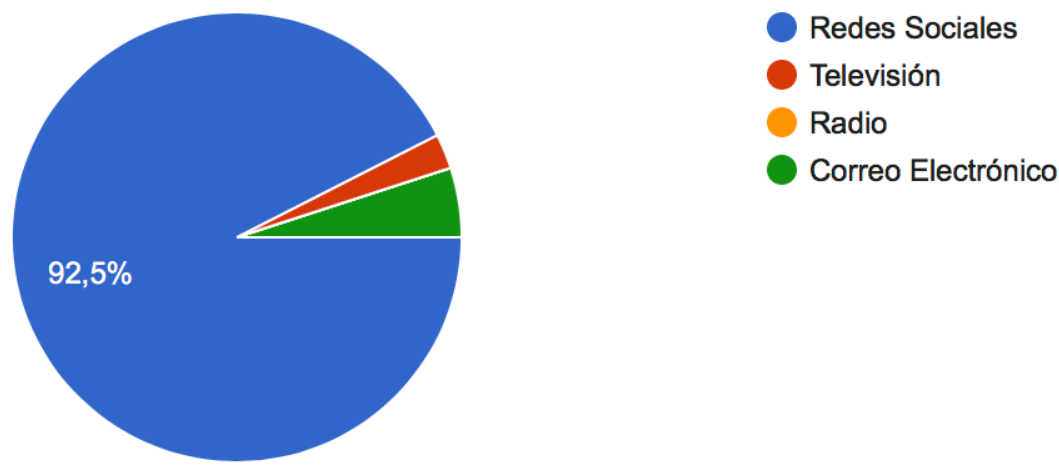

Elaboración propia

Hay muchas razones por las cuales conviene grandemente el enfoque en las redes sociales como medio de publicidad y promoción. Las dos más importantes son que las redes sociales forman el medio de comunicación más utilizado por el mercado meta elegido para la propuesta de bar automatizado y también que el costo de publicidad por redes sociales es mínimo en comparación con alternativas como televisión o incluso publicidad por radio.

En cuanto a la estrategia de redes sociales, inicialmente se implementarán campañas de pauta paga para maximizar el alcance del mercado potencial. Las campañas 
pagadas se mantendrán por 3 meses, mientras el negocio esté en pleno crecimiento; luego de este período, las campañas de marketing digital serán predominantemente orgánicas, ya que los perfiles de la empresa en las diferentes redes sociales ya tendrán una base saludable de seguidores.

Entrando más a detalle en el plan de medios, la palanca digital que se utilizará para las campañas pagadas será Facebook, ya que tiene el mayor potencial de alcance en el mercado peruano. La campaña será abierta, segmentada por edad (+18 años), ubicación (Lima Moderna, que hayan hecho "check-in" en bares o discotecas, etc.) e intereses (vida nocturna, negocios relacionados con el alcohol, conciertos, etc.).

Aparte de las segmentaciones mencionadas previamente, se limitará el alcance de las campañas con una inversión tope de S/ 4500 mensuales para conseguir impactar a todo el mercado potencial (270 000, previamente calculado en el sub-capitulo 2.4). El plan de medios se puede ver en la siguiente tabla.

Tabla 2.10

Cálculo de la población alcanzada a través de redes sociales

\begin{tabular}{c|cccccc} 
Mes & $\begin{array}{c}\text { Tope } \\
\text { Inversión (S/) }\end{array}$ & $\begin{array}{c}\text { Tope } \\
\text { Inversión }\end{array}$ & $\begin{array}{c}\text { CPM } \\
\mathbf{( \$ )}\end{array}$ & Impresiones & $\begin{array}{c}\text { Frecuencia } \\
\text { Mensual }\end{array}$ & $\begin{array}{c}\text { Personas } \\
\text { Impactadas }\end{array}$ \\
\hline $\mathbf{1}$ & 4500 & 1364 & 0.2 & 6818182 & 24 & 284091 \\
$\mathbf{2}$ & 4500 & 1364 & 0.2 & 6818182 & 24 & 284091 \\
$\mathbf{3}$ & 4500 & 1364 & 0.2 & 6818182 & 24 & 284091 \\
Elaboración propia & & & & & &
\end{tabular}

Las métricas referentes a CPM (Costo por millar de impresiones) y la frecuencia mensual, se obtuvieron a partir de una entrevista con Álvaro Martínez, gerente de ebusiness y marketing digital del BCP. El plan presentado permite impactar a todo el mercado deseado (270 000 personas) durante los primeros 3 meses del negocio.

\subsubsection{Análisis de precios}

Se formuló la pregunta: “¿Cuánto estás dispuesto a pagar por un coctel personalizado sin tiempo de preparación?" durante la encuesta precisamente para investigar cuál sería el precio óptimo para cobrar por un coctel. Se presenta la respuesta en la Figura 2.8. a continuación: 
Figura 2.8

Elección de precio para un cóctel personalizado

\section{¿Cuánto estás dispuesto a pagar por un coctel personalizado sin tiempo de preparación?}
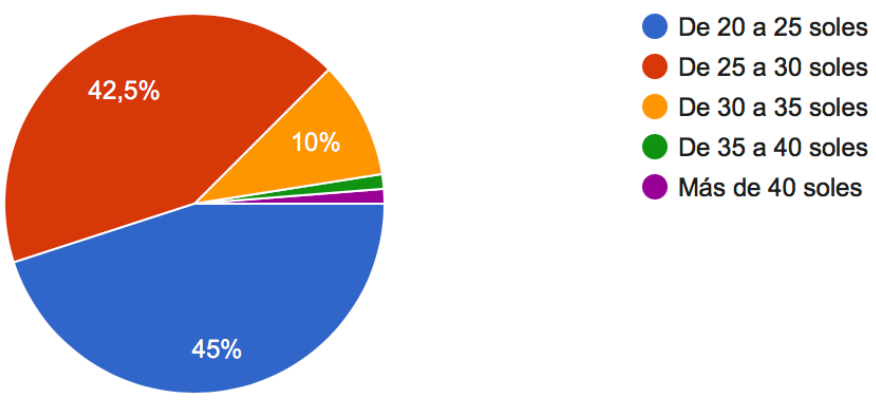

Elaboración propia

Como las respuestas más populares fueron entre 20 y 25 soles y entre 25 y 30 soles, se ha decidido que el precio óptimo para un coctel será $\mathrm{S} / 25$, el punto de encuentro entre ambas respuestas. Esto tiene el beneficio de aprovechar el precio que están dispuestos a pagar los más generosos y al mismo tiempo cuidar las ventas hacia los clientes que no están dispuestos a pagar tanto por cada coctel.

Este precio también parece sensato al compararlo a competidores como La Cachina, Huaringas o La Emolientería, cuyos precios fluctúan entre S/ 25 y S/ 27 por coctel.

\section{Estrategia de precios}

La estrategia de precios a desarrollar será la estrategia de diferenciación o superior. Esto se debe a que el precio que se cobrará por coctel estará a la par con los bares premium como Huaringas, La Destilería o Ayahuasca en el distrito de Barranco.

Sin embargo, es importante recordar que la propuesta de valor del bar automatizado será superior a la de la competencia debido a todos los factores diferenciadores expuestos anteriormente en los capítulos 1 y 2: la capacidad de personalización guiada y completa que se le da al cliente, los múltiples ambientes especializados en diferentes intereses, la precisión de la elaboración de los tragos, la 
velocidad de atención, etc. Se buscará educar al cliente acerca de todos estos beneficios adicionales para que sepan que el precio que están pagando cada vez que compran un coctel es bajo en comparación a todos los beneficios que están consiguiendo.

Mas aún, se emplearán múltiples estrategias de precios para mantener al cliente feliz y motivado para seguir asistiendo al local, semana tras semana. Estas estrategias incluyen: ofertas en un tipo de coctel diferente cada día, promociones de happy hour, ofertas 2x1 en un tipo de coctel todos los sábados, etc. 


\section{CAPÍTULO III: LOCALIZACIÓN DEL SERVICIO}

Debido a que ya se realizó la marcolocalización en donde se eligió el distrito de Miraflores y en particular, la zona del parque Kennedy como el ideal para implementar la propuesta del bar automatizado, se deberá elegir el local indicado para el servicio mediante la microlocalización.

Con el propósito de realizar una comparación justa y rigurosa se ha optado por comparar a las alternativas de manera equitativa a través del uso del procedimiento jerárquico analítico, o AHP por sus siglas en inglés. Para ello, se han seguido los siguientes pasos:

\subsection{Identificación y análisis detallado de los factores de microlocalización}

Los factores a tomar en consideración, deben ser lo suficientemente relevantes para poder diferenciar las diferentes posibilidades de local. Es por ello, que se han identificado los siguientes cinco factores:

- Costo mensual del derecho de superficie.

- Cercanía a otros bares.

- Área del terreno o local.

- Licencias Municipales en cuanto al tipo de comercio permitido

- Licencias Municipales en cuanto a permisos de altura de construcción.

Cada uno de los factores mencionados serán explicados a continuación:

\section{Cercanía a otros bares}

Este factor es sumamente importante ya que permite identificar cuán probable es que haya presencia de público potencial flotante. Esto se debe a que el público característico de este tipo de negocio no suele quedarse en el mismo bar toda la noche; una de las razones, por ejemplo, son los populares tours de bares en los que los clientes acuden a una gran cantidad de diferentes bares en un corto periodo de tiempo para probar qué bar tiene las mejores bebidas o simplemente para divertirse. 
Este público flotante puede llegar a ser muy beneficioso para el bar ya que si la propuesta de valor es mejor que los bares cercanos, existe la posibilidad de capturar a los clientes por toda la noche ya que dicho público flotante siempre está a la búsqueda del mejor lugar donde se pueda divertir por la noche.

Para poder evaluar la cercanía a los establecimientos, se ha realizado un análisis de centro de gravedad. Con ese fin, utilizando el sistema de información geográfica para emprendedores (SIGE) del INEI, se analizó la cantidad de locales en la zona del parque Kennedy.

Mapa 3.1

Distribución de bares y pubs en la zona aledaña al parque Kennedy

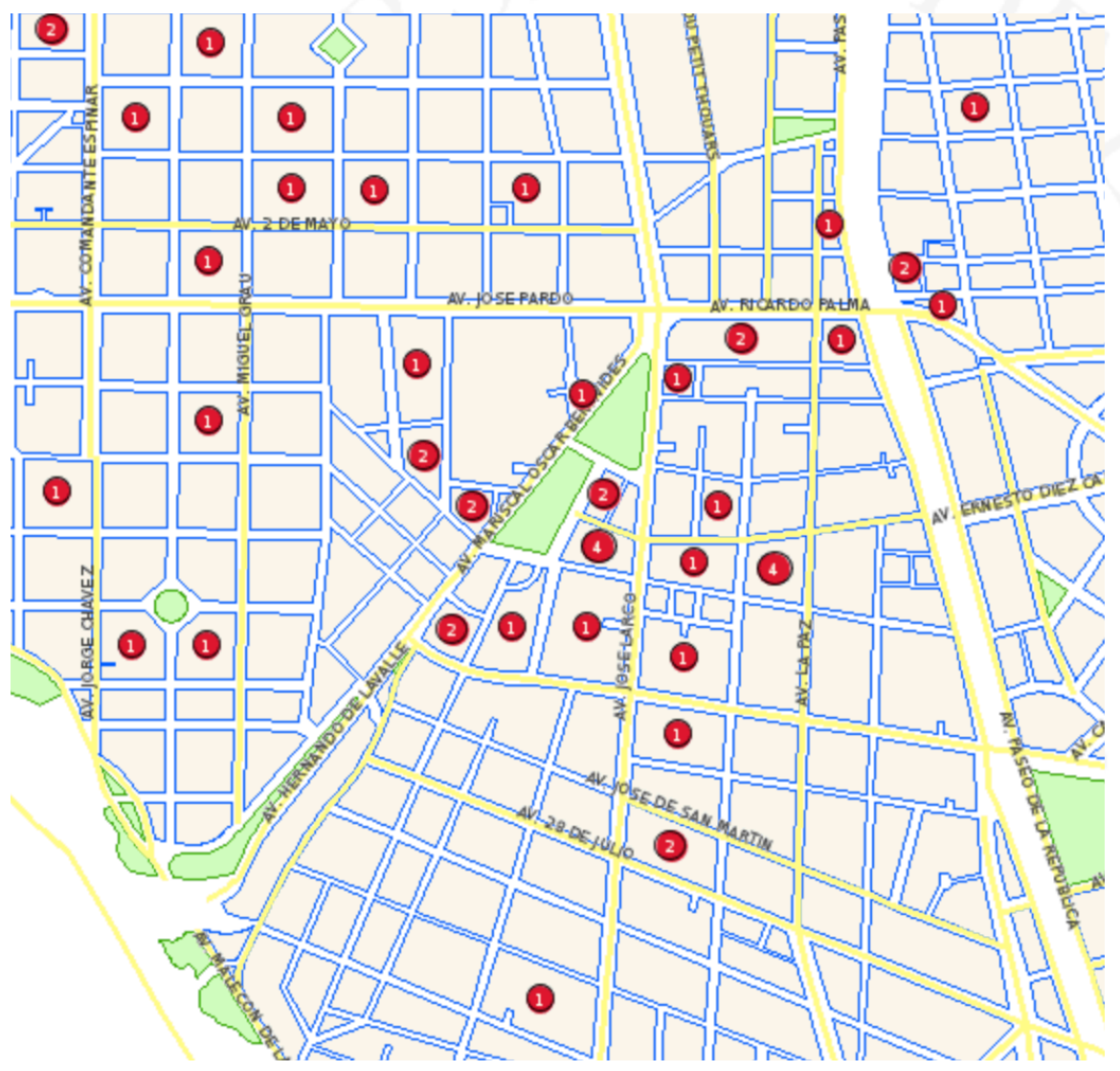

Fuente: Sistema de Información Geográfica para Emprendedores (SIGE), INEI (2017)

Posteriormente, se eligió el punto $(0 ; 0)$ y se procedió a determinar el centro de gravedad, de acuerdo a la cantidad de locales.

En la siguiente página se encuentra una versión del mapa anterior, al cual se le ha aplicado una cuadrícula, con el fin de determinar el punto centro. 
Mapa 3.2

Determinación del centro de gravedad de bares y pubs cercanos al parque Kennedy

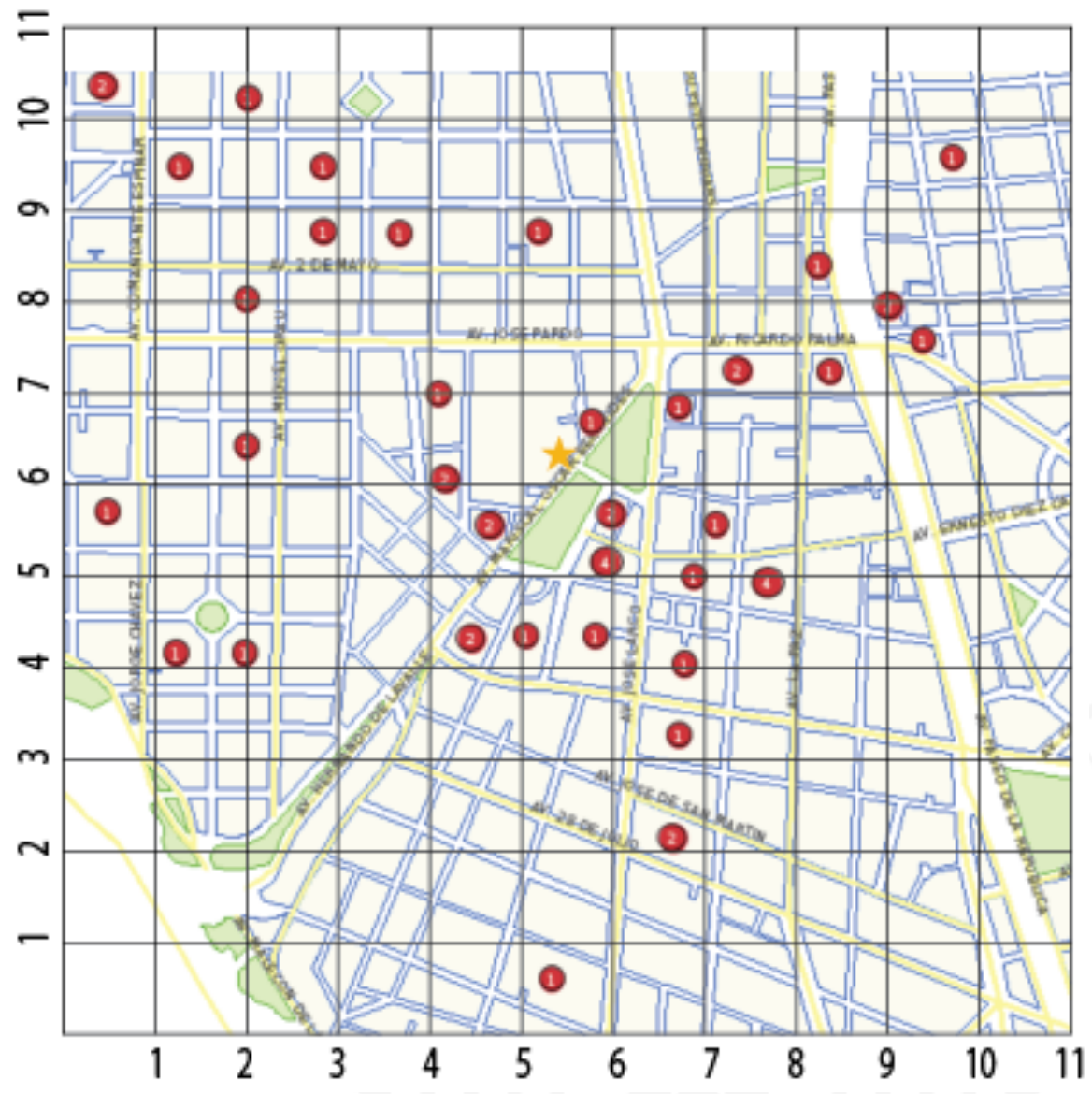

Elaboración propia

Es así que se determinó que el centro de gravedad se encuentra en el punto (5.3;6.3), es decir en la calle Mártir José Olaya, específicamente en el campus de la Universidad de Piura. Este es el punto que se utilizará para determinar la cercanía a otros locales.

\section{Costo del local}

Es necesario tener el costo del local en consideración para elegir la localización. Sin embargo, este factor no debe ser el de mayor importancia ya que es posible que los beneficios que otorgue cierto local sean mayores que sus costos, aunque el local llegue a costar más que las otras alternativas. También se puede dar el caso contrario, donde cierto local puede ser extremadamente barato pero que no ofrezca valor alguno. 
Área

Es importante considerar el área disponible, ya que un local demasiado pequeño no permitirá atender a todo el público objetivo, mientras que uno demasiado grande significará incurrir en gastos innecesarios. El área mínima necesaria es de 240 metros cuadrados.

\section{Licencias Municipales en cuanto a tipo de comercio permitido}

La municipalidad de Miraflores otorga tres tipos de licencias de funcionamiento, de acuerdo al tipo de comercio que se lleva a cabo en las localidades. Estas licencias son:

- Comercio Vecinal

- Comercio Zonal

- Comercio Metropolitano

Cada licencia otorga diferencias en cuanto a horas de funcionamiento, tipo de establecimientos permitido y permisos para venta de bebidas alcohólicas, siendo la más licencia de Comercio Metropolitano la más apropiada, a pesar de que se permitan los pubs o bares en las otras zonas del distrito.

\section{Licencias Municipales en cuanto a permisos de altura de construcción}

Debido a que ya se ha establecido que el local contará con 3 pisos, y un ambiente en la terraza, es necesario considerar si los locales se encuentran en zonas dentro de las cuales se permiten construcciones de estas características.

El siguiente paso, es otorgarle pesos ponderados a cada uno de los factores, de acuerdo a la importancia relativa que se ha considerado. En este caso, se ha considerado el siguiente orden de importancia:

- Licencias Municipales por tipo de comercio

- Licencias Municipales por alturas de construcción

- Área

- Costo del derecho de superficie / Cercanía a otros bares 


\subsection{Identificación y descripción de las alternativas de localización}

Se realizó una búsqueda de posibles locales aledaños al parque Kennedy, y se han elegido tres alternativas posibles para la ubicación del bar automatizado propuesto:

- Local 1: Calle Porta 251

- Local 2: Esquina de bajada Balta con Calle Jose Galvez

- Local 3: Calle Mártir José Olaya (junto a Universidad de Piura).

- A continuación, se realizará una breve descripción de cada alternativa:

\section{Porta 251}

El local se encuentra ubicado en la calle porta, dentro de una zona de comercio zonal. Cuenta con 240 metros cuadrados y se permite la construcción de hasta 8 pisos. El costo del derecho de superficie se encuentra en 4500 dólares mensuales. El local se encuentra a una distancia de 12 cuadras del centro de gravedad.

\section{Bajada Balta}

Este local también se encuentra dentro de una zona de comercio zonal. A diferencia del local anterior, el área total es de 336 metros cuadrados, y también se permite una construcción superior de la requerida, de hasta 10 pisos. El costo es de 4000 dólares mensuales, y se encuentra ubicado a 7 cuadras de los demás establecimientos.

\section{Mártir José Olaya}

Esta última opción es atractiva ya que se encuentra a 1 cuadra del centro de gravedad, y, a diferencia de las otras dos, es la única dentro de un área de comercio metropolitano. Por otro lado, el costo del derecho de superficie es muy superior al de los otros locales, alcanzando los 6000 dólares mensuales. Esta opción también permite construcciones de mayor altura a la requerida, y tiene un área de 377 metros cuadrados.

En vista que todas las opciones cuentan con la misma licencia de alturas de construcción, se ha optado por no considerar este factor dentro del AHP, por lo que el análisis de los pesos ponderados queda de la siguiente manera:

- Factor A: Costo 
- Factor B: Cercanía a otros Bares

- Factor C: Área

- Factor D: Licencias Municipales por tipo de comercio

Tabla 3.1

Matriz de enfrentamiento de factores de localización

\begin{tabular}{|c|c|c|c|c|c|c|}
\hline & A & B & C & D & Peso & Ponderación \\
\hline A & & 1 & 0 & 0 & 1 & 0.14 \\
\hline B & 1 & & 0 & 0 & 1 & 0.14 \\
\hline C & 1 & 1 & & 0 & 2 & 0.29 \\
\hline D & 1 & 1 & 1 & & 3 & 0.43 \\
\hline \multicolumn{7}{|c|}{ Total } \\
\hline
\end{tabular}

Elaboración propia

\subsection{Evaluación y selección de localización}

A continuación, se presentarán los criterios de evaluación para cada uno de los factores antes mencionados, de acuerdo a la metodología AHP.

- Costo de derecho de superficie: Por cada 500 dólares de diferencia se otorga un punto al local con menor costo.

- Cercanía a otros locales: Por cada 2 cuadras de diferencia, se otorga 1 punto al local más cercano.

- Área total: Por cada 50 metros cuadrados de diferencia se otorga 1 punto al local con mayor área.

- Licencia Municipal: Se define el nivel vecinal como "1", el nivel zonal como nivel "2", y el nivel metropolitano como nivel "3". Por cada nivel de diferencia se otorgan 2 puntos al local con mayor nivel.

Posteriormente se procede con el análisis para cada uno de los factores, de acuerdo al procedimiento. Los locales han sido clasificados de la siguiente manera:

- Local A: Porta 251

- Local B: Bajada Balta

- Local C: Mártir José Olaya 
Los resultados del análisis para cada uno de los factores se presentan a continuación:

Tabla 3.2

Resultado de análisis para el factor "Costo"

\begin{tabular}{|c|c|c|c|c|c|}
\cline { 2 - 6 } \multicolumn{1}{c|}{} & A & B & C & Suma & Promedio \\
\hline A & 0.3 & 0.29 & 0.4 & 1 & 0.320 \\
\hline B & 0.6 & 0.57 & 0.5 & 1.7 & 0.557 \\
\hline C & 0.1 & 0.14 & 0.1 & 0.4 & 0.123 \\
\hline & 1 & 1 & 1 & & 1 \\
\hline
\end{tabular}

Elaboración propia

Tabla 3.3

Resultado de análisis para el factor "Cercanía a otros bares"

\begin{tabular}{|c|c|c|c|c|c|}
\cline { 2 - 6 } \multicolumn{1}{c|}{} & A & B & C & Suma & Promedio \\
\hline A & 0.09 & 0.05 & 0.1 & 0.3 & 0.09 \\
\hline B & 0.36 & 0.19 & 0.2 & 0.7 & 0.24 \\
\hline C & 0.55 & 0.76 & 0.7 & 2 & 0.67 \\
\hline & 1 & 1 & 1 & & 1 \\
\hline
\end{tabular}

Elaboración propia

Tabla 3.4

Resultado de análisis para el factor "Área total"

\begin{tabular}{|c|c|c|c|c|c|}
\cline { 2 - 6 } \multicolumn{1}{c|}{} & A & B & C & Suma & Promedio \\
\hline A & 0.13 & 0.14 & 0.1 & 0.4 & 0.13 \\
\hline B & 0.38 & 0.43 & 0.4 & 1.2 & 0.42 \\
\hline C & 0.5 & 0.43 & 0.4 & 1.4 & 0.46 \\
\hline & 1 & 1 & 1 & & 1 \\
\hline
\end{tabular}

Elaboración propia

Tabla 3.5

Resultado de análisis del factor "Licencias Municipales"

\begin{tabular}{|c|c|c|c|c|c|}
\hline & A & B & C & Suma & Promedio \\
\hline A & 0.25 & 0.25 & 0.3 & 0.8 & 0.25 \\
\hline B & 0.25 & 0.25 & 0.3 & 0.8 & 0.25 \\
\hline C & 0.5 & 0.5 & 0.5 & 1.5 & 0.5 \\
\hline & 1 & 1 & 1 & & 1 \\
\hline
\end{tabular}

Elaboración propia

Una vez obtenidos estos resultados, se les aplican los pesos respectivos, para determinar el local que se adapta de mejor manera a las características requeridas por el 
negocio. A continuación, se presenta la tabla final del procedimiento AHP, en la que se muestra el local seleccionado:

Tabla 3.6

Resultados del procedimiento de jerarquía analítica (AHP)

\begin{tabular}{|c|c|c|c|c|c|}
\hline & Factor A & Factor B & Factor C & Factor D & Puntaje \\
\hline Local A & 0.32 & 0.085 & 0.1 & 0.3 & 0.20 \\
\hline Local B & 0.557 & 0.244 & 0.4 & 0.3 & 0.34 \\
\hline Local C & 0.123 & 0.671 & 0.5 & 0.5 & 0.46 \\
\hline Pesos & 0.14 & 0.14 & 0.29 & 0.43 & 1 \\
\hline
\end{tabular}

Fuente: Elaboración propia

Es así que se obtiene que el local ideal es el "C", es decir el local ubicado en la calle Mártir José Olaya. Este local supera a las otras dos alternativas en los dos factores de mayor importancia, que son el área total y el tipo de comercio permitido. Por otro lado, se encuentra mejor ubicado en lo que se refiere a la cercanía a otros bares. Su puntaje en cuanto a costo es inferior, sin embargo, se considera que este sobrecosto es una inversión necesaria, al compararlo con los beneficios que aporta el local. 


\section{CAPÍTULO IV: DIMENSIONAMIENTO DEL SERVICIO}

\subsection{Relación tamaño-mercado}

La relación que el servicio tiene con el mercado está dada por la demanda. Sin embargo, si bien ya se estableció una demanda potencial en capítulos anteriores, esta cantidad no refleja la realidad que se da al momento de implementar un nuevo servicio, además que no refleja el posible crecimiento en la demanda. Es por esto, que se tomó la información obtenida de las encuestas, y se proyectó el crecimiento esperado de la población, así como la captación esperada para los primeros años.

A continuación, se presenta un cuadro con la relación tamaño mercado para los próximos 6 años.

Tabla 4.1

Proyección de relación "Tamaño - Mercado"

\begin{tabular}{l|ccccc}
\multicolumn{1}{c|}{ Año } & $\mathbf{2 0 1 9}$ & $\mathbf{2 0 2 0}$ & $\mathbf{2 0 2 1}$ & $\mathbf{2 0 2 2}$ & $\mathbf{2 0 2 3}$ \\
\hline Clientes potenciales & 268734.69 & 282684.09 & 307646.76 & 317324.46 & 327521.93 \\
Número de Locales & 60 & 60 & 60 & 60 & 60 \\
Participación del & 4478.91 & 4711.40 & 5127.45 & 5288.74 & 5458.70 \\
mercado & 22.07 & 22.07 & 22.07 & 22.07 & 22.07 \\
Frecuencia de Compra & 98849.58 & 103980.63 & 113162.73 & 116722.51 & 120473.48 \\
Visitas potenciales & 72.47 & 72.47 & 72.47 & 72.47 & 72.47 \\
Ticket Promedio & 7163628.8 & 7535476.2 & 8200903.1 & 8458880.6 & 8730713.2 \\
Demanda (Soles) & 5 & 9 & 7 & 3 & 1 \\
Captación esperada & $30 \%$ & $50 \%$ & $75 \%$ & $80 \%$ & $100 \%$ \\
Demanda real (Soles) & 2149088 & 3767738 & 6150677 & 6767104 & 8730713
\end{tabular}

Elaboración propia

\subsection{Relación tamaño-recursos}

Si bien el servicio principal es proporcionar a los clientes con bebidas alcohólicas y piqueos, los insumos necesarios para su producción no son limitantes para el proceso de servucción. Esto se debe a la pequeña cantidad de insumos que este bar utilizará en comparación con la oferta disponible, considerando que dichos insumos se pueden comprar tanto localmente como por importación. 
Contrariamente, sí es necesario analizar la disponibilidad de terrenos o locales ya que es indispensable contar con un espacio apropiado para poder instalar el servicio. Para ello, se tomaron los diferentes locales mencionados en el capítulo anterior como referencia. Cada uno de los locales descritos se ajusta a las necesidades del bar, por lo que se consideran como recursos disponibles para la instalación del bar.

Por otra parte, ya que se eligió el local de la calle Mártir Olaya, es posible calcular el aforo real del local para así determinar la capacidad de atención de demanda que provee el local como recurso.

Para esto, es necesario considerar solo el área destinada para la clientela; ya que el terreno elegido tiene un área de $377 \mathrm{~m} 2$ y el local tendrá 4 pisos, el área del local podrá ser de máximo $1508 \mathrm{~m} 2$. A esta área se le restarán los estacionamientos y la recepción ya que estas áreas solo tendrán 1 piso de altura y tampoco son zonas en las que la clientela permanezca durante la servucción.

Adicionalmente, se restarán todas las otras áreas que no estén orientadas para la permanencia prolongada de la clientela, la lista de estas áreas se encuentra en el sub-capítulo 5.11. Una vez restadas dichas áreas, se obtiene el área disponible para la servucción: 1086 m2.

Seguidamente, se realizaron los cálculos para determinar el tamaño real del servicio en base al aforo. Esto se traduce en un total de 141312 clientes al año, cantidad superior a la demanda del último año, por lo que el recurso analizado no es limitante para la implementación del bar automatizado en la zona del Parque Kennedy de Miraflores.

\subsection{Relación tamaño-tecnología}

La tecnología no suele ser un factor limitante para servicios como restaurantes o bares; esto se debe a que la tecnología requerida para este tipo de servicios es bastante básica. Sin embargo, debido a la naturaleza tecnológica del servicio propuesto, esta empresa si necesitará una cantidad considerable de maquinaria y aparatos tecnológicos para funcionar. La tecnología que se considerará para calcular la relación tamaño-tecnología será únicamente la que determina la capacidad de servicio, es decir, los tanques de acrílico.

Estos tanques de acrílico transparente servirán para almacenar todos los insumos líquidos de la barra. Estarán empotrados a la pared y se extenderán desde $1 \mathrm{~m}$ arriba del piso hasta $0.5 \mathrm{~m}$ del techo y serán iluminados por detrás con luminaria cálida para resaltar los tonos bronces de la mayoría de bebidas alcohólicas. Como explicamos anteriormente, 
la capacidad volumétrica de almacenaje de los tanques será el factor determinante para la capacidad de atención del bar. El resto de la tecnología utilizada se especificará en el sub-capítulo 5.2 .

Los tanques que se utilizarán en la barra tendrán un diámetro exterior de $14 \mathrm{~cm}$, un diámetro interior de $12.7 \mathrm{~cm}$ y una altura total de $3 \mathrm{~m}$. Esto quiere decir que la capacidad de cada tanque será de 38 litros. Por lo general se utilizará un tanque por cada insumo líquido, pero se utilizarán más tanques para los insumos con mayor demanda, como la cerveza Cusqueña, como se puede ver en la siguiente figura:

Figura 4.1

Cerveza más consumida

¿Cuál es tu marca favorita de cerveza?
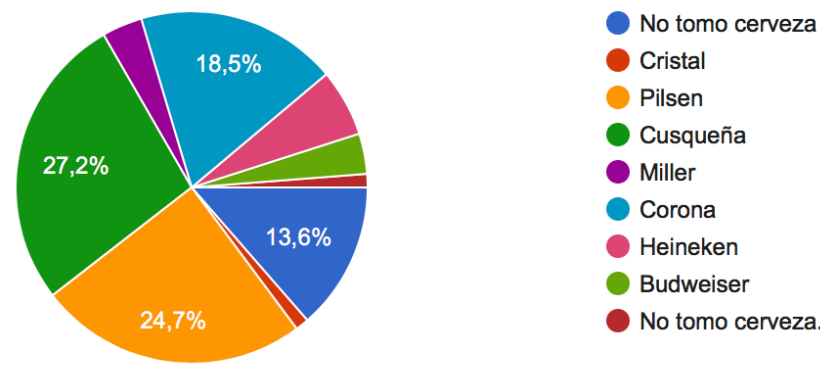

Elaboración propia

Según las encuestas, el $27.2 \%$ de las personas tenían como cerveza preferida a Cusqueña; estimando que el $70 \%$ de la demanda del bar sea a cervezas gracias a un reporte del diario Gestión, podremos asumir que la demanda anual de Cusqueña será de 20800 litros para el año 2023, el horizonte de vida del proyecto. Esto se traduce a 100 litros diarios, que sería cubierto por 3 tanques de acrílico, los cuales se rellenarían todos los días para poder suplir la demanda del día siguiente. Alternativamente, se podrían tener 6 tanques que deberían ser rellenados cada dos días.

El diámetro externo de $14 \mathrm{~cm}$ nos permite calcular que en una barra de $4 \mathrm{~m}$ se podrían colocar 26 tanques de acrílico con un espacio de $1 \mathrm{~cm}$ entre cada tanque. Estos 26 tanques de acrílico equivalen a un volumen de 844 litros, ya que cada tanque tendrá una altura de $2.5 \mathrm{~m}$. Ya que la demanda total en litros del bar automatizado para el año 
2023 será de 500 litros diarios, podemos asumir que la capacidad de atención que ofrece el factor tecnología no es limitante para el negocio.

Alternativamente, cada tanque de acrílico transparente de los diámetros internos y externos especificados anteriormente costará \$59.00/pie, alrededor de $\$ 480$ o $\mathrm{S} / 1$ 560.00 cada tanque ${ }^{3}$. Adicionalmente, existen varios proveedores de tuberías de acrílico en Lima: Coplast, Acrilex, SX/EW Del Perú S.A.C., T\&T Ingeniería Y Construcción S.A., etc. Esto quiere decir que el factor tecnología es relativamente sencillo de conseguir y por lo tanto no será un limitante para el negocio.

\subsection{Relación tamaño-punto de equilibrio}

Más adelante, dentro del capítulo de presupuestos y evaluación económica-financiera, se detallan todas las inversiones y los gastos que se realizarán anualmente en la empresa. Sin embargo, estos cálculos son necesarios para la determinación del punto de equilibrio, y si este es una posible limitante para la empresa. A continuación, se detallan los gastos fijos de la empresa para los 5 años de vida del negocio:

Tabla 4.2

Proyección de los gastos fijos del negocio

\begin{tabular}{c|ccccc} 
Año & $\mathbf{2 0 1 9}$ & $\mathbf{2 0 2 0}$ & $\mathbf{2 0 2 1}$ & $\mathbf{2 0 2 2}$ & $\mathbf{2 0 2 3}$ \\
\hline Gastos fijos (S/) & 852711.12 & 946575.19 & 1084758.45 & 1115836.27 & 1229700.17 \\
Elaboración propia & & & &
\end{tabular}

Estos gastos incluyen el pago de salarios y todos los beneficios, los gastos de depreciación, el consumo de materiales, y el pago de servicios como luz, agua, teléfonos, Wi-Fi y derechos de superficie.

Adicionalmente, se calcularon los márgenes de contribución de cada una de la familia de tragos y piqueos, en base a las cotizaciones obtenidas. En la siguiente página, se detallan los márgenes de contribución por tipo de producto, así como la participación de dichos productos en las ventas.

\footnotetext{
${ }^{3}$ Costos referenciales de tuberías de acrílico moldeado modelo KM-873, marca K-Mac Plastics
} 
Tabla 4.3

Margen de contribución y proporción a las ventas por producto

\begin{tabular}{lccccc} 
Productos & Precios & $\begin{array}{c}\text { Costos } \\
\text { variables }\end{array}$ & $\begin{array}{c}\text { Margen de } \\
\text { Contribución }\end{array}$ & $\begin{array}{c}\text { Contribución } \\
\text { a Ventas }\end{array}$ & Factor \\
\hline Pilsen & 20 & 0.95 & 19.05 & $18.53 \%$ & 3.52 \\
Cusqueña & 20 & 1.03 & 18.96 & $20.40 \%$ & 3.86 \\
Corona & 20 & 1.07 & 18.92 & $13.13 \%$ & 2.48 \\
Pisco Sour & 25 & 4.24 & 20.75 & $3.60 \%$ & 0.74 \\
Maracuyá Sour & 25 & 5.93 & 19.06 & $3.60 \%$ & 0.68 \\
Mojito & 25 & 2.06 & 22.93 & $2.89 \%$ & 0.66 \\
Cuba Libre & 25 & 3.20 & 21.80 & $2.89 \%$ & 0.62 \\
Margarita & 25 & 7.10 & 17.89 & $0.98 \%$ & 0.17 \\
Vodkatini & 25 & 2.85 & 22.15 & $4.50 \%$ & 0.99 \\
Whiskey & 25 & 4.32 & 20.68 & $4.50 \%$ & 0.93 \\
Tequeños & 25 & 1.89 & 23.10 & $8.33 \%$ & 1.92 \\
Langostinos & 25 & 4.52 & 20.48 & $8.33 \%$ & 1.70 \\
Yucas & 25 & 4.07 & 20.93 & $8.33 \%$ & 1.74 \\
Elaboración propia & & & & &
\end{tabular}

Es así que se obtiene que, en base a los costos variables y a los precios fijados, se obtiene la siguiente evolución del punto de equilibrio.

Tabla 4.4

Determinación del punto de equilibrio

\begin{tabular}{l|ccccc} 
Año & $\mathbf{2 0 1 9}$ & $\mathbf{2 0 2 0}$ & $\mathbf{2 0 2 1}$ & $\mathbf{2 0 2 2}$ & $\mathbf{2 0 2 3}$ \\
\hline Gastos fijos & 852711 & 946575 & 1084758 & 1115836 & 1229700 \\
Margen Ponderado & 20.08 & 20.08 & 20.08 & 20.08 & 20.08 \\
Punto De EQ & 42449.26 & 47121.96 & 54000.94 & 55548.04 & 61216.36 \\
Bebidas & 31836.95 & 35341.47 & 40500.70 & 41661.03 & 45912.27 \\
Visitas & 10612.32 & 11780.49 & 13500.23 & 13887.01 & 15304.09
\end{tabular}

Elaboración propia

\subsection{Selección de la dimensión del servicio}

Tras la elaboración de los diferentes relaciones de tamaño, se pudo determinar que el factor limitante para la dimensión del servicio será el mismo mercado. El tamaño estará decidido por la cantidad máxima de personas que recibirá el bar para el horizonte de vida del proyecto en el año 2023, equivalente a 8730713.21 soles anuales. 


\section{CAPÍTULO V: INGENIERÍA DEL PROYECTO}

\subsection{Proceso para la realización del servicio}

El propósito del capítulo, es definir con exactitud todos los elementos que se requieren para poner en marcha el servicio. En ese sentido, es necesario establecer el proceso exacto de servucción, y las relaciones que se establecen entre los clientes, las evidencias físicas y el personal existente en el negocio. Por ello, en los próximos sub-capítulos se redescribirá el proceso de una manera más detallada y se adjuntan los diagramas de procesos.

\subsubsection{Descripción del proceso del servicio}

El proceso del servicio inicia con la llegada del cliente al establecimiento. Al ingresar, se encontrará con un anfitrión o anfitriona, quien será el encargado de recibir al cliente, y preguntarle si es la primera vez que visita el establecimiento. De ser afirmativa la respuesta, el anfitrión debe explicar al cliente el funcionamiento del servicio. En cualquiera de los casos, el cliente debe entregar su DNI al anfitrión, para que este verifique su edad y pueda enlazar el DNI con una tarjeta que permita realizar consumos dentro del establecimiento. Este proceso no se lleva a cabo si el cliente es frecuente y posee una tarjeta propia que le permita pagar su cuenta a fin de mes.

Ya que se busca que el servicio sea socialmente responsable, esta modalidad de verificar DNI a través de un sistema, permite evitar el ingreso con DNI falsos a menores de edad. Por otro lado, si existiese un conductor designado dentro de un grupo de clientes, no se le proporcionaría tarjeta, para que no se le pueda vender alcohol, promoviendo así el consumo responsable.

Continuando con el servicio, el cliente debe elegir el ambiente al que se dirigirá. Dentro del establecimiento existirán 4 ambientes principales:

- Ambiente principal (primer piso): En esta zona del local se encontrarán las mesas para juegos de mesa, el escenario para cuando exista música en vivo, además de la barra automatizada. 
- Ambiente deportivo (segundo piso): Este ambiente estará dedicado a entretener a personas que deseen participar de actividades deportivas, como lo son jugar dardos, jugar billar, etc. Además contará con la cocina principal del servicio.

- Ambiente de Video Juegos (tercer piso): En esta zona se entretendrá a la clientela enfocada en divertirse en grupo de manera menos competitiva, y que guste de jugar videojuegos grupales. Contará con una barra automatizada al igual que las otras zonas.

- Ambiente para fumadores (terraza superior): Ubicada en la azotea del edificio, esta terraza está dedicada a aquellos clientes que deseen fumar dentro del servicio.

Una vez que el cliente haya decidio sobre el ambiente en el que desea ubicarse, puede acercarse a la barra automatizada, y, en cualquiera de los módulos, realizar su pedido a través de las interfaces táctiles. Para realizar su pedido, es necesario que el cliente pase la tarjeta que se le entregó al inicio del proceso, para que se almacene el pedido en una base de datos. Posteriormente, el cliente selecciona la o las bebidas que desea, e indica si quiere personalizarlas. La programación interna de los módulos se encarga de realizar el despacho del producto, y el cliente colecta su bebida y se dirige a su mesa.

Si el cliente lo desea puede realizar un pedido de piqueos acercándose a cualquier miembro del personal de apoyo o llamando la atención de un mozo. De igual manera, el mozo pasa la tarjeta para poder realizar el pedido y alamacenarlo en la base de datos. Esta comanda es enviada a la cocina, en la que se preparan los piqueos para luego ser despachados.

Para finalizar el proceso, en caso el cliente posea membresía, puede retirarse y el cobro se realizará al final de cada mes. Caso contrario, el cliente o grupo de clientes, debe acercarse a una de las cajas o llamar la atención de los mozos para realziar el pago. Gracias al sistema de tarjetas, es posible realizar el cobro en tres modalidades:

- Cuentas separadas: Se pasa la tarjeta de cada cliente uno por uno, y se realiza el cobro de manera individual 
- Una sola cuenta: Se pasan las tarjetas de cada cliente, una después de la otra, y se suman los totales para obtener una cuenta que incluya el consumo de todo el grupo.

- Promedio simple: Se pasan las tarjetas de todos los clientes, y se obtiene un promedio para que cada cliente pague el mismo monto.

Luego de la consolidación del pago los clientes proceden a retirarse, pasando primero por el mostrador de la entrada, en los cuales devolverán las tarjetas. En caso los clientes se retiren sin pagar, el sistema de tarjetas permite que se realice el cobro, ya que cada tarjeta se encuentra ligada a un número de DNI.

\subsubsection{Diagrama del flujo del servicio}

A partir del servicio descrito, se generarán los diagramas de proceso que permitan analizar detalladamente los requerimientos de personal, maquinaria, mobiliario, etc. Los diagramas a utilizar son: El diagrama trirelacional, que servirá de apoyo para determinar la mano de obra y la maquinaria necesaria, y el esquema del servicio, que detallará todas las actividades que se realizan, que no son vistas por el cliente. A continuación se muestra el diagrama trirelacional del servicio, en el qe se detallan todas las actividades del cliente, y los requerimientos del sistema.

\section{Diagrama 5.1}

Diagrama trirelacional del bar automatizado

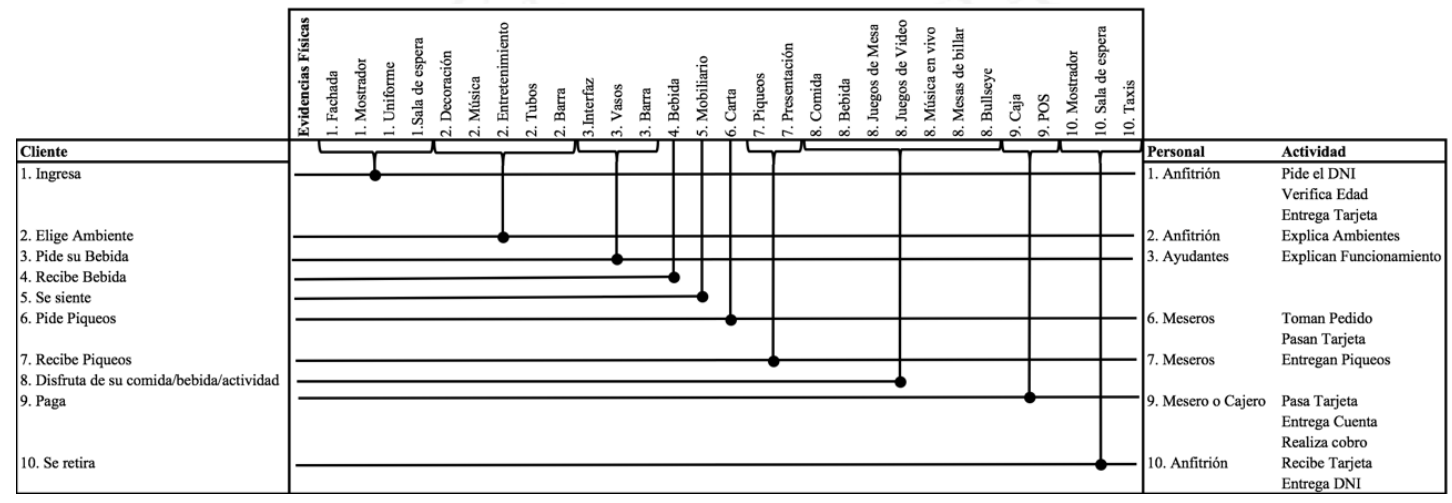

Elaboración propia 
Finalmente, se detalla el esquema del servicio, con todas las actividades del BackOffice y los procesos de apoyo.

Diagrama 5.2

Esquema de servicio del bar automatizado

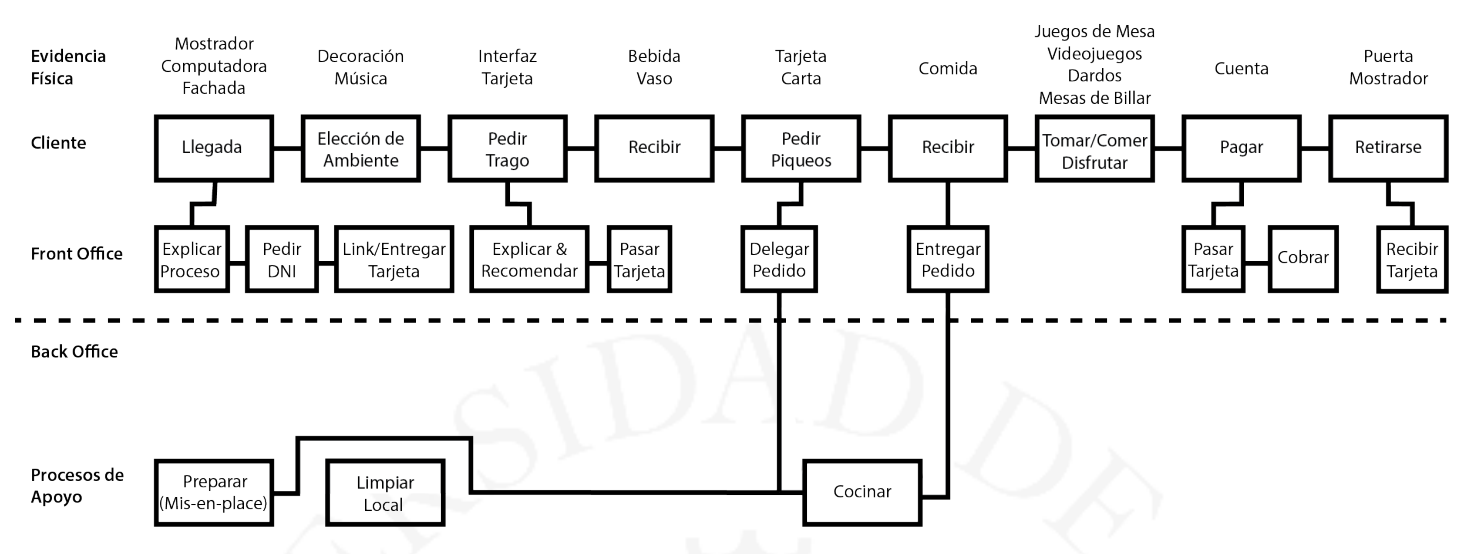

Elaboración propia

\subsection{Descripción del tipo de tecnología}

A continuación, se detallará toda la tecnología necesaria para la implementación del bar automatizado, junto con sus diferentes usos, figuras y precios referenciales.

\section{PLC - Logo (Siemens)}

Este será el cerebro del bar automatizado y sin duda, su componente más importante. Se decidió utilizar un PLC - Logo debido a su gran poder de procesamiento de datos simultáneos y a su robustez, haciéndolo capaz de soportar ambientes hostiles (húmedos, calientes, etc.) que otros microcontroladores no podrían soportar sin recubrimientos protectores.

Se eligió utilizar un PLC - Logo y no un PLC más completo porque las funcionalidades que ofrece son más que suficientes para el tipo de trabajos que el bar necesitará realizar. El PLC - Logo de Siemens costará alrededor de 300 soles y se podrá conseguir tanto nuevo como usado ya que al ser un producto con fines industriales y que no interactúa directamente con el producto, no tendrá mayor desgaste debido a su constante utilización.

A continuación, se presenta una imagen del PLC - Logo de Siemens: 
Figura 5.1

PLC Logo

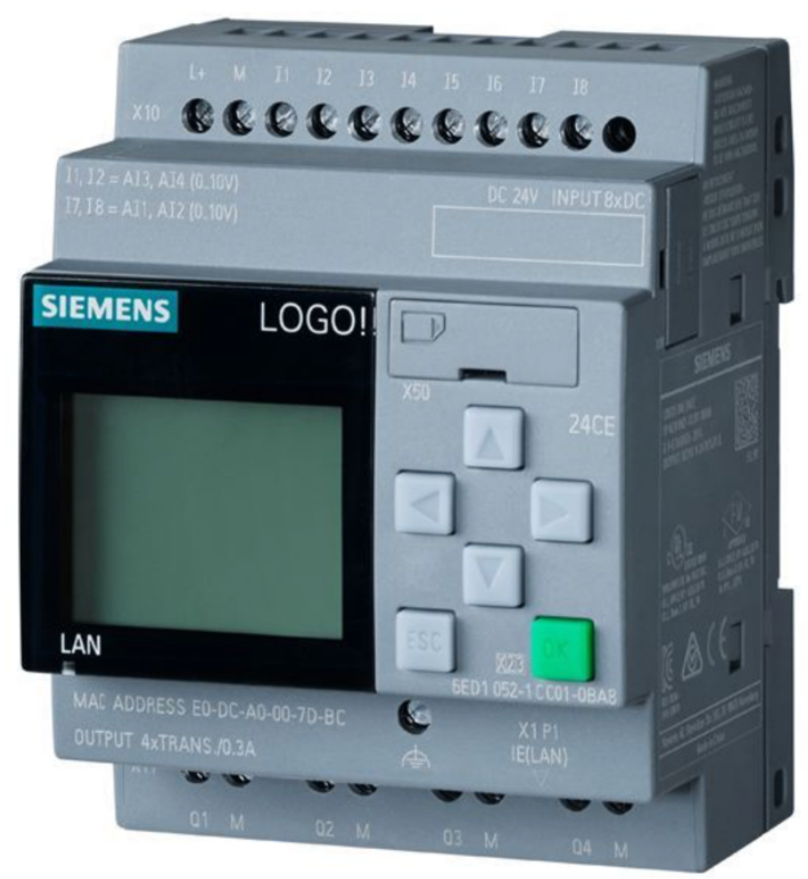

Fuente: Siemens Perú (2016)

\section{Sensores de temperatura}

Los sensores de temperatura serán muy importantes para poder asegurar un servicio rápido y efectivo ya que asegurarán, junto al sistema de refrigeración, que los insumos siempre se encuentren a la temperatura óptima de entre $-5^{\circ} \mathrm{C}$ y $-15^{\circ} \mathrm{C}$.

Estos sensores se colocarán en los tanques de los insumos más importantes, como en el caso de las cervezas, o que necesiten estar a una cierta temperatura para preservarse por más tiempo como el caso de las claras de huevo.

\section{Manómetros}

Los manómetros se encargarán de medir la presión interna de los tanques, ayudando a asegurar que ésta siempre se mantenga constante. Estos sensores estarán conectados al PLC como inputs, otorgándole información de las mediciones de forma periódica. 


\section{Sistema de refrigeración}

El sistema de refrigeración afectará a los insumos dentro de los tanques de acrílico, asegurando que estén a sus temperaturas ideales con ayuda de los sensores de temperatura.

\section{Válvulas On-Off}

Las válvulas, junto con los actuadores, se encargarán de suministrar las cantidades solicitadas para los diferentes pedidos de forma precisa y rápida. Serán de tipo On-Off ya que los tanques tendrán presión interna constante, haciendo posible medir el volumen de insumo suministrado tan sólo variando el tiempo de apertura.

\section{Actuadores}

Los actuadores suministrarán la cantidad y el tipo de energía necesario para abrir las diferentes válvulas, de esta manera podrán suministrar el volumen de los diferentes insumos requerido para la elaboración del pedido.

\section{Cajas registradoras}

El bar automatizado utilizará cajas registradoras como una de sus dos principales modalidades de cobro. Estas cajas registradoras estarán conectadas a la red del bar para así ingresar la data detallada de las transacciones, incluyendo productos pedidos, cantidades, porcentajes utilizados, precio, monto total de la orden, etc.

\section{POS}

También se utilizarán POS como la segunda principal modalidad de cobro. Estos harán posible el cobro a tarjetas de crédito y débito tanto desde la barra como en las diferentes mesas del local con ayuda de los meseros. 


\subsection{Capacidad instalada}

Si bien en el capítulo anterior se determinó que el tamaño del servicio estaría delimitado por la demanda del mercado, esta dimensión no representa fielmente la capacidad de atención del negocio. Esta situación se da debido a que aún no se han considerado factores como lo son: El número de módulos o colas, el número de personas encargadas de la preparación de los piqueos, la utilización del servicio y la eficiencia de la barra automatizada. A continuación, se detallan los factores que influyen en la capacidad real del servicio, y el cálculo final de la capacidad real.

\subsubsection{Identificación y descripción de los factores que intervienen en brindar el servicio}

Como se mencionó en la introducción del capítulo, la capacidad está delimitada por diversos factores. Al tratarse de un servicio, la mayoría de estos factores se relacionan de manera directa con los procesos de atención al cliente.

\section{Factor: Atención en la barra automatizada}

Este factor hace referencia al número de colas y módulos que existen dentro del establecimiento y que servirán para atender los pedidos del cliente. Se ha determinado que el tiempo que demora cada cliente en realizar su pedido y recibirlo es alrededor de 1.5 minutos por bebida. Además, se ha obtenido de las encuestas que cada cliente consume en promedio 3 bebidas por visita.

\section{Factor: Preparación de Piqueos}

Ya que el servicio principal es la preparación de bebidas alcohólicas, no todos los clientes que visiten el establecimiento consumirán piqueos. En base a las entrevistas tenidas, se ha estimado que alrededor del $60 \%$ de clientes pide piqueos. Por otro lado, al tratarse de parte de un servicio complementario que se debe dar casi instantáneamente, se ha determinado que el tiempo máximo que se deberá esperar por los piqueos es de 7 minutos. 
Si bien cada piqueo puede llegar a tener un tiempo estándar de preparación particular, se ha tomado el tiempo máximo para el cálculo de la capacidad, ya que, en el peor de los casos, la capacidad obtenida es la mínima que se debería poder atender.

\section{Factor: Atención del Anfitrión}

Otro factor que afecta la capacidad el servicio, es la rapidez de los anfitriones en atender a los clientes. Durante el proceso de servucción, el anfitrión recibe a los clientes y verifica su DNI. Al final del servicio, es el anfitrión quien recoge las tarjetas devueltas por los clientes que no posean membresía. Al inicio del servicio, el tiempo estándar que debe tomar el anfitrión al atender al cliente es de aproximadamente 1 minuto. El proceso de recojo de tarjetas tiene un tiempo despreciable.

\section{Factor: Cantidad de Meseros y Asistentes}

La cantidad de meseros y asistentes determina no sólo la capacidad de atención al cliente, sino también el nivel de satisfacción. Un número elevado de meseros permite que los clientes sean atendidos de manera veloz, sin embargo, esto puede resultar demasiado costoso. Es necesario balancear el nivel de servicio al cliente con el costo logístico que este representa.

\section{Factor: Aforo}

El aforo de un servicio está determinado por la cantidad de personas que pueden permanecer adentro en un determinado momento. De acuerdo al área construida dentro del establecimiento, se determina una cantidad máxima de personas que pueden ser atendidas. De acuerdo con el artículo 8 de la modificación a la norma A070 del ministerio de vivienda del Perú, un bar está clasificado dentro del grupo denominado "Cafeterías". El aforo para estos establecimientos se subdivide en 2 partes.

- Aforo en las cocinas: Para el personal de cocina, se calcula que cada miembro del staff requiere de $9.3 \mathrm{~m}^{2}$.

- Aforo para el área de clientes: Para el cálculo de aforo de los clientes se estima que es necesario considerar $1.5 \mathrm{~m}^{2}$ por persona. 


\section{Factor: Número de mesas.}

Independientemente del aforo, el número de mesas podría ser un determinante para la capacidad: si el cliente no desease mantenerse de pie, podría terminar por retirarse sin haber consumido el servicio.

\subsubsection{Determinación del factor limitante de la capacidad}

Los factores antes mencionados afectan de manera directa la capacidad el servicio, sin embargo, no todos ellos son limitantes; incluso, muchos de ellos están en función de otros factores. Este es el caso de recursos como la cantidad de módulos de la barra y el número de asistentes.

Es por este motivo que se ha determinado que los factores limitantes de la capacidad del servicio serán aquellos que tengan que ver con la atención directa al cliente, es decir:

- Factor: Atención del Anfitrión

- Factor: Preparación de piqueos

- Factor: Atención en la barra automatizada

En el subcapítulo siguiente, se determina la cantidad de recursos necesarios para cada uno de estos factores.

\subsubsection{Determinación del número de recursos del factor limitante}

El número de recursos de cada factor está determinado por la demanda real de clientes que existe para ese factor. Para analizar de manera real la capacidad se tomarán en cuenta todos los años de vida del proyecto y se determinará el máximo requerimiento de cada uno de los recursos.

A continuación, se presenta el cuadro de demanda en visitas para cada uno de los años de vida. 
Tabla 5.1

Demanda en visitas por año

\begin{tabular}{l|ccccc} 
Año & $\mathbf{2 0 1 9}$ & $\mathbf{2 0 2 0}$ & $\mathbf{2 0 2 1}$ & $\mathbf{2 0 2 2}$ & $\mathbf{2 0 2 3}$ \\
\hline Participación del mercado & 4478 & 4711 & 5127 & 5288 & 5458 \\
Frecuencia de Compra & 22.07 & 22.07 & 22.07 & 22.07 & 22.07 \\
Visitas potenciales & 98849 & 103980 & 113162 & 116722 & 120473
\end{tabular}

Elaboración propia

A partir de estos datos, es posible determinar la cantidad de recursos necesarios en cada actividad crítica, tomando como base la siguiente fórmula:

$$
M=\frac{D \times T_{s}}{H \times U \times E}
$$

En donde "M" representa el número de máquinas o recursos, "D” la demanda anual de la actividad, "H" las horas disponibles, "Ts" el tiempo estándar, y "U" y "E" los porcentajes de utilización y eficiencia. Para todas las estaciones, el tiempo disponible está determinado por la cantidad de horas que se encuentra abierto el servicio. En este caso, el bar automatizado abrirá de miércoles a sábado, de 7 pm a 3 am, las 52 semanas del año. Esto indica que se tiene un total de 1664 horas al año. Debido a que la maquinaria es automatizada, se ha establecido una eficiencia de 0.9 para todas las actividades, y una utilización de 0.8 .

A continuación, se detalla el cálculo de módulos de preparación de bebidas necesarios para cada año.

Tabla 5.2

Cálculo de cantidad de módulos de preparación de bebidas

\begin{tabular}{l|ccccc} 
Año & $\mathbf{2 0 1 9}$ & $\mathbf{2 0 2 0}$ & $\mathbf{2 0 2 1}$ & $\mathbf{2 0 2 2}$ & $\mathbf{2 0 2 3}$ \\
\hline Demanda en Personas & 29654.87 & 51990.32 & 84872.05 & 93378.01 & 120473.48 \\
Demanda en bebidas & 88964.62 & 155970.95 & 254616.15 & 280134.04 & 361420.44 \\
Tiempo en Minutos & 133446.93 & 233956.42 & 381924.22 & 420201.05 & 542130.67 \\
Cantidad de Módulos & 1.49 & 2.60 & 4.25 & 4.68 & 6.03
\end{tabular}

Elaboración propia 
Es así que se obtiene que el máximo de módulos necesarios es 7 módulos. Sin embargo, a fin de facilitar el servicio se ha determinado la existencia de 4 módulos por piso y al tener 4 pisos, se tendrán 2 pisos con módulos, contando en total con 8 módulos. La capacidad ociosa de los módulos permitirá atender a los clientes con mayor facilidad.

Por otro lado, en esta tabla se detalla el cálculo del número de trabajadores del área de preparación de piqueos.

\section{Tabla 5.3}

Cálculo de trabajadores en cocina

\begin{tabular}{l|ccccc} 
Año & $\mathbf{2 0 1 9}$ & $\mathbf{2 0 2 0}$ & $\mathbf{2 0 2 1}$ & $\mathbf{2 0 2 2}$ & $\mathbf{2 0 2 3}$ \\
\hline Demanda en Personas & 29654.87 & 51990.32 & 84872.05 & 93378.01 & 120473.48 \\
Demanda de Piqueos & 7413.72 & 12997.58 & 21218.01 & 23344.50 & 30118.37 \\
Tiempo de preparación & 51896.03 & 90983.05 & 148526.09 & 163411.52 & 210828.59 \\
Cantidad de Personas & 0.72 & 1.27 & 2.07 & 2.27 & 2.93
\end{tabular}

Elaboración propia

Es así que se tendrán 3 personas encargadas de la preparación de piqueos en el área de cocina. Si bien existe un poco de capacidad ociosa, no es posible considerar que en todos los días la demanda será constante, por lo que esta servirá para atender a aquellos días en los que el bar se encuentre excesivamente lleno y exista una cantidad de pedidos superior a la normal.

Finalmente, en la siguiente tabla se presenta el cálculo realizado para la obtención del número de anfitriones necesarios.

Tabla 5.4

Cálculo del número de anfitriones

\begin{tabular}{l|ccccc} 
Año & $\mathbf{2 0 1 9}$ & $\mathbf{2 0 2 0}$ & $\mathbf{2 0 2 1}$ & $\mathbf{2 0 2 2}$ & $\mathbf{2 0 2 3}$ \\
\hline Demanda personas & 29654.87 & 51990.31 & 84872.04 & 93378 & 120473.48 \\
Tiempo atención & 29654.87 & 51990.31 & 84872.04 & 93378 & 120473.48 \\
Cantidad de Personas & 0.41 & 0.72 & 1.18 & 1.30 & 1.68
\end{tabular}

Elaboración propia

Así pues, se tendrán dos personas encargadas de recibir a los clientes, y verificar el DNI. La capacidad ociosa de este recurso servirá para recibir las tarjetas de los clientes al momento de su salida, y para reiniciar cada tarjeta en el sistema. 


\subsubsection{Determinación del número de recursos de los demás factores}

En cuanto a los demás factores de producción, estos están dados en relación a los factores principales. Por ejemplo, el número de asistentes o mozos, debe ser mayor o igual a la cantidad de módulos que existan en el bar. Es por este motivo que se ha determinado una cantidad de 4 asistentes que se mantendrán fijos en las estaciones, y 8 mozos en cada piso, que serán los encargados de realizar los pedidos de piqueos y despacharlos al cliente.

\subsubsection{Cálculo de la capacidad de atención}

Con los factores críticos definidos, es posible determinar la capacidad instalada del bar. A continuación, se detalla una tabla de comparación entre la capacidad disponible de cada uno de los factores.

\section{Tabla 5.5}

Capacidad de atención por actividad

\begin{tabular}{l|cccccccc} 
Proceso & TS & H/día & días/sem & sem/año & M & U & E & CO \\
\hline Preparación de Bebidas & 0.025 & 8 & 4 & 52 & 8 & 0.9 & 1 & 479232 \\
Preparación de Piqueos & 0.117 & 8 & 4 & 52 & 3 & 0.9 & 0.8 & 30807.77 \\
Atención Anfitrión & 0.0167 & 8 & 4 & 52 & 2 & 0.9 & 0.8 & 143769.6 \\
Elaboración propia & & & & & & & &
\end{tabular}

Cada una de estas actividades posee una capacidad instalada otorgada en diferentes unidades, por lo que es necesario realizar una conversión que permita determinar cuál es la menor capacidad en términos de clientes. En la siguiente tabla se muestra la tabla en la cual se ha realizado la conversión, de acuerdo a las siguientes equivalencias: Una persona consume en promedio tres bebidas, mientras que un piqueo es consumido por 4 personas, y los anfitriones atienden a una persona por vez.

Tabla 5.6

Capacidad de atención del servicio

\begin{tabular}{l|ccc} 
Proceso & CO & Equivalencias & Capacidad \\
\hline Preparación de Bebidas & 479232 & 0.333333333 & 159744 \\
Preparación de Piqueos & 30807.77 & 4 & 123231.09 \\
Atención Anfitrión & 143769.6 & 1 & 143769.6
\end{tabular}

Elaboración propia 
Finalmente, se obtiene una capacidad instalada de 123231 visitas al año, delimitada por el personal de piqueos. Esta capacidad resulta mayor que la demanda anual de visitas, que, para el último año de vida del proyecto, se calcula en 120474 visitas.

\subsection{Resguardo de la calidad}

Asegurar la calidad es extremadamente importante para el negocio ya que tiene una relación directamente proporcional a la experiencia del usuario, que es lo que determinará el posible nivel de acogida del bar automatizado; es decir, determinará si las personas se convertirán en clientes frecuentes, si los clientes recomendarán el servicio a sus conocidos, etc. El resguardo de la calidad puede quebrar o levantar al negocio.

En este sub-capítulo se describirán los métodos que se utilizarán para asegurar la buena calidad del servicio y la experiencia del usuario. Para poder ofrecer siempre la mejor calidad, se definirán las especificaciones de los productos servidos, se medirán los niveles de satisfacción del cliente y se verificará que la calidad sea consistente.

\subsubsection{Calidad del proceso y del servicio}

Dado que el estudio propone la implementación de un servicio en el que se entregarán productos alimentarios y bebidas, es de suma importancia mantener un altísimo nivel de higiene y salubridad, para que se pueda mantener la calidad y esterilidad de los productos. Así mismo, es necesario tomar medidas para asegurar la estandarización en la preparación de los platos y bebidas, de manera que el cliente esté siempre satisfecho con lo que se le presenta.

En este sentido, la automatización de la barra facilita el aseguramiento de la calidad en la preparación de las bebidas alcohólicas, ya que elimina el error humano en la medición y en la preparación.

A continuación, se presenta como ejemplo, el cuadro de especificaciones de la bebida Pisco Sour, y el cuadro de especificaciones del piqueo Tequeños de Lomo Saltado, para el aseguramiento de la calidad. 
Tabla 5.7

Cuadro de especificaciones de calidad para bebidas

\begin{tabular}{|c|c|c|c|c|c|c|}
\hline $\begin{array}{l}\text { Nombre del } \\
\text { producto: }\end{array}$ & \multicolumn{2}{|c|}{ Pisco Sour $250 \mathrm{ml}$} & $\begin{array}{l}\text { Desarrollado } \\
\text { por: }\end{array}$ & & & \\
\hline Función: & \multicolumn{2}{|c|}{ Satisfacer la sed del cliente } & Verificado por: & \multicolumn{3}{|c|}{ Supervisor de Personal } \\
\hline $\begin{array}{l}\text { Insumos } \\
\text { requeridos: }\end{array}$ & \multicolumn{2}{|c|}{$\begin{array}{l}\text { Pisco, Jarabe de goma, Clara } \\
\text { de huevo, } \\
\text { Amargo de angostura, Jugo } \\
\text { de limón }\end{array}$} & $\begin{array}{l}\text { Autorizado } \\
\text { por: }\end{array}$ & \multicolumn{3}{|c|}{ Gerente General } \\
\hline $\begin{array}{l}\text { Costo del } \\
\text { producto: }\end{array}$ & & & Fecha & \multicolumn{3}{|c|}{23 de septiembre de 2017} \\
\hline \multirow{2}{*}{$\begin{array}{l}\text { Características } \\
\text { del producto }\end{array}$} & \multicolumn{2}{|c|}{ Tipo de característica } & $\begin{array}{l}\text { Norma técnica } \\
\text { o especificación }\end{array}$ & \multirow{2}{*}{\multicolumn{2}{|c|}{ 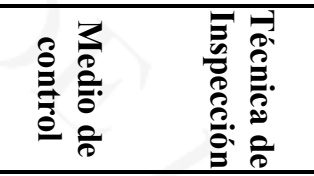 }} & \multirow{2}{*}{$\stackrel{2}{2}$} \\
\hline & $\begin{array}{l}\text { Variable / } \\
\text { Atributo }\end{array}$ & $\begin{array}{l}\text { Nivel de } \\
\text { Criticidad }\end{array}$ & & & & \\
\hline Volumen & Variable & Mayor & $250 \mathrm{ml}+/-5$ & Visual & Muestreo & $>1.0 \%$ \\
\hline Color & Atributo & Mayor & Verde Pastel & Visual & Muestreo & $>1.0 \%$ \\
\hline Olor & Atributo & Crítico & $\begin{array}{c}\text { Cítrico - } \\
\text { Alcoholizado }\end{array}$ & Sensorial & Muestreo & $<0,1 \%$ \\
\hline Sabor & Atributo & Crítico & Cítrico & Sensorial & Muestreo & $<0,1 \%$ \\
\hline $\begin{array}{l}\text { Limpieza del } \\
\text { Vaso }\end{array}$ & Atributo & Crítico & Impecable & Visual & Muestreo & $<0,1 \%$ \\
\hline
\end{tabular}

Elaboración propia

En la siguiente página se encuentra el cuadro de especificaciones de calidad para uno de los piqueos definidos para el bar automatizado. 
Tabla 5.8

Cuadro de especificaciones de calidad para piqueos

\begin{tabular}{|c|c|c|c|c|c|c|}
\hline $\begin{array}{l}\text { Nombre del } \\
\text { producto: }\end{array}$ & \multicolumn{2}{|c|}{ Tequeños de Lomo Saltado } & $\begin{array}{l}\text { Desarrollado } \\
\text { por: }\end{array}$ & & & \\
\hline Función: & \multicolumn{2}{|c|}{ Alimentación } & Verificado por: & \multicolumn{3}{|c|}{ Supervisor de Personal } \\
\hline $\begin{array}{l}\text { Insumos } \\
\text { requeridos: }\end{array}$ & \multicolumn{2}{|c|}{$\begin{array}{c}\text { Carne, Masa, Aceite, } \\
\text { Cebolla, Queso }\end{array}$} & $\begin{array}{l}\text { Autorizado } \\
\text { por: }\end{array}$ & \multicolumn{3}{|c|}{ Gerente General } \\
\hline $\begin{array}{l}\text { Costo del } \\
\text { producto: }\end{array}$ & & & Fecha & \multicolumn{3}{|c|}{23 de septiembre de 2017} \\
\hline \multirow{2}{*}{$\begin{array}{l}\text { Características } \\
\text { del producto }\end{array}$} & \multicolumn{2}{|c|}{ Tipo de característica } & $\begin{array}{l}\text { Norma técnica } \\
\text { o especificación }\end{array}$ & \multirow{2}{*}{\multicolumn{2}{|c|}{ 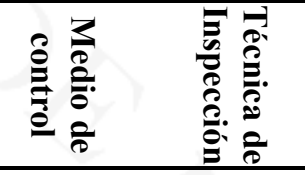 }} & \multirow{2}{*}{$\stackrel{Z}{2}$} \\
\hline & $\begin{array}{l}\text { Variable / } \\
\text { Atributo }\end{array}$ & $\begin{array}{l}\text { Nivel de } \\
\text { Criticidad }\end{array}$ & V.N. \pm Tol & & & \\
\hline Cantidad & \multicolumn{2}{|l|}{ Variable } & 8 & \multirow{2}{*}{$\begin{array}{l}\text { Contar } \\
\text { Visual }\end{array}$} & Muestreo & $>1.0 \%$ \\
\hline Sabor & Atributo & Mayor & \multirow{2}{*}{$\begin{array}{c}\text { Salado } \\
\text { De acuerdo a lo } \\
\text { establecido }\end{array}$} & & Muestreo & $>1.0 \%$ \\
\hline Presentación & Atributo & Crítico & & Sensorial & Muestreo & $<0,1 \%$ \\
\hline $\begin{array}{l}\text { Limpieza del } \\
\text { Plato }\end{array}$ & Atributo & Crítico & Impecable & Visual & Muestreo & $<0,1 \%$ \\
\hline
\end{tabular}

Elaboración propia

Estos cuadros hacen referencia a la calidad en los productos ofrecidos al cliente. Sin embargo, es necesario establecer estándares sobre la satisfacción del cliente con la calidad del servicio prestado.

\subsubsection{Niveles de satisfacción del cliente}

Para afrontar el problema de nivel de satisfacción al cliente, primero es necesario determinar las vías de ingreso de este tipo de información, como medir los datos y como interpretar la información recibida.

A través del uso de la página web del bar, páginas en redes sociales, y encuestas anónimas durante el proceso de servucción, se puede obtener la información respecto a la satisfacción del cliente. Así mismo, es posible que los meseros y los asistentes entreguen reportes cada noche sobre las sugerencias verbales realizadas por los clientes.

Entrando más a detalle, el servidor del bar automatizado recolectará los datos de las quejas y sugerencias provenientes de la casilla de la página web y de los correos 
enviados al mail de quejas y sugerencias. Las redes sociales tendrán opción de comentar en las publicaciones puestas por la empresa, dejar sus propios posts e incluso chatear en tiempo real con la empresa.

Adicionalmente, se lanzarán concursos esporádicamente en los que se les permitirá a los clientes presentar propuestas de mejora o eventos que puedan ser del interés de los demás clientes. Dichas propuestas se someterán a votación y se le ofrencerán premios al ganador; estos concursos servirán un doble propósito: el de dar una motivación común a los clientes para manterlos involucrados activamente con el negocio y el de la mejora continua del proceso de servicio mediante la implementación de ideas que sean verdaderamente satisfactorias para el cliente.

Toda esta información deberá ser recopilada y almacenada en un mismo lugar para ser posteriormente procesada y analizada. De esta forma se podrán descubirir tendencias de satisfacción, especialmente los elementos que más satisfacen al cliente y aquellos aspectos en los que hay posibilidad de mejora.

\subsubsection{Medidas de resguardo de la calidad}

Con el propósito de mantener óptimo el nivel de calidad, se plantean las siguientes medidas:

- Capacitar constantemente al personal en lo que se refiere a atención al cliente y el uso de los módulos automáticos.

- Realizar auditorías del sistema de gestión de higiene dentro de la cocina y la barra.

- Utilizar tanto las redes sociales como la página web del bar para realizar votaciones sobre temáticas para nuevos eventos, sugerencias de promociones, preferencias de géneros musicales, sugerencias de bandas a tocar en vivo, etc. De esta manera se optimizará la calidad de la experiencia del cliente en el servicio.

- Analizar los comentarios de los clientes en las páginas de redes sociales, responder a sus reclamos y resolverlos lo antes posible, de manera que el servicio mejore constantemente.

- Realizar controles de calidad de los insumos en general, para garantizar el buen estado de los piqueos y las bebidas.

- Controles de calidad al comienzo de la operación de cada día para asegurar la perfección de las bebidas. 


\subsection{Impacto ambiental}

A lo largo de esta investigación se ha descrito al servicio, su propósito y las maneras en las que va a operar para ofrecerle a los clientes la mayor propuesta de valor posible. Haciendo esto, nos aseguraremos de que la demanda crezca orgánicamente gracias a la buena reputación proveniente de una empresa con numerosas ventajas competitivas.

Sin embargo, la futura empresa no solo tiene que tener claro su identidad en relación a los clientes, sino que tiene que estar consciente del impacto que tendrá en sus alrededores, tanto en la sociedad como en el medio ambiente del lugar que lo hospedará a lo largo de su horizonte de vida. Se debe buscar optimizar los procesos no solo para mejorar la rentabilidad de la empresa, reduciendo los costos, sino para buscar tener el menor impacto ambiental negativo.

A continuación, se presentará una matriz de Aspectos e Impactos ambientales, analizando las actividades del bar que perjudiquen al ambiente junto con sus consecuencias:

Tabla 5.9

Matriz de aspectos e impactos ambientales

\begin{tabular}{|c|c|c|}
\hline Actividad & Aspecto & Impacto \\
\hline $\begin{array}{c}\text { Disposición de residuos } \\
\text { líquidos }\end{array}$ & $\begin{array}{l}\text { Vertido de agua residual, generación de } \\
\text { malos olores }\end{array}$ & Contaminación del agua \\
\hline Lavado/Limpieza & Consumo de agua & Contaminación del agua \\
\hline $\begin{array}{c}\text { Disposición de residuos } \\
\text { sólidos } \\
\end{array}$ & $\begin{array}{l}\text { Solidos contaminantes, generación de } \\
\text { malos olores }\end{array}$ & $\begin{array}{l}\text { Contaminación del } \\
\text { agua/suelo }\end{array}$ \\
\hline \multirow{3}{*}{$\begin{array}{l}\text { Aire acondicionado/ } \\
\text { Sistema de refrigeración }\end{array}$} & Consumo de electricidad & Desperdicio de recursos \\
\hline & Posibles fugas de refrigerante & $\begin{array}{l}\text { Contaminación del } \\
\text { agua/suelo/aire }\end{array}$ \\
\hline & Generación de ruido & Contaminación acústica \\
\hline Sala de fumadores & Emisión de contaminantes al aire & Contaminación del aire \\
\hline Aire comprimido & Generación de ruido & Contaminación acústica \\
\hline Música & Generación de ruido & Contaminación acústica \\
\hline
\end{tabular}

Elaboración propia

Gracias a la matriz anterior, se puede ver que las actividades más problemáticas, ambientalmente hablando, son las de disposición de residuos líquidos y sólidos, limpieza y el uso de sistemas de refrigeración. Es por eso que se deberá tener especial cuidado en asegurar que estas tres actividades se lleven a cabo lo más efectivamente posible. 
En el caso de la disposición de residuos líquidos y sólidos, se buscará segregar los residuos en reciclables y no reciclables. Aparte, una de las razonas por la cual se optó por el bar automatizado fue porque no necesita botellas, los insumos se tratarán de comprar en envases más grandes como galones o barriles rellenables para reducir la generación de desperdicios sólidos.

En cuanto a las actividades de limpieza, el impacto se reducirá también con la implementación de la barra automatizada ya que el proceso de preparación y servido ensuciará menos contenedores. El tanque de mezclado será lo único que se tendrá que limpiar después de cada pedido; este se hará con aire comprimido para evitar el malgasto de agua potable en trabajos de limpieza de poca intensidad. Adicionalmente, se realizará un proceso de limpieza diaria del establecimiento para reducir, en lo posible, el uso de agentes limpiadores más potentes.

Finalmente, los sistemas de refrigeración y de aire acondicionado se racionarán solo para las ocasiones que lo ameriten. En el caso del aire acondicionado, solo se activará en las noches más calientes de verano ya que cuando el sistema no esté activado se aprovechará la buena ventilación que el local tendrá gracias a su estructura. En el caso del sistema de refrigeración para los insumos, se buscará que los tanques sean lo más herméticos posible y solo se utilizará este sistema de refrigeración para los insumos que lo necesiten, como la cerveza, los diferentes tragos, los huevos, etc. Adicionalmente, con ayuda de los sensores de temperatura se podrá controlar la temperatura de manera que el sistema de refrigeración solo esté activo cuando sea necesario.

\subsection{Seguridad y salud ocupacional}

Será política mantener los estándares de seguridad y salud tanto para los trabajadores como para los clientes Es por ello que es necesario realizar un análisis preliminar de riesgos para determinar cuáles son los peligros y riesgos que requieran mayor nivel de cuidado para evitar inconvenientes.

Mantener el local libre de riesgos será una de las prioridades del negocio ya que un ambiente seguro ayudará a brindarle al cliente una experiencia agradable, permitiéndole vivir la experiencia completa sin preocupación.

A continuación, se muestra el análisis preliminar de riesgos enfocado en los peligros que podría encontrar el cliente durante su estadía en el bar: 
Tabla 5.10

Análisis preliminar de riesgos

\begin{tabular}{|c|c|c|c|c|}
\hline Peligro & Riesgo & Causa & Consecuencia & $\begin{array}{c}\text { Medidas } \\
\text { Preventivas }\end{array}$ \\
\hline Piso mojado & $\begin{array}{c}\text { Probabilidad de } \\
\text { resbalar }\end{array}$ & $\begin{array}{c}\text { Derramamiento } \\
\text { de bebidas }\end{array}$ & Traumas físicos & $\begin{array}{c}\text { Colocar pisos con } \\
\text { relieve }\end{array}$ \\
\hline $\begin{array}{c}\text { Clientes fuera } \\
\text { de sus } \\
\text { facultades }\end{array}$ & $\begin{array}{c}\text { Probabilidad de } \\
\text { incurrir en } \\
\text { confrontaciones } \\
\text { físicas }\end{array}$ & $\begin{array}{c}\text { Consumo } \\
\text { excesivo de } \\
\text { alcohol }\end{array}$ & $\begin{array}{c}\text { Moretones, } \\
\text { rasguños, heridas, } \\
\text { sangrado, fracturas }\end{array}$ & $\begin{array}{c}\text { Contar con } \\
\text { personal de } \\
\text { seguridad disuasivo }\end{array}$ \\
\hline $\begin{array}{c}\text { Dardos } \\
\text { Probabilidad de } \\
\text { perforación }\end{array}$ & $\begin{array}{c}\text { Negligencia de } \\
\text { los clientes, falta } \\
\text { de señalización }\end{array}$ & $\begin{array}{c}\text { Heridas, sangrado } \\
\text { culturizar a los } \\
\text { clientes acerca de } \\
\text { practicas }\end{array}$ \\
\hline $\begin{array}{c}\text { Ambiente } \\
\text { abierto en } \\
\text { altura }\end{array}$ & $\begin{array}{c}\text { Probabilidad de } \\
\text { caer desde altura }\end{array}$ & $\begin{array}{c}\text { Consumo } \\
\text { excesivo de } \\
\text { alcohol, descuido }\end{array}$ & $\begin{array}{c}\text { Muerte, fractura, } \\
\text { roturas de huesos } \\
\text { del establecimiento }\end{array}$ & $\begin{array}{c}\text { Barandas, accesos } \\
\text { restringidos }\end{array}$ \\
\hline Música & $\begin{array}{c}\text { Probabilidad de } \\
\text { entrar en contacto } \\
\text { con música a } \\
\text { volumen excesivo }\end{array}$ & $\begin{array}{c}\text { Volumen alto de } \\
\text { la música }\end{array}$ & $\begin{array}{c}\text { Tinnitus, perdida } \\
\text { temporal y parcial } \\
\text { de capacidad } \\
\text { auditiva }\end{array}$ & $\begin{array}{c}\text { Mantener volumen } \\
\text { en un límite } \\
\text { aceptable }\end{array}$ \\
\hline
\end{tabular}

Elaboración propia

Como se puede ver, el mayor riesgo para los clientes sería caerse desde la azotea, es por eso que instalaremos barandas rígidas perimetrales y el personal estará constantemente vigilando que nadie se suba a dichas barandas. Adicionalmente, se prevé que el problema más frecuente en el bar será el de incurrir en confrontaciones físicas, es por eso que es sumamente importante contratar personal de seguridad de carácter disuasivo, especialista en disolver disputas antes de que ocurran o escalen a mayores intensidades. 


\subsection{Sistema de mantenimiento}

La gestión del mantenimiento es esencial en un servicio de naturaleza tan tecnológica como el bar automatizado, especialmente porque la capacidad de atención da por hecho el buen funcionamiento de la barra y de todos sus componentes.

Para asegurar el buen funcionamiento de los componentes de la barra se ha decidido realizar un análisis tipo FMECA en el que se describen las posibles fallas, sus causas, efectos y criticidad para posteriormente definir la falla más crítica y adaptar los mantenimientos a su alrededor.

Tabla 5.11

Matriz FMECA

\begin{tabular}{|c|c|c|c|c|c|c|}
\hline $\begin{array}{c}\text { Modo } \\
\text { Potencial } \\
\text { de Fallo }\end{array}$ & $\begin{array}{c}\text { Causa Potencial de } \\
\text { Fallo }\end{array}$ & Consecuencias & Frecuencia & Gravedad & Detección & NPR \\
\hline $\begin{array}{l}\text { Válvulas } \\
\text { trabadas }\end{array}$ & $\begin{array}{l}\text { Cortocircuito de } \\
\text { actuadores; } \\
\text { impurezas }\end{array}$ & $\begin{array}{l}\text { Paro parcial de } \\
\text { producción }\end{array}$ & 1 & 2 & 2 & 44 \\
\hline \multirow{2}{*}{$\begin{array}{l}\text { PLC no } \\
\text { funciona }\end{array}$} & Código corrupto & \multirow{2}{*}{$\begin{array}{l}\text { Paro total de } \\
\text { producción }\end{array}$} & \multirow{2}{*}{1} & \multirow{2}{*}{4} & \multirow{2}{*}{4} & \multirow{2}{*}{161} \\
\hline & Cortocircuito en PLC & & & & & \\
\hline $\begin{array}{l}\text { Válvulas } \\
\text { no sellan }\end{array}$ & Sello gastado & $\begin{array}{c}\text { Fuga de } \\
\text { insumos a } \\
\text { cámara de } \\
\text { mezcla }\end{array}$ & 2 & 3 & 2 & $12_{2}$ \\
\hline $\begin{array}{l}\text { Interfaz } \\
\text { rota }\end{array}$ & $\begin{array}{c}\text { Manipulación } \\
\text { negligente del cliente }\end{array}$ & $\begin{array}{l}\text { Módulo de } \\
\text { pedido } \\
\text { inhabilitado }\end{array}$ & 3 & 2 & 1 & 63 \\
\hline
\end{tabular}

Elaboración propia

Se puede ver que la falla más crítica y amenazante para el sistema de servido es la que afecta al PLC, el cerebro de la barra y sin duda el componente más importante, ya que si fuera a fallar toda la producción cesaría y no se podría atender a ningún cliente.

Por suerte, los cortocircuitos en el PLC serán muy poco frecuentes ya que el PLC está construido para soportar estrés de uso industrial para producción continua y en este negocio solo se utilizará para el proceso de servido. Además, el PLC estará situado en un lugar protegido y aislado de los líquidos que estará controlando, así se evitarán cortocircuitos por humedad o polvo. 
Adicionalmente, la posibilidad de que la programación del PLC se corrompa, aunque baja, es existente y se debe considerar a la hora de gestionar el mantenimiento de la barra. Viéndolo del lado positivo, la solución para la corrupción de la programación es simplemente volver a cargar el código de programación al PLC; del lado negativo, esta corrupción ocurre de forma espontánea y su probabilidad aumenta conforme aumenta el número de iteraciones del proceso programado.

Es por eso que, para remediar este tipo de falla, se taclearán sus dos diferentes causas: para la primera causa, se llevará a cabo una limpieza profunda del PLC y de los diferentes componentes electrónicos de la barra cada 6 meses. Para la segunda causa, se verificará el correcto funcionamiento del proceso de servido de manera parcial cada día que el bar esté abierto al público y se sobrescribirá el código al PLC cada 3 meses para prevenir mutaciones anormales en el código.

\subsection{Programación de operaciones del negocio.}

En este subcapítulo se determinarán las características del negocio tanto la vida útil esperada del proyecto, como el horario de atención, los días, y las semanas de atención.

\subsubsection{Consideraciones sobre la vida útil del proyecto}

Debido a que se espera un retorno rápido del capital, se considerará como vida útil, los primeros 5 años del proyecto. Esto, sin embargo, no implica que pasados los 5 años cesarán todas las actividades, sino que es en estos primeros 5 años en los que se espera recuperar la inversión, y obtener los fondos necesarios para ampliar el servicio con algún otro proyecto.

Estos 5 años empezarán a contarse desde el 2019, ya que el año 2018, servirá para la instalación del servicio, y para realizar pruebas del negocio.

\subsubsection{Programa de operaciones durante la vida útil del proyecto}

Debido a las características del negocio, y de acuerdo a las respuestas obtenidas durante las entrevistas con expertos, se pudo determinar que un servicio de esta índole, no requiere permanecer en operaciones todos los días de la semana. Como primera opción, 
se ha establecido un horario de 4 días de atención a la semana. La atención se realizará de miércoles a sábado, y en un horario de 7:00 pm a 3:00 am, de acuerdo a las normas municipales del distrito de Miraflores para servicios como este.

Para brindar mayor facilidad al cliente, este horario estará disponible en las páginas en redes sociales, en la página web, y además se encontrará grabado en la puerta del local. Si bien este es el horario de atención, se ha establecido que el personal debe presentarse por lo menos desde las 5:00 pm, para asegurarse del correcto funcionamiento de las instalaciones.

Así mismo, se programarán las recepciones de materiales para un horario posterior a la atención al cliente, de manera que no se interfiera con el proceso de servucción. Como se mencionó en el subcapítulo de capacidad instalada, se contará con personal de servicio al cliente distribuido en 3 áreas principales:

- Preparación de piqueos

- Asistentes y mozos

- Anfitriones

El personal de preparación de piqueos constará de 1 jefe de cocina, y 2 cocineros subordinados. Ubicados en la cocina principal del segundo piso, este personal debe realizar el "mis-en-place" casda día antes de la apertura del bar, y preparar los piqueos apenas llegue una comanda.

Los asistentes y mozos serán el front-office del servicio. Estarán en contacto directo con el cliente durante el proceso, y al cierre serán los encargados de verificar los tanques de almacenamiento, y determinar los requerimientos de materia prima. Finalmente, los anfitriones serán los encargados de recibir al cliente, y verificar que todos ellos posean la edad requerida para entrar en el establecimiento.

De acuerdo al horario establecido, la programación de operaciones del servicio es la que se encuentra en la página siguiente: 
Tabla 5.12

Horarios de trabajo para el bar automatizado

\begin{tabular}{|c|c|c|c|c|}
\hline Horario & Miércoles & Jueves & Viernes & Sábado \\
\hline $\begin{array}{l}5 \text { pm - } 6 \text { pm } \\
6 \text { pm - } 7 \text { pm } \\
\end{array}$ & Mis- en-Place & Mis-en-Place & Mis-en-Place & Mis-en-Place \\
\hline $\begin{array}{l}7 \mathrm{pm}-8 \mathrm{pm} \\
8 \mathrm{pm}-9 \mathrm{pm} \\
9 \mathrm{pm}-10 \mathrm{pm} \\
10 \mathrm{pm}-11 \mathrm{pm} \\
11 \mathrm{pm}-12 \mathrm{am} \\
12 \mathrm{am}-1 \mathrm{am} \\
1 \mathrm{am} \mathrm{-} 2 \mathrm{am} \\
2 \mathrm{am} \mathrm{-} 3 \mathrm{am} \\
\end{array}$ & Atención & Atención & Atención & Atención \\
\hline $\begin{array}{l}3 \mathrm{am}-4 \mathrm{am} \\
4 \mathrm{am}-5 \mathrm{am} \\
\end{array}$ & $\begin{array}{l}\text { Limpieza - } \\
\text { Inventario }\end{array}$ & $\begin{array}{l}\text { Limpieza - } \\
\text { Inventario }\end{array}$ & $\begin{array}{l}\text { Limpieza - } \\
\text { Inventario }\end{array}$ & $\begin{array}{l}\text { Limpieza - } \\
\text { Inventario }\end{array}$ \\
\hline $\begin{array}{l}\text { Total, de horas } \\
\text { Elaboración propi }\end{array}$ & 12 & 12 & 12 & 12 \\
\hline
\end{tabular}

Durante la vida útil del negocio se utilizarán metodologías de planeamiento y control de las operaciones para programar y optimizar el proceso de servucción, así como los procesos de compras e inventarios. Algunas de las herramientas a utilizar serán el Plan Agregado, el Diagrama de Gozinto y el MRP. En el anexo 6 se muestra un ejemplo de plan agregado y diagrama de Gozinto. El plan agregado no muestra valores reales, ya que es una herramienta de planeación a mediano plazo.

\subsection{Requerimiento de Materiales, Personas y Servicios}

Dado que el negocio se basa en la comercialización de bebidas y piqueos, es necesario mantener un control adecuado de los requerimientos de insumos como licores, frutas, jarabes, etc. Por ello, este subcapítulo determina los requerimientos anuales de insumos en cantidades brutas, $\mathrm{y}$, posteriormente en el subcapítulo de presupuestos, se realizará un análisis de compras a proveedores.

El presente acápite tratará también sobre el personal de servicio al cliente necesario, así como el requerimiento de servicios de terceros, para finalmente tratar el tema de los gastos generales. 


\subsubsection{Materiales para el servicio}

El primer paso para la determinación de los materiales necesarios para el servicio, fue la determinación de las proporciones de consumo de los productos. En base a un estudio publicado por el diario Gestión, se estima que el 70\% del consumo de alcohol en bares se refiere a la venta de cervezas. El resto de ventas se distribuye entre Pisco, Ron, Whiskey, Vodka y finalmente Tequila. Otros licores no poseen un porcentaje de importancia en cuanto al consumo en bares.

Para determinar las marcas de cerveza más importantes, se preguntó sobre hábitos de consumo en la encuesta de estudio de mercado. Los resultados fueron los siguientes:

- Cerveza Cusqueña: Lidera el consumo entre las personas de Lima moderna, con un $27,2 \%$ de participación.

- Cerveza Pilsen: Se encuentra en segundo lugar, con $24,7 \%$ de consumo en bares de Lima moderna.

- Cerveza Corona: La única cerveza de importación que se encuentra entre las más importantes en consumo, posee el 18,5\% de participación

El resto de cervezas como Cristal, Heineken, Miller, entre otras, constituye el 29,6 $\%$ restante. Por otro lado, el Pisco lidera el consumo de licores con $9 \%$, el Ron le sigue con $7 \%$ y el vodka y el whisky con $6 \%$ cada uno. El 2\% restante se le puede adjudicar al tequila.

Como el componente principal es la venta de bebidas alcohólicas, en este punto se evalúan los requerimientos de estos materiales, sin dejar de lado el resto de insumos, que serán analizados en la elaboración del presupuesto de compras.

A continuación, se muestra la tabla en la que se indica los requerimientos generales de licores, medidos en vasos de sus bebidas representativas. 
Tabla 5.13

Requerimiento de bebidas

\begin{tabular}{c|ccccc} 
Año & $\mathbf{2 0 1 9}$ & $\mathbf{2 0 2 0}$ & $\mathbf{2 0 2 1}$ & $\mathbf{2 0 2 2}$ & $\mathbf{2 0 2 3}$ \\
\hline Visitas & 29654.87 & 51990.32 & 84872.05 & 93378.01 & 120473.48 \\
Cantidad de Bebidas: & 88964.62 & 155970.95 & 254616.15 & 280134.04 & 361420.44 \\
Cerveza & 61741.45 & 108243.84 & 176703.61 & 194413.02 & 250825.79 \\
Corona & 11422.17 & 20025.11 & 32690.17 & 35966.41 & 46402.77 \\
Cusqueña & 16793.67 & 29442.32 & 48063.38 & 52880.34 & 68224.61 \\
Pilsen & 15250.14 & 26736.23 & 43645.79 & 48020.02 & 61953.97 \\
Otras Cervezas & 18275.47 & 32040.18 & 52304.27 & 57546.25 & 74244.43 \\
Otros Tragos & 27223.17 & 47727.11 & 77912.54 & 85721.01 & 110594.66 \\
Pisco & 8540.60 & 14973.21 & 24443.15 & 26892.87 & 34696.36 \\
Ron & 6850.28 & 12009.76 & 19605.44 & 21570.32 & 27829.37 \\
Vodka & 5337.88 & 9358.26 & 15276.97 & 16808.04 & 21685.23 \\
Whiskey & 5337.88 & 9358.26 & 15276.97 & 16808.04 & 21685.23 \\
Tequila & 1156.54 & 2027.62 & 3310.01 & 3641.74 & 4698.47
\end{tabular}

Elaboración propia

Este cuadro no permite identificar la cantidad, en litros de licor o botellas, que se necesitan consumir. Es por ello, que se tomó como base de cálculo la bebida más representativa de cada uno de los licores, para el cálculo de las onzas, litros, y botellas necesarias. Las bebidas consideradas se eligieron gracias a las entrevistas mantenidas con expertos, y son las siguientes:

- Pisco Sour

- Maracuyá Sour

- Mojito

- Margarita

- Martini

- Whiskey (neat).

- Cuba Libre

Para cada uno de los licores, se calculó el requerimiento anual, basado en la demanda de su trago representativo. Las tablas en las que se detallan los requerimientos se encuentran en los anexos. 


\subsubsection{Determinación del requerimiento de personal de atención al cliente}

Dado que la atención al cliente es lo primordial en el servicio, este factor es el que determina la capacidad de atención. Por ello, los requerimientos de personal ya fueron calculados y están distribuidos de la siguiente manera:

- Asistentes: 4 (2 para cada piso / uno para cada 2 módulos)

- Mozos: 8 (2 en cada ambiente)

- Anfitriones: 2

Sin embargo, a parte de estos trabajadores, también se tendrá personal encragado de la seguridad y personal encargado de la limpieza en los servicios.

\subsubsection{Servicios de terceros}

En cuanto a la tercerización o outsourcing, se debe realizar de manera estratégica para que beneficie al negocio. Esto permitirá que el negocio se centre en realizar las tareas en las que se especializa, como el servicio al cliente, y no incurra en gastos innecesarios o malas inversiones.

En general, el outsourcing se dará en el área de mantenimiento principalmente. Ya que el buen funcionamiento de los PLC's es fundamental para el negocio, pero que no se poseen los conocimientos necesarios para realizar mantenimientos internos, es necesario contratar a empresas externas. Como se mencionó en el acápite 5.7, es necesario que se realicen mantenimientos preventivos, si es que se quiere mantener el régimen de RCM, por lo que lo mejor es contratar una empresa especializada, como Allen Bradley, para que realice estos mantenimientos periódicos.

Por otro lado, debido a la información que se manejará en las bases de datos, como historial de consumo de clientes, información de tarjetas de crédito, así como también información de la empresa, como el código patentado, es necesario manejar un buen sistema de seguridad en los sistemas de información. Ya que no se poseen los conocimientos necesarios para implementar un sistema propio, resulta más conveniente contratar a una empresa que se dedique específicamente a manejar la seguridad informática.

Así mismo, en pos de promover el consumo responsable, es posible mantener alianzas estratégicas con empresas de taxis, para que realicen el transporte de los clientes 
a sus casas, evitando que tomen y manejen. Esto no solo beneficia a los clientes, sino también a toda la comunidad.

Finalmente, la empresa deberá contar con servicio de Wi-Fi gratuito para los clientes, por lo que se debe contratar a una empresa externa que implemente estos sistemas.

\subsubsection{Otros: energía eléctrica, agua, transportes, etc.}

El cálculo del costo de energía y agua estará basado en estimaciones de benchmarking de los consultores españoles MontarunNegocio: 10 - 15\% de la facturación del negocio en el período será gastada en este tipo de insumos complementarios. Dicho porcentaje incluirá gastos de agua, luz, servicios de internet y teléfono.

El bar ofrecerá internet Wi-Fi gratuito para clientes con una velocidad de $40 \mathrm{Mbps}$ por un costo de alrededor de S/ 140 mensuales según las tarifas de Claro y Movistar. Adicionalmente, el costo de S/140 mensuales cubrirá también la línea telefónica.

Seguidamente, la opción tarifaria a utilizar para el servicio de luz será el BT5A: "Tarifa con doble medición de energía activa 2E" ya que hace distinción entre consumo de energía activa en horas punta y no punta. Esto convendrá al negocio ya que las horas de operación serán mayormente en horas no punta, consiguiendo una mejor tarifa eléctrica por la misma cantidad de energía consumida a comparación a las otras opciones tarifarias. Los diferentes costos dentro de la opción tarifaria elegida se encuentran en la tabla a continuación, utilizando a la compañía proveedora de energía eléctrica, Luz del Sur, como base:

Figura 5.2

Desplegado de costos de tarifa BT5-A

\begin{tabular}{|l|c|c}
\hline DOBLE MEDICION DE ENERGIA (2E) & Unidad & BT5A \\
\hline Cargo Fijo mensual & S/./Usuario & 3,75 \\
Cargo por Energía en punta para demandas hasta $20 \mathrm{~kW}$ en horas punta y fue & cent S/./kW.h & 148,01 \\
Cargo por Energía en punta para demandas hasta $20 \mathrm{~kW}$ en hor.punta y 50 kV & cent S/./kW.h & 166,79 \\
Cargo por Energía fuera de punta & cent S/./kW.h & 22,99 \\
Cargo por exceso de potencia en horas fuera de punta & S/./kW-mes & 45,57 \\
Cargo por exceso de potencia en horas de punta & S/./kW-mes & 45,57 \\
\hline
\end{tabular}

Fuente: Luz del Sur (2017) 
Continuamente, recalcamos que el es necesario ajustar el benchmark del costo de servicios de agua y luz de la empresa a estándares nacionales debido a que el $10-15 \%$ es cierto para España, donde estos servicios son más costosos. Es por esto que se compararon los costos de los diferentes servicios tanto en Perú como en España; se notó que el costo del servicio de agua es 4 veces más caro en España y que el costo de electricidad es equiparable. Debido a que el costo del agua y luz son los de mayor magnitud, solo se tomaron en cuenta estos dos factores para el re-cálculo del benchmark. Como resultado de la diferencia de costos de agua, se decidió fijar la nueva tasa en 7\% de la facturación de la empresa.

Mas aún, se emplearán diferentes métodos y tecnologías para reducir el monto utilizado de cada uno de los servicios anteriormente descritos. Los métodos y tecnologías se detallan a continuación:

- Local con buena ventilación pasiva para reducir el uso de aire acondicionado, reduciendo consumo de luz

- Urinarios secos para reducir el gasto de agua

- Lavamanos activados por sensores para reducir el gasto de agua

- Iluminación tipo LED para reducir consumo de luz

- Compartir Wi-Fi de manera gratuita solo con los clientes para reducir el uso excesivo de la banda ancha que lleva a velocidad de navegación reducida

\subsection{Soporte físico del servicio}

El último factor a analizar en cuanto a la instalación del servicio se refiere a los requerimientos de la infraestructura y el inmueble en el que se encuentra instalado el bar automatizado. Ya sea el edificio mismo o su ambiente, es necesario analizar el soporte físico pues determina ciertas limitaciones de la disposición del local.

\subsubsection{Factor Edificio}

En el estudio del factor edificio se deben considerar factores que se refieran al inmueble y su localización. Los suelos, la construcción, las vías de acceso y salidas de emergencia 
son puntos que se deben considerar al momento de instalar un servicio y son los que se detallan a continuación.

\section{Suelos}

Debido a la fuerte actividad sísmica de la zona en la que se encuentra la ciudad de Lima, es necesario realizar un estudio de suelos previo a la construcción de cualquier edificación. Por suerte, gracias a estudios del Instituto Geofísico del Perú, se conoce que el distrito de Miraflores es uno de los distritos con suelos más resistentes a la actividad sísmica.

\section{Niveles de la construcción}

Para la instalación de este servicio, se construirá un establecimiento de 3 pisos y una azotea, en la que se encontrarán los 4 diferentes ambientes. En el primer piso se encontrará el área de música en vivo y una de las barras automáticas. El segundo piso contará con la cocina principal. El tercer piso contará con la segunda barra automatizada, y finalmente, la azotea contará con el área de fumadores y por lo tanto será más abierta.

\section{Puertas de acceso}

La puerta principal del servicio será la del acceso de los clientes. Esta se encontrará en la fachada, en la calle Manuel Bonilla. Sin embargo, existirán puertas de emergencia en caso ocurriese cualquier siniestro. Adicionalmente, habrá una puerta por la que se accederá al almacén y por la cual se recibirán las entregas de los proveedores. Finalmente, la zona de almacén estará conectada con la cocina en el segundo piso para asegurar que el abastecimiento de insumos siempre sea invisible para el cliente, aunque normalmente este proceso se realizará en horario de oficina.

\subsubsection{Ambiente del Servicio}

Como ya se ha mencionado con anterioridad en la descripción del servicio, este contará con 4 ambientes principales, los cuales se describen a continuación: 
- Ambiente principal (primer piso): En esta zona del local se encontrarán las mesas para juegos de mesa, el escenario para cuando exista música en vivo, además de la barra automatizada.

- Ambiente deportivo (segundo piso): Este ambiente estará dedicado a entretener a personas que deseen participar de actividades deportivas, como lo son jugar dardos, jugar billar, etc. Además contará con la cocina principal del servicio.

- Ambiente de Video Juegos (tercer piso): En esta zona se entretendrá a la clientela enfocada en divertirse en grupo de manera menos competitiva, y que guste de jugar videojuegos grupales. Contará con una barra automatizada al igual que las otras zonas.

- Ambiente para fumadores (terraza superior): Ubicada en la azotea del edificio, esta terraza está dedicada a aquellos clientes que deseen fumar dentro del servicio.

En cada uno de estos ambientes se contará con música diferente, que esté de acuerdo con cada una de las temáticas. La decoración de los espacios también se encontrará alineada a la temática.

\subsection{Disposición del Servicio}

El último punto a analizar en cuanto a la ingeniería del proyecto es la disposición y distribución de las áreas dentro del local. En los acápites siguientes, se analizan las relaciones entre las áreas, el tamaño del local, y se presenta el plano preliminar del negocio.

\subsubsection{Disposición General}

Debido a que el área para los servicios se calcula en base a la cantidad de personas que se atenderán, no es necesario realizar el análisis de Guerchet. Por este motivo, solamente se procederá a mencionar las áreas que existirán dentro del servicio, y sus dimensiones de acuerdo con lo establecido en el reglamento general de edificaciones.

- Área de atención al cliente (primer piso).

- Área de atención al cliente (segundo piso).

- Área de atención al cliente (tercer piso).

- Área de atención al cliente (cuarto piso). 
- Área de cocina (segundo piso).

- Área de almacén de insumos (primer piso)

- Área de recepción (primer piso)

- Área de almacén de juegos de mesa y videojuegos

- Baños (1 de cada tipo en cada piso).

- Área de oficina (primer piso).

Para las áreas de atención al cliente, se calcularán las dimensiones en base a la capacidad instalada para el último año de vida útil del negocio. La cantidad de visitas para el 2023 es de 120473 personas anuales. Se estima que estas visitas se distribuyen uniformemente en los diferentes ambientes del bar, por lo que cada piso podrá atender a 157 personas cada noche. Gracias a la entrevista con Víctor Parra, se pudo determinar que el cliente promedio permanece en el bar por 4 horas, por lo que cada piso alberga aproximadamente a 80 personas a la vez.

En base a esta cantidad de personas, se determina que el área mínima para cada uno de los pisos es de $120 \mathrm{~m}^{2}$ para la atención al cliente. En base a esto, se ha realizado la siguiente modificación:

- El primer piso debe contar con un escenario de $20 \mathrm{~m}^{2}$, por lo que se debe añadir este espacio a lo calculado anteriormente.

Por otro lado, se han calculado las dimensiones del resto de espacios de la siguiente manera:

- El área de cocina cuenta con $30 \mathrm{~m}^{2}$, ya que la norma considera $10 \mathrm{~m}^{2}$ por cocinero.

- La recepción consta de $25 \mathrm{~m}^{2}$, ya que consta de un mostrador y una pequeña sala de espera para los clientes.

- Los baños constan de 2 lavatorios, y 2 inodoros, de acuerdo con lo establecido en el reglamento de edificaciones. Cada baño consistirá de $20 \mathrm{~m}^{2}$. A demás se contará con baños para el personal en el tercer piso, uno para mujeres y uno para hombres, cada uno con 1 lavatorio y 1 inodoro. Cada uno de estos tendrá un área de $6 \mathrm{~m}^{2}$.

- La oficina albergará al gerente general y al subgerente, por lo que consistirá de $15 \mathrm{~m}^{2}$. Esta oficina se encontrará en el tercer piso del establecimiento. 
- El almacén de insumos tendrá un área de $30 \mathrm{~m}^{2}$, y se encontrará en el primer piso. Para el transporte de los insumos se utilizará un montacargas.

- El almacén de juegos de mesa y videojuegos tendrá un área total de $15 \mathrm{~m}^{2}$, y se encontrará en el primer piso.

Es así que se obtiene para cada uno de los pisos, la siguiente definición mínima de áreas:

- Primer piso: $252 \mathrm{~m}^{2}$

- Segundo piso: $185 \mathrm{~m}^{2}$

- Tercer piso: $187 \mathrm{~m}^{2}$

- Cuarto piso: $160 \mathrm{~m}^{2}$

Sin embargo, los pisos del 2 al 4 tendrán dimensiones de 14 m x 17 m $\left(238 \mathrm{~m}^{2}\right)$, $14 \mathrm{~m}^{2}$ más grande en promedio que el área mínima calculada. Esto tendrá el fin de aprovechar lo más posible las dimensiones del terreno comprado.

\subsubsection{Disposición al Detalle}

Una vez definidas las áreas, es necesario determinar las relaciones que existen entre ellas. Para este propósito, se utilizará el análisis relacional. A continuación, se presenta la tabla indicando cada una de las áreas establecidas:

\section{Tabla 5.14}

Numeración de las áreas del servicio

\begin{tabular}{|c|l|}
\hline 1. & Atención al cliente \\
\hline 2. & Cocina \\
\hline 3. & Oficina \\
\hline 4. & Baños de Personal \\
\hline 5. & Baños de Clientes \\
\hline 6. & Recepción \\
\hline 7. & Almacén Juegos \\
\hline 8. & Almacén Insumos \\
\hline
\end{tabular}

Elaboración propia

Dado que ya se ha determinado el piso en el que se ubicará cada una de las áreas, no existe mayor razón para determinar las relaciones entre las zonas. Sin embargo, sí cabe 
resaltar que es importante que los baños de los clientes se encuentren lejos de la cocina, para evitar contaminación, y que los baños de personal se deben encontrar cerca de las oficinas, por necesidades básicas.

En los anexos, se adjuntan los planos de cada uno de los pisos de la construcción, de acuerdo a lo que se ha establecido en este subcapítulo.

\subsection{Cronograma de implementación del proyecto}

Una vez determinada la disposición de las instalaciones, habiendo definido dónde se encontrarán cada una de las diferentes áreas del bar, se procederá a definir los tiempos de duración de los múltiples pasos de la implementación del proyecto. A continuación, se muestra el cronograma Gantt de la implementación del proyecto:

Diagrama 5.3

Diagrama de Gantt para la implementación del proyecto

\begin{tabular}{|c|c|c|c|c|c|c|c|c|c|c|c|c|c|c|c|c|c|c|c|c|c|c|c|c|c|c|c|c|c|c|c|c|}
\hline Actividad & 1 & 2 & 3 & 4 & 5 & 6 & 7 & 8 & 9 & 10 & 11 & 12 & 13 & 14 & 15 & 16 & 17 & 18 & 19 & 20 & 21 & 22 & 23 & 24 & 25 & 26 & 27 & 28 & 29 & 30 & 31 & 32 \\
\hline Compra del Terreno & & & & & & & & & & & & & & & & & & & & & & & & & & & & & & & & \\
\hline $\begin{array}{l}\text { Trámite de Permiso de } \\
\text { Construcción }\end{array}$ & & & & & & & & & & & & & & & & & & & & & & & & & & & & & & & & \\
\hline Preparación del Terren & & & & & & & & & & & & & & & & & & & & & & & & & & & & & & & & \\
\hline Construcción & & & & & & & & & & & & & & & & & & & & & & & & & & & & & & & & \\
\hline Cableado & & & & & & & & & & & & & & & & & & & & & & & & & & & & & & & & \\
\hline Pintura & & & & & & & & & & & & & & & & & & & & & & & & & & & & & & & & \\
\hline Decoración & & & & & & & & & & & & & & & & & & & & & & & & & & & & & & & & \\
\hline $\begin{array}{l}\text { Trámite de Permiso de } \\
\text { Defensa Civil \& } \\
\text { Funcionamiento }\end{array}$ & & & & & & & & & & & & & & & & & & & & & & & & & & & & & & & & \\
\hline
\end{tabular}

Elabpración propia

Como se puede ver, todo el proceso de compra de terreno y construcción demorará alrededor de 7 meses. La compra del terreno durará 1 mes ya que incluirá la evaluación del local por el banco ya que se solicitará un crédito para comprar el terreno. Mientras que el proceso de construcción se expandirá alrededor de 6 meses, incluyendo el trámite del permiso de construcción que será llevado a cabo por la empresa constructora.

El cableado se dará durante la última semana de construcción, luego se dará 1 semana adicional para el proceso de pintado exterior e interior. La decoración del local demorará cerca de 2 semanas debido a la compra y el transporte de mobiliario que se requerirá. 
Finalmente, el trámite de la licencia de funcionamiento demorará máximo 1 semana, después de la cual se hará la recepción de llave del local y se podrá comenzar a operar. Se resalta que el local, al tener dimensiones de entre 100 y $500 \mathrm{~m}^{2}$, solo necesita la licencia de funcionamiento ya que la licencia de defensa civil está incluida en la anterior. De ser un local mayor a $\operatorname{los} 500 \mathrm{~m}^{2}$, se deberían tramitar las dos licencias por separado, lo cual demandaría una mayor cantidad de tiempo. 


\section{CAPÍTULO VI: ORGANIZACIÓN ADMINISTRATIVA}

\subsection{Formación de la organización empresarial}

Para la elección del tipo de empresa a crear se tuvo la oportunidad de hablar con un abogado, quien sugirió constituir la empresa como una Sociedad Anónima Cerrada (SAC), debido a su bajo costo y simplicidad en cuanto a los trámites. Cada motivo se explicará a continuación:

\section{Facilidad de manejo y simplicidad}

La Sociedad Anónima Cerrada posee la ventaja de no requerir un directorio para su manejo, simplemente se necesita un gerente general que dirija la compañía. Por otro lado, debido a que el capital se divide en acciones clasificadas como títulos valores, no es necesario realizar mayor trámite al momento de transferirlas, salvo entregar el certificado de acciones al nuevo socio.

\section{Bajos costos}

El hecho de no tener directorio, significa que no será necesario gastar dinero y recursos en remunerar las contribuciones de los directores. Así mismo, debido a que se requiere de menor cantidad de trámites al momento de transferir acciones, se abaratan los costos de estas operaciones. El tener una menor cantidad de trámites, significa que la empresa podrá iniciar sus operaciones con anterioridad, generando ingresos más rápidamente, lo cual indica un menor costo de oportunidad.

Finalmente, se tienen otros beneficios adicionales, como el hecho de dar preferencia de compra de acciones a los accionistas. Si bien esto se puede lograr en una sociedad anónima común, es necesario pactarlo en un contrato con anterioridad. 


\section{Pasos para constituir una empresa SAC}

1. Escoger la denominación social/nombre de la empresa (no necesariamente será el nombre del negocio).

2. Una vez elegida la denominación social, se debe realizar una búsqueda en los índices de Registros Públicos, para verificar si el nombre ya existe o no. En caso esté libre, uno de los socios fundadores procederá a realizar la reserva del nombre. Esta reserva permite realizar los trámites hasta dentro de 30 días.

3. Los fundadores deberán hacer la minuta o pacto social. Este documento indica el capital que se aporta, ya sea en dinero o bienes muebles, tangibles o intangibles. En el caso de una SAC, no se puede realizar el aporte de servicios como capital social. Así mismo, la minuta indica los estatutos de la empresa (reglas que rigen la vida de la sociedad).

4. Este documento, es llevado a notaria, en donde un notario ingresa la minuta a trámite, y entrega a los fundadores un número de Kárdex. Con este número, se deben realizar 2 trámites adicionales:

- Abrir cuenta de banco en la que se depositará el aporte de capital social.

- Obtener un RUC de la SUNAT.

5. Con el recibo obtenido de la apertura de cuenta, se deberá regresar a la notaria. Allí, se elevará la minuta a escritura publica, transcribiéndola, e insertando el deposito bancario. En caso se aportasen bienes, el gerente general deberá hacer declaraciones juradas en las que se indica lo que se recibió y su valor. Estas inserciones indican que el capital está pagado. Todos los socios firman al igual que los notarios.

6. Luego de formar, el notario entrega el parte notarial. El parte debe ser enviado a la oficina registral de la localidad en la que se abrirá el servicio. Esta debe revisar la escritura, y que se cumplan los requisitos. De ser el caso, se inscribe la sociedad y se crea una partida registral. Finalmente, se transcribe el resumen de la minuta.

7. La oficina registral realizará la entrega del testimonio con constancia de inscripción. Este documento permitirá ir al banco y habilitar la cuenta, recibiendo la chequera.

8. Así mismo, se debe acudir a SUNAT, habilitar el RUC con el testimonio, regularizando la situación de la empresa. Es necesario indicar los impuestos a los que la empresa se verá afecta: Renta de quinta y cuarta categoría, IGV, aportes 
seguridad social y aportes a Essalud. A partir de esa fecha, se deben presentar las declaraciones mensuales.

9. Una vez regularizada la empresa, se debe regularizar el local. Es necesario ir a la municipalidad y realizar el tramite de licencia municipal de funcionamiento. Es necesario presentar el título de propiedad, el testimonio de inscripción, el RUC y el certificado de parámetros. Así mismo, se debe pasar la inspección de defensa civil. Al tratarse de un establecimiento de comidas y bebidas, es necesario obtener una licencia sanitaria.

10. Se deben abrir los libros sociales de la empresa, el libro de actas de junta de accionistas y los libros contables (diario, mayor, caja banco, inventarios, balance).

11. Finalmente, es necesario descargar los programas de declaraciones telemáticas de impuestos (PDT).

\subsection{Requerimiento de personal directivo, administrativo y de servicios}

Para poder determinar los gastos referentes a las remuneraciones, es necesario definir los puestos que existirán dentro de la organización. En el capítulo anterior, se determinaron los puestos requeridos para las diferentes operaciones del bar junto con sus cantidades respectivas, por lo que a continuación se presentarán los puestos directivos, administrativos y de servicios.

Primeramente, es necesario contar con un gerente general definido ya que es requerido por la ley peruana. Asimismo, es necesario contratar a un contador y un asesor legal, quienes recibirán pagos por honorarios ya que solo se les solicitarán sus servicios cuando sean necesarios.

Estos se encargarán de todos los trámites legales y contables de la empresa ya que por un lado, la ley manda que todos los registros contables y estados financieros que se entreguen a la SUNAT deben estar firmados por un contador colegiado. Por otro lado, la representación de un abogado experto dará a la empresa un respaldo reconfortante para cualquier decisión que se tome, asegurando que siempre se opere dentro del marco de lo legal.

Adicionalmente, la empresa también contará con un subgerente quien liberará al gerente de carga laboral, encargandose directamente del manejo del personal operativo. 


\subsection{Esquema de la estructura organizacional y funciones generales de los principales puestos}

Para poder visualizar mejor la estructura de puestos que manejará la empresa, se ha elaborado un organigrama, presentado a continuación:

Diagrama 6.1

Organigrama del bar automatizado

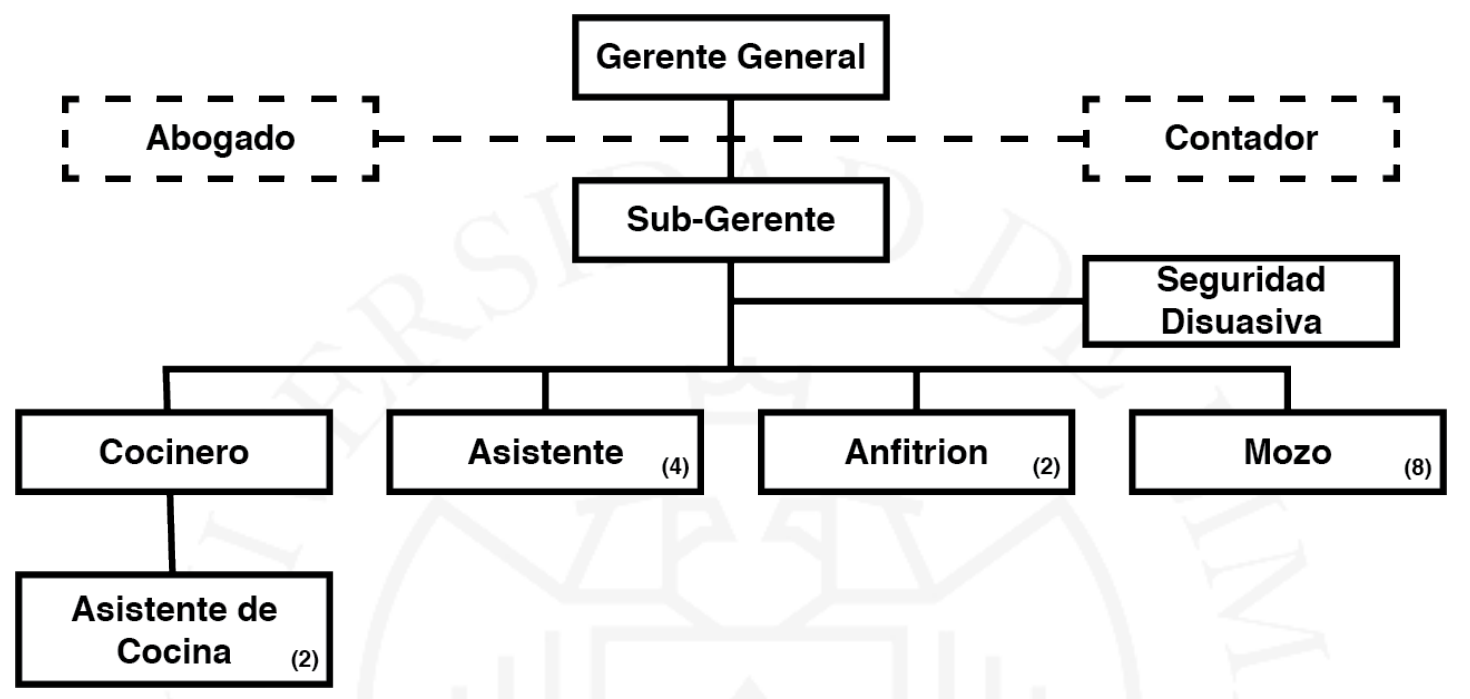

Elaboración propia

\section{Funciones}

Gerente general:

- Realizar el planeamiento estratégico de la compañía de acuerdo a los objetivos a largo plazo de los accionistas.

- Determinar las campañas publicitarias o promociones que existirán durante la operación del servicio.

- Contactar con artistas, bandas o sus agentes para proveer entretenimiento musical a los clientes en determinadas noches de la semana.

- Producir música y crear playlists para el ambiente durante las noches en las que no haya presentaciones en el establecimiento.

- Decidir, en conjunto con el subgerente sobre posibles expansiones, adquisiciones $\mathrm{u}$ otras estrategias del negocio. 
Sub-gerente:

- Supervisar al personal y determinar los horarios de trabajo. Establecer la planilla y controlar el cumplimiento por parte de todos los colaboradores.

- Contactar con los proveedores y realizar el proceso de cotizaciones y compras, de acuerdo a los requerimientros de inventarios.

- Planear la prestación del servicio en conjunto con el área operativa y administrativa del bar.

- Supervisar la operación durante las horas de apertura del bar, resolver los conflictos que se presenten con el cliente o con los mismos trabajadores.

- Llevar la contabilidad principal de la empresa.

Abogado:

- Aconsejar al gerente general con respecto a las decisiones que se tomen, para evitar conflictos legales para la empresa y sus accionistas.

- Resolver los posibles conflictos que se puedan presentar durante la prestación del servicio.

Contador:

- Asistir en la preparación de los estados contables que se deban presentar a la SUNAT cada mes.

- Actuar como consejero financiero de la empresa en base a analisis contables.

Seguridad disuasiva:

- Mantener el orden dentro del local.

- Retirar del local a aquellos clientes que resulten un peligro para la seguridad del resto de clientes o del local.

- Resolver conflictos entre clientes de manera disuasiva para evitar confrontaciones físicas. 
Mozo:

- Realizar los pedidos de piqueos y entregarselos a los clientes dentro de los tiempos establecidos en la política de atención al cliente.

- Entregar a los clientes los juegos de mesa, videojuegos o elementos que necesiten durante su estadía en el bar.

- Recoger vasos y platos sucios de las mesas desocupadas.

- Realizar el cobro a los clientes con la modalidad que prefieran, regida por la política de cobranzas.

Anfitrión:

- Dar la bienvenida a los clientes y solicitar los DNI, para verificar que cumplan con la mayoría de edad.

- Explicar el funcionamiento del bar y los beneficios ofrecidos en cada uno de los ambientes.

- Enlazar el DNI del cliente respectivo con una tarjeta de consumo y entregársela.

- Recibir la tarjeta de consumo del cliente respectivo al momento de su partida.

Asistente:

- Ayudar a los clientes a realizar sus pedidos en la barra automatizada.

- Dar recomendaciones a los clientes con respecto a las bebidas.

- Verificar el correcto funcionamiento de los módulos antes de la apertura del local.

Cocinero:

- Supervisar la correcta preparación de los piqueos.

- Determinar los requerimientos de insumos y materiales del área de cocina.

- Crear nuevos piqueos para ofrecer a los clientes.

- Supervisar el mantenimiento de los estándares de calidad e higiene dentro del área de cocina.

- Mantener la cuenta de cada insumo y el almacén, según lo especificado en el sistema. 
Asistente de cocina:

- Preparar los piqueos de acuerdo a las especificiones del cliente.

- Mantener limpia el área de cocina para cumplir los estándares de calidad e higiene. 


\section{CAPÍTULO VII: ASPECTOS ECONÓMICOS}

\subsection{Inversiones}

En este subcapítulo se detallarán las inversiones a realizar, tanto de largo como de corto plazo. Estas inversiones consisten de los recursos monetarios necesarios para establecer el negocio, y también los activos necesarios para su operación.

\subsubsection{Estimación de las inversiones de largo plazo (tangibles e intangibles)}

Las inversiones de largo plazo que se deberán realizar consisten de la construcción, la decoración, la maquinaria de tanto la barra como la cocina, etc. El detalle de las inversiones junto con sus montos respectivos en soles se encuentra en la siguiente tabla:

Tabla 7.1

Inversiones de largo plazo (Activo Fijo)

\begin{tabular}{l|l} 
Inversiones & Monto \\
\hline Freidoras & $1,080.00$ \\
Congelador & $4,000.00$ \\
Horno + Encimera & $1,000.00$ \\
Construcción & $1,600,000.00$ \\
Tanques & $40,560.00$ \\
PLC's & 600.00 \\
Válvulas & $17,680.00$ \\
Televisores & $22,400.00$ \\
Juegos 2 piso & $8,000.00$ \\
iPhones SE & $10,800.00$ \\
Juegos de Mesa & $9,600.00$ \\
Consolas & $8,000.00$ \\
Juegos de Video & $6,000.00$ \\
Pasarelas de pago & $1,194.00$ \\
Servicios de decoración & $20,000.00$ \\
\hline Total Inversión Activo Fijo & $1,750,914.00$ \\
\hline Elaboracion propia &
\end{tabular}

Elaboración propia

Como se puede ver, la inversión en activo fijo alcanza la magnitud de S/ 1,750,914.00; sin embargo, la gran mayoría de la inversión viene del costo de construcción $(\mathrm{S} / 1,600,000)$. 
Adicionalmente, no se incluirá el costo del terreno como una inversión (ni de largo de ni corto plazo) ya que se elaborará un contrato de derecho de superficie con el dueño del terreno. En esencia, se alquilará el terreno a un precio de $\mathrm{S} / 80 \mathrm{el} \mathrm{m}^{2}$, en el cual se construirá el local del bar tal como se especificó en el capítulo 5.

Esta construcción pertenecerá a la empresa gracias al acuerdo de derecho de superficie; dicho contrato establece que la construcción en el terreno es propiedad de la empresa inquilina del terreno por 99 años, la construcción puede ser alquilada, usada como garantía para un préstamo, el derecho de superficie incluso puede ser vendido o transferido a otra empresa o persona. Una vez pasada esta cantidad de tiempo, la construcción se vuelve propiedad del dueño del terreno.

\subsubsection{Estimación de las inversiones de corto plazo (capital de trabajo)}

Las inversiones de corto plazo o el capital de trabajo es la cantidad de dinero que se tendrá invertir para poder operar el negocio durante el primer periodo de ciclo de conversión de efectivo. Debido a que todas las transacciones se realizarán al contado, se tomará como inversión, los gastos para el primer mes.

Tabla 7.2

Inversiones de corto plazo (Capital de Trabajo)

\begin{tabular}{l|l} 
Inversiones & Monto \\
\hline Sueldos 1 mes & 85500.00 \\
Gastos 1 mes & 12254.46 \\
Compra materiales 3 mes & 19448.57 \\
Derecho de superficie 3 meses & 62400.00 \\
\hline Total, Inversión Capital & $\mathbf{1 7 9 6 0 3 . 0 3}$ \\
\hline
\end{tabular}

Elaboración propia

Como se puede observar en la tabla, este monto incluye los gastos de salarios, servicios como agua, luz y teléfono, compra de materiales y pago por derecho de superficie. Este monto llega a un total de 117503 soles, que se deberán tener en caja al momento de iniciar las operaciones. 


\subsection{Costos de operaciones del servicio}

A continuación se determinarán los presupuestos de costos de operación del servicio. Estos costos incluyen los materiales, los servcios generles, y el personal.

\subsubsection{Costos de materiales del servicio}

Los costos de materiales se han determinado en base a los requerimientos y a los inventarios de materia prima e insumos. A continuación, se detallan los presupuestos de consumo y compras de materiales, tanto para bebidas como para piqueos. Los presupuestos de requerimientos e inventarios se encuentran detallados en los anexos.

\section{Tabla 7.3}

Presupuesto de compras de materiales

\begin{tabular}{l|ccccc} 
Año & $\mathbf{2 0 1 9}$ & $\mathbf{2 0 2 0}$ & $\mathbf{2 0 2 1}$ & $\mathbf{2 0 2 2}$ & $\mathbf{2 0 2 3}$ \\
\hline Desembolso & 233382.80 & 408327.96 & 666826.05 & 733675.97 & 946547.71 \\
Elaboración propia & & & & &
\end{tabular}

Tabla 7.4

Presupuesto de consumo de materiales

\begin{tabular}{l|ccccc} 
Año & $\mathbf{2 0 1 9}$ & $\mathbf{2 0 2 0}$ & $\mathbf{2 0 2 1}$ & $\mathbf{2 0 2 2}$ & $\mathbf{2 0 2 3}$ \\
\hline Consumo & 197446.71 & 346159.52 & 565091.16 & 621725.17 & 802130.97 \\
Elaboración propia & & &
\end{tabular}

Elaboración propia

\subsubsection{Costo de los servicios}

El costo de los servicios se despliega en tres ámbitos importantes: el servicio de luz, el servicio de agua, y el servicio de teléfono e internet. Como se mencionó en el apartado 5.9.4, estos servicios constarán de aproximadamente el 7\% de la facturación del negocio.

\section{Tabla 7.5}

Presupuesto de gastos generales

\begin{tabular}{l|ccccc} 
Año & $\mathbf{2 0 1 9}$ & $\mathbf{2 0 2 0}$ & $\mathbf{2 0 2 1}$ & $\mathbf{2 0 2 2}$ & $\mathbf{2 0 2 3}$ \\
\hline Gastos & 135691.65 & 218485.72 & 356668.98 & 392413.47 & 506277.37 \\
Elaboración propia & & & &
\end{tabular}




\subsubsection{Costo del personal}

Finalmente, el costo de personal se calcula en base a las remuneraciones y beneficios sociales que se deben pagar a los trabajadores del servicio. Es importante recalcar que los salarios destinados a los puestos de Gerente General y de Subgerente, se han definido como 10000 y 9000, por motivos buscar mantener una buena liquidez inicial en el negocio. La idea es empezar con salarios relativamente bajos e ir aumentando gradualmente las remuneraciones, conforme la empresa gane tracción y sostenibilidad económica.

Esto será posible debido a que el gerente general y el subgerente son quienes van a invertir en el negocio, por lo que estarán razonablemente dispuestas a sacrificar el salario inicial para poder ver crecer a la empresa con mayor velocidad. A continuación, se presenta una tabla con las remuneraciones básicas y beneficios de los trabajadores.

Tabla 7.6

Remuneraciones y Beneficios

\begin{tabular}{l|cccc} 
& Gerente & Sub gerente & Jefe de Cocina & $\begin{array}{c}\text { Asistente } \\
\text { de cocina }\end{array}$ \\
\hline Remuneraciones & 10000 & 9000 & 7000 & 4500 \\
Sueldos & 120000 & 108000 & 84000 & 54000 \\
Gratificaciones & 20000 & 18000 & 14000 & 9000 \\
CTS & 11667 & 10500 & 8167 & 5250 \\
Bonificación extra & 1800 & 1620 & 1260 & 810 \\
Essalud & 10800 & 9720 & 7560 & 4860 \\
Total, por persona & 164267 & 147840 & 114987 & 73920 \\
Cantidad de Personas & 1 & 1 & 1 & 2 \\
Total & 164267 & 147840 & 114987 & 147840 \\
Elaboración propia & & & &
\end{tabular}

A continuación, se presenta la continuación de la tabla presentada anteriormente. 
Tabla 7.7

Remuneraciones y beneficios (Continuación)

\begin{tabular}{l|ccccc} 
& Anfitriones & Asistentes & Mozos & $\begin{array}{c}\text { Personal } \\
\text { disuasivo }\end{array}$ & Total \\
\hline Remuneraciones & 3000 & 4000 & 3000 & 4500 & 45000 \\
Sueldos & 36000 & 48000 & 36000 & 54000 & 540000 \\
Gratificaciones & 6000 & 8000 & 6000 & 9000 & 90000 \\
CTS & 3500 & 4667 & 3500 & 5250 & 52500 \\
Bonificación extra & 540 & 720 & 540 & 810 & 8100 \\
Essalud & 3240 & 4320 & 3240 & 4860 & 48600 \\
Total, por persona & 49280 & 65707 & 49280 & 73920 & 739200 \\
Cantidad de Personas & 2 & 4 & 8 & 1 & \\
Total & 98560 & 262827 & 394240 & 73920 & 1404480
\end{tabular}

Elaboración propia

\section{Mano de Obra Directa}

La mano de obra directa consiste del personal del personal de cocina, ya sea el jefe de cocina o los asistentes, ya que ellos son los únicos que participan de la transformación de la materia. A continuación, se presenta el presupuesto de gastos en Mano de Obra directa.

Tabla 7.8

Presupuesto de mano de obra directa (MOD)

\begin{tabular}{l|ccccc} 
Año & $\mathbf{2 0 1 9}$ & $\mathbf{2 0 2 0}$ & $\mathbf{2 0 2 1}$ & $\mathbf{2 0 2 2}$ & $\mathbf{2 0 2 3}$ \\
\hline \multicolumn{7}{l}{ MOD } \\
\hline Remuneraciones & 192000.00 & 192000.00 & 192000.00 & 192000.00 & 192000.00 \\
Gratificaciones & 32000.00 & 32000.00 & 32000.00 & 32000.00 & 32000.00 \\
CTS & 18666.67 & 18666.67 & 18666.67 & 18666.67 & 18666.67 \\
Bonificaciones & 2880.00 & 2880.00 & 2880.00 & 2880.00 & 2880.00 \\
Total, MOD & 245546.67 & 245546.67 & 245546.67 & 245546.67 & 245546.67 \\
Elaboración propia & & & & &
\end{tabular}

\section{Mano de Obra Indirecta}

La mano de obra indirecta, se compone de los demás miembros de personal, ya sean de atención al cliente o de sporte al servicio. 
Tabla 7.9

Presupuesto de mano de obra indirecta (MOI)

\begin{tabular}{l|ccccc} 
Año & $\mathbf{2 0 1 9}$ & $\mathbf{2 0 2 0}$ & $\mathbf{2 0 2 1}$ & $\mathbf{2 0 2 2}$ & $\mathbf{2 0 2 3}$ \\
\hline \multicolumn{7}{l}{ MOI } \\
\hline Remuneraciones & 834000.00 & 834000.00 & 834000.00 & 834000.00 & 834000.00 \\
Gratificaciones & 139000.00 & 139000.00 & 139000.00 & 139000.00 & 139000.00 \\
CTS & 81083.33 & 81083.33 & 81083.33 & 81083.33 & 81083.33 \\
Bonificaciones & 12510.00 & 12510.00 & 12510.00 & 12510.00 & 12510.00 \\
Total, MOI & 1066593.33 & 1066593.33 & 1066593.33 & 1066593.33 & 1066593.33
\end{tabular}

Elaboración propia

\subsection{Presupuesto de ingresos y egresos}

Los presupuestos operativos se componen de la proyección de las ventas, y los costos principales del servicio.

\subsubsection{Presupuesto de ingreso por ventas}

Se obtuvo el presupuesto de ingresos por ventas en base a la cantidad de visitas que se recibirán, y lo que se espera consuman tanto en bebidas como en piqueos. Se consideró un promedio de 3 bebidas por visita y un piqueo cada 4 personas.

Tabla 7.10

Presupuesto de ingreso por ventas

\begin{tabular}{l|ccccc} 
Año & $\mathbf{2 0 1 9}$ & $\mathbf{2 0 2 0}$ & $\mathbf{2 0 2 1}$ & $\mathbf{2 0 2 2}$ & $\mathbf{2 0 2 3}$ \\
\hline Visitas & 29655 & 51991 & 84873 & 93379 & 120474 \\
Bebidas & 88965 & 155973 & 254619 & 280137 & 361422 \\
Cerveza & 61742 & 108246 & 176706 & 194416 & 250827 \\
Precio Cerveza & 20 & 20 & 20 & 20 & 20 \\
Cocteles & 27223 & 47727 & 77913 & 85721 & 110595 \\
Precio Cocteles & 25 & 25 & 25 & 25 & 25 \\
Piqueos & 7414 & 12998 & 21219 & 23345 & 30119 \\
Precio Piqueos & 25 & 25 & 25 & 25 & 25 \\
Ingresos por ventas & 2100765 & 3683045 & 6012420 & 6614970 & 8534390
\end{tabular}

Elaboración propia 


\subsubsection{Presupuesto de costos del servicio}

En cuanto a los costos, estos consideran los ya mencionados, los gastos de depreciación y el pago de los alquileres.

Tabla 7.11

Presupuesto de depreciación operativa

\begin{tabular}{l|ccccc} 
Año & $\mathbf{2 0 1 9}$ & $\mathbf{2 0 2 0}$ & $\mathbf{2 0 2 1}$ & $\mathbf{2 0 2 2}$ & $\mathbf{2 0 2 3}$ \\
\hline Desembolso & 16584.00 & 16584.00 & 16584.00 & 12984.00 & 12984.00
\end{tabular}

Elaboración propia

Tabla 7.12

Presupuesto de pago de alquileres

\begin{tabular}{l|ccccc} 
Año & $\mathbf{2 0 1 9}$ & $\mathbf{2 0 2 0}$ & $\mathbf{2 0 2 1}$ & $\mathbf{2 0 2 2}$ & $\mathbf{2 0 2 3}$ \\
\hline Desembolso & 249600.00 & 249600.00 & 249600.00 & 249600.00 & 249600.00
\end{tabular}

Elaboración propia

Finalmente, se obtiene el costo de ventas, a partir del consumo de materiales, la mano de obra directa y la depreciación operativa

Tabla 7.13

Presupuesto de costo de ventas

\begin{tabular}{l|ccccc} 
Año & $\mathbf{2 0 1 9}$ & $\mathbf{2 0 2 0}$ & $\mathbf{2 0 2 1}$ & $\mathbf{2 0 2 2}$ & $\mathbf{2 0 2 3}$ \\
\hline Costo de Ventas & 495117.78 & 670203.22 & 928682.82 & 991892.47 & 1204731.05
\end{tabular}

Elaboración propia

\subsubsection{Presupuesto operativo de gastos generales}

Los gastos generales incluyen los gastos administrativos y los gastos operativos. Estos, a su vez incluyen la depreciación administrativa, los pagos a essalud y los alquileres, y la mano de obra indirecta y los servicios generales respectivamente. En la siguiente página se detallan ambos presupuestos.

Tabla 7.14

Presupuesto de gastos administrativos

\begin{tabular}{l|ccccc} 
Año & $\mathbf{2 0 1 9}$ & $\mathbf{2 0 2 0}$ & $\mathbf{2 0 2 1}$ & $\mathbf{2 0 2 2}$ & $\mathbf{2 0 2 3}$ \\
\hline Desembolso & 436045.47 & 436045.47 & 436045.47 & 431378.80 & 431378.80
\end{tabular}

Elaboración propia 
Tabla 7.15

Presupuesto de gastos operativos

\begin{tabular}{l|ccccc} 
Año & $\mathbf{2 0 1 9}$ & $\mathbf{2 0 2 0}$ & $\mathbf{2 0 2 1}$ & $\mathbf{2 0 2 2}$ & $\mathbf{2 0 2 3}$ \\
\hline Desembolso & 1227146.88 & 1324406.48 & 1487462.73 & 1529641.23 & 1664000.63 \\
Elaboración propia & & & &
\end{tabular}

\subsection{Presupuestos financieros}

Finalmente, el último concepto a considerar en la elaboración de los presupuestos incluye los gastos financieros y la proyección de los estados financieros de la empresa. El préstamo se ha tomado en función al dinero necesario para la adquisición del activo fijo. Este monto ha sido redondeado a 1760000 soles, con el fin de facilitar la obtención y pago del mismo. La tasa que se ha tomado como base es la ofrecida por Interbank para pequeñas y medianas empresas, que en este caso es de 14\%. A continuación, se presenta una tabla detallando la inversión necesaria para el negocio, y la procedencia de los fondos.

Tabla 7.16

Inversión requerida para un Bar Automatizado

\begin{tabular}{l|c|c|c}
\hline Concepto & Monto & Fuente & Monto \\
\hline Activo Fijo & 1750914 & Financiamiento & 1760000 \\
Capital de Trabajo & 179603.03 & Capital Social & 170517.03
\end{tabular}

Elaboración propia

\subsubsection{Presupuesto de servicio de deuda}

Con el fin de obtener la mayor ventaja del préstamo, la modalidad de pago se realizará en cuotas decrecientes, con un periodo de gracia parcial. A continuación, se presenta el cronograma de servicio de la deuda.

Tabla 7.17

Presupuesto de servicio de deuda

\begin{tabular}{l|ccccc} 
Año & $\mathbf{2 0 1 9}$ & $\mathbf{2 0 2 0}$ & $\mathbf{2 0 2 1}$ & $\mathbf{2 0 2 2}$ & $\mathbf{2 0 2 3}$ \\
\hline Saldo Inicial & 1760000.00 & 1760000.00 & 1320000.00 & 880000.00 & 440000.00 \\
Amortización & - & 440000.00 & 440000.00 & 440000.00 & 440000.00 \\
Intereses & 246400.00 & 246400.00 & 184800.00 & 123200.00 & 61600.00 \\
Cuota & 246400.00 & 686400.00 & 624800.00 & 563200.00 & 501600.00 \\
Saldo Final & 1760000.00 & 1320000.00 & 880000.00 & 440000.00 & - \\
Elaboración propia & & & & &
\end{tabular}


A partir de los datos calculados, ya es posible realizar proyecciones de los estados financieros de la empresa.

\subsubsection{Presupuesto de estado de resultados}

El estado de resultados ha sido proyectado para cada uno de los cinco años de vida útil, con el fin de generar una base para el cálculo de los flujos de fondos de efectivo. El presupuesto de estados de resultados, permitirá asimismo determinar la rentabilidad que se espera obtener del bar en cada año, y su compararla con los valores normales del sector de alimentos y bebidas.

Tabla 7.18

Presupuesto de proyección del estado de resultados

\begin{tabular}{l|cccccc}
\hline \multicolumn{7}{|c|}{$\begin{array}{c}\text { Estado de Resultados } \\
\text { (Expresado en Soles) }\end{array}$} \\
\hline Año & $\mathbf{2 0 1 9}$ & $\mathbf{2 0 2 0}$ & $\mathbf{2 0 2 1}$ & $\mathbf{2 0 2 2}$ & $\mathbf{2 0 2 3}$ \\
\hline Ventas & 2100765.00 & 3683045.00 & 6012420.00 & 6614970.00 & 8534390.00 \\
Costo de Ventas & $(495117.78)$ & $(670203.22)$ & $(928682.82)$ & $(991892.47)$ & $(1204731.05)$ \\
Utilidad Bruta & 1605647.22 & 3012841.78 & 5083737.18 & 5623077.53 & 7329658.95 \\
Gastos operativos & $(1227146.88)$ & $(1324406.48)$ & $(1487462.73)$ & $(1529641.23)$ & $(1664000.63)$ \\
Gastos administrativos & $(436045.47)$ & $(436045.47)$ & $(436045.47)$ & $(431378.80)$ & $(431378.80)$ \\
Utilidad Operativa & $(57545.13)$ & 1252389.83 & 3160228.98 & 3662057.49 & 5234279.51 \\
Gastos Financieros & $(246400.00)$ & $(246400.00)$ & $(184800.00)$ & $(123200.00)$ & $(61600.00)$ \\
Utilidad antes de impuestos & $(303945.13)$ & 1005989.83 & 2975428.98 & 3538857.49 & 5172679.51 \\
Impuesto a la Renta & 89663.81 & $(296767.00)$ & $(877751.55)$ & $(1043962.96)$ & $(1525940.46)$ \\
Utilidad Neta & $(214281.32)$ & 709222.83 & 2097677.43 & 2494894.53 & 3646739.06 \\
Utilidad de libre disposición & $(214281.32)$ & 709222.83 & 2097677.43 & 2494894.53 & 3646739.06 \\
Elaboración propia & & & & &
\end{tabular}

A partir de estos datos, se puede observar que, si bien durante el primer año existe pérdida, la rentabilidad neta del negocio es de 19\% durante el segundo, lo cual es relativamente bajo para el sector. Sin embargo, esto se debe a la baja captación de los primeros año de vida útil, ya que en el último año se obtiene una rentabilidad de $47 \%$, un valor normal para este ámbito.

\subsubsection{Presupuesto de estado de situación financiera}

El estado de situación financiera, solo ha sido proyectado para el primer año del negocio, ya que este sirve para analizar la gestión económica-financiera del servicio, y dado que 
aún se encuentra en fase proyecto, este análisis no es posible. Para la determinación de las cuentas de efectivo se utilizó un presupuesto auxiliar, el de flujo de efectivo de corto plazo.

Tabla 7.19

Presupuesto de flujo de efectivo de corto plazo

\begin{tabular}{l|ccccc} 
Año & $\mathbf{2 0 1 9}$ & $\mathbf{2 0 2 0}$ & $\mathbf{2 0 2 1}$ & $\mathbf{2 0 2 2}$ & $\mathbf{2 0 2 3}$ \\
\hline Ingreso por Ventas & 2100765.00 & 3683045.00 & 6012420.00 & 6614970.00 & 8534390.00 \\
Egreso por Compras & 233382.80 & 408327.96 & 666826.05 & 733675.97 & 946547.71 \\
Sueldos & 1312140.00 & 1312140.00 & 1312140.00 & 1312140.00 & 1312140.00 \\
Alquileres & 249600.00 & 249600.00 & 249600.00 & 249600.00 & 249600.00 \\
Servicios Generales & 160553.55 & 257813.15 & 420869.40 & 463047.90 & 597407.30 \\
Pago de la Deuda & 246400.00 & 246400.00 & 184800.00 & 123200.00 & 61600.00 \\
Impuesto a la Renta & $(89663.81)$ & 296767.00 & 877751.55 & 1043962.96 & 1525940.46 \\
Pagos a Essalud & 92340.00 & 92340.00 & 92340.00 & 92340.00 & 92340.00 \\
Pago de garantía & 41600.00 & - & & - & - \\
Flujo de efectivo & $(145587.53)$ & 819656.89 & 2208093.01 & 2597003.17 & 3748814.53 \\
Saldo Inicial & 179603.03 & 34015.50 & 853672.38 & 3061765.39 & 5658768.56 \\
Saldo Final & 34015.50 & 853672.38 & 3061765.39 & 5658768.56 & 9407583.09
\end{tabular}

Elaboración propia

A continuación, se presenta el estado de situación financiera del 31 de diciembre de 2019. 
Tabla 7.20

Presupuesto de estado de situación financiera proyectado

\begin{tabular}{|c|c|c|c|}
\hline \multicolumn{4}{|c|}{$\begin{array}{c}\text { Estado de Situación Financiera } \\
\text { al 31/12/2019 } \\
\text { (Expresado en Soles) }\end{array}$} \\
\hline Activ & & \multicolumn{2}{|c|}{ Pasivo y Patrimonio } \\
\hline Activo Co & & \multicolumn{2}{|c|}{ Pasivo } \\
\hline Efectivo & 34015.50 & \multicolumn{2}{|c|}{ Pasivo Corriente } \\
\hline Cuentas por cobrar & 41600.00 & \multicolumn{2}{|l|}{ Cuentas por Pagar } \\
\hline Inventarios & 395.68 & \multirow[t]{2}{*}{ Obligaciones de corto plazo } & 440000.00 \\
\hline Total Activo Corriente & 76011.18 & & \\
\hline \multicolumn{2}{|c|}{ Activo No Corriente } & Total Pasivo Corriente & 440000.00 \\
\hline Inmueble Maquinaria y Equipos & 1750914.00 & \multicolumn{2}{|c|}{ Pasivo No Corriente } \\
\hline ( - ) Depreciación Acumulada & $(110689.47)$ & Obligaciones de largo Plazo & 1320000.00 \\
\hline \multirow[t]{8}{*}{ Total Activo No Corriente } & 1640224.53 & Total Pasivo No Coriente & 1320000.00 \\
\hline & & Total Pasivo & 1760000.00 \\
\hline & & \multicolumn{2}{|c|}{ Patrimonio } \\
\hline & & Capital Social & 170517.03 \\
\hline & & Resultado del ejercicio & $(214281.32)$ \\
\hline & & Utilidades Retenidas & \\
\hline & & Reserva Legal & \\
\hline & & Total Patrimonio & \\
\hline Total Activo & 1716235.71 & Total Pasivo y Patrimonio & 1716235.71 \\
\hline
\end{tabular}

Elaboración propia

\subsection{Flujo de fondos netos}

Para realizar el análisis económico-financiero, se deben establecer los flujos de fondos netos. Para tal propósito se ha considerado la utilidad neta y sus respectivos ajustes.

\subsubsection{Flujo de fondos económicos}

Para la elaboración del flujo económico se ha considerado toda la inversión, y no se ha incluido el concepto de amortización de la deuda. 
Tabla 7.21

Flujo de fondos económicos

\begin{tabular}{|c|c|c|c|c|c|c|}
\hline Año & 2018 & 2019 & 2020 & 2021 & 2022 & 2023 \\
\hline Inversión & 1930517 & & & & & \\
\hline Ventas & & 2100765 & 3683045 & 6012420 & 6614970 & 8534390 \\
\hline Costo de Ventas & & (495 118) & $(670203)$ & (928 683) & (991 892) & (1 204731$)$ \\
\hline Utilidad Bruta & & 1605647 & 3012842 & 5083737 & 5623078 & 7329659 \\
\hline Gastos operativos & & (1 227 147) & (1 324406$)$ & (1 487463$)$ & (1 529641$)$ & (1 664001$)$ \\
\hline Gastos administrativos & & $(436045)$ & $(436045)$ & (436 045) & (431 379) & (431 379) \\
\hline Utilidad Operativa & & $(57545)$ & 1252390 & 3160229 & 3662057 & 5234280 \\
\hline Gastos Financieros & & & - & - & - & - \\
\hline Utilidad antes de impuestos & & $(57545)$ & 1252390 & 3160229 & 3662057 & 5234280 \\
\hline Crédito fiscal & & - & 16976 & - & - & - \\
\hline Impuesto a la Renta & & - & $(369455)$ & (932 268) & $\left(\begin{array}{llll}1 & 080 & 307\end{array}\right)$ & $\left(\begin{array}{l}1 \\
5\end{array} 44\right.$ 112) \\
\hline Utilidad Neta & & $(57545)$ & 899911 & 2227961 & 2581751 & 3690167 \\
\hline Reversión de la Depreciación & & 110689 & 110689 & 110689 & 102423 & 102423 \\
\hline Amortización de deuda & & - & - & - & - & - \\
\hline Ajuste de Cuentas por cobrar & & - & - & - & - & - \\
\hline Ajuste de Cuentas por pagar & & - & - & - & - & - \\
\hline Ajuste por Inventario & & 396 & 255 & 274 & 314 & 347 \\
\hline Recupero de Capital de Trabajo & & & & & & 170517 \\
\hline Flujo de fondos Económicos & (1 930517$)$ & 53540 & 1010856 & 2338925 & 2684487 & 3792937 \\
\hline Elaboración propia & & & & & & \\
\hline
\end{tabular}

\subsubsection{Flujo de fondos financieros}

El flujo financiero sí considera una inversión con parte proveniente de préstamo. En la página siguiente se encuentra el presupuesto detallado del flujo de fondos financieros. 
Tabla 7.22

Presupuesto del flujo de fondos financieros

\begin{tabular}{|c|c|c|c|c|c|c|}
\hline Año & 2018 & 2019 & 2020 & 2021 & 2022 & 2023 \\
\hline Inversión & 170517 & & & & & \\
\hline Ventas & & 2100765 & 3683045 & 6012420 & 6614970 & 8534390 \\
\hline Costo de Ventas & & (495 118) & (670 203) & (928 683) & (991 892) & (1 204731$)$ \\
\hline Utilidad Bruta & & 1605647 & 3012842 & 5083737 & 5623078 & 7329659 \\
\hline Gastos operativos & & (1 227 147) & (1 324406$)$ & (1 487463$)$ & (1 529641$)$ & (1 664001$)$ \\
\hline Gastos administrativos & & (436 045) & $(436045)$ & (436 045) & (431 379) & (431 379) \\
\hline Utilidad Operativa & & (57 545) & 1252390 & 3160229 & 3662057 & 5234280 \\
\hline Gastos Financieros & & $(246400)$ & $(246400)$ & $(184800)$ & (123 200) & $(61600)$ \\
\hline Utilidad antes de impuestos & & (303 945) & 1005990 & 2975429 & 3538857 & 5172680 \\
\hline Crédito fiscal & & - & 89664 & - & - & - \\
\hline Impuesto a la Renta & & - & (296 767) & $(877752)$ & $\left(\begin{array}{lll}1 & 043 & 963\end{array}\right)$ & (1 525940$)$ \\
\hline Utilidad Neta & & (303 945) & 798887 & 2097677 & 2494895 & 3646739 \\
\hline Reversión de la Depreciación & & 110689 & 110689 & 110689 & 102423 & 102423 \\
\hline Amortización de deuda & & - & 440000 & 440000 & 440000 & 440000 \\
\hline Ajuste de Cuentas por cobrar & & - & - & - & - & - \\
\hline Ajuste de Cuentas por pagar & & - & - & - & - & - \\
\hline Ajuste por Inventario & & 396 & 255 & 274 & 314 & 347 \\
\hline Recupero de capital de trabajo & & & & & & 170517 \\
\hline Flujo de fondos Financieros & $(170517)$ & $(192860)$ & 469832 & 1768641 & 2157631 & 3309509 \\
\hline Elaboración propia & & & & & & \\
\hline
\end{tabular}




\section{CAPÍTULO VIII: EVALUACIÓN ECONÓMICAY Y FINANCIERA}

Con el fin de determinar si el proyecto de instalación de un Bar Automatizado es rentable, es necesario determinar los principales indicadores económico-financieros, como el VAN, la TIR, el periodo de recupero y la relación beneficio costo. Para ello, se estableció una tasa de descuento en base al método de CAPM, que considera la rentabilidad del mercado, el riesgo general de realizar inversiones en el Perú, una tasa libre de riesgo y la relación que existe entre el riesgo del mercado y el riesgo del sector, expresado en términos de un "beta" apalancado.

Desde el 2017, el riesgo país de Perú ha disminuido a 1.33\%. La rentabilidad promedio del sector restaurantes y bares es del $25 \%$. La rentabilidad libre de riesgo se obtiene como la rentabilidad obtenida al invertir en un bono de tesorería de Estados Unidos. Esta rentabilidad es aproximadamente 5.75\%. Finalmente, el "beta" apalancado del sector es de 0.9 , por lo que las inversiones en restaurantes y bares son menos riesgosas que el mercado en general. Estos datos permitieron obtener una tasa mínima de descuento de $24 \%$. Ya que los accionistas de la empresa no poseen una cartera de inversiones amplia, esta rentabilidad mínima es la adecuada para fijar el CoK o costo de capital. Con el fin de realizar un análisis de mayor acidez, se realizará la evaluación económica y financiera utilizando como tasa de descuento el CoK únicamente. Es decir, no se utilizará el WACC.

\subsection{Evaluación económica}

Tabla 8.1

Evaluación económica del proyecto

\begin{tabular}{l|cccccc} 
Año & $\mathbf{2 0 1 8}$ & $\mathbf{2 0 1 9}$ & $\mathbf{2 0 2 0}$ & $\mathbf{2 0 2 1}$ & $\mathbf{2 0 2 2}$ & $\mathbf{2 0 2 3}$ \\
\hline $\begin{array}{l}\text { Flujo de fondos } \\
\begin{array}{l}\text { Económicos } \\
\text { Flujo actualizado de } \\
\text { fondos }\end{array}\end{array}$ & $(1930517)$ & 53540 & 1010856 & 2338925 & 2684487 & 3792937 \\
$\begin{array}{l}\text { Flujo acumulado de } \\
\text { fondos }\end{array}$ & $(1930517)$ & 43037 & 653151 & 1214794 & 1120753 & 1272877 \\
$\begin{array}{l}\text { Elaboración propia } \\
\text { (1930 517) }\end{array}$ & $(1887480)$ & $(1234329)$ & $(19535)$ & 1101218 & 2374095 \\
& & & & & &
\end{tabular}


El VAN obtenido es de 2374095 soles. Los demás indicadores obtenidos para el proyecto son los siguientes:

- Tasa Interna de Retorno (TIR): 56\%

- Relación Beneficio-Capital: 2.23

- Periodo de Recupero: 3 años, 0 meses y 5 días.

Estos resultados son favorables para la rentabilidad del accionista por los siguientes motivos:

- Al obtener un Valor Actual Neto positivo, se observa que no existe pérdida de dinero por parte de los accionistas. Es decir que el proyecto aporta valor para los inversionistas.

- La tasa interna de retorno es muy superior a la exigida por los accionistas. Es incluso superior a la rentabilidad exigida por los negocios más rentables del sector.

- Finalmente, el periodo de recupero se encuentra por debajo de la vida útil del proyecto.

\subsection{Evaluación financiera}

Una vez analizada la situación económica, es necesario determinar la rentabilidad de los fondos financieros, para verificar si estos son más favorables para el negocio.

Tabla 8.2

Evaluación financiera del proyecto

\begin{tabular}{l|cccccc} 
Año & $\mathbf{2 0 1 8}$ & $\mathbf{2 0 1 9}$ & $\mathbf{2 0 2 0}$ & $\mathbf{2 0 2 1}$ & $\mathbf{2 0 2 2}$ & $\mathbf{2 0 2 3}$ \\
\hline Flujo de fondos Financieros & $(170517)$ & $(192860)$ & 469832 & 1768641 & 2157631 & 3309509 \\
Flujo actualizado de fondos & $(170517)$ & $(155026)$ & 303575 & 918599 & 900795 & 1110643 \\
Flujo acumulado de fondos & $(170517)$ & $(325543)$ & $(21968)$ & 896632 & 1797427 & 2908069 \\
Elaboración propia & & & & &
\end{tabular}

El VAN obtenido es de S/ 2908 069. Los demás indicadores obtenidos para el proyecto son los siguientes: 
- Tasa Interna de Retorno (TIR): $160 \%$

- Relación Beneficio-Capital: 18.05

- Periodo de recupero: 2 años, 0 meses y 27 días.

Estos resultados son favorables para la rentabilidad del accionista por los siguientes motivos:

- Al obtener un Valor Actual Neto positivo, se observa que no existe pérdida de dinero por parte de los accionistas. Es decir que el proyecto aporta valor para los inversionistas.

- La tasa interna de retorno es muy superior a la exigida por los accionistas. Es incluso superior a la rentabilidad exigida por los negocios más rentables del sector.

- Finalmente, el periodo de recupero se encuentra por debajo de la vida útil del proyecto.

\subsection{Análisis de los resultados económicos y financieros del proyecto}

A partir de los resultados obtenidos, es posible obtener las siguientes conclusiones con respecto a la viabilidad económico-financiera del proyecto:

- Tanto en el caso financiero como en el económico, el valor actual neto es positivo y alto, por lo que la tasa interna de retorno es muy superior a la rentabilidad esperada. Tras un análisis detallado, se determinó que la razón de estos valores es principalmente la negociación de un derecho de superficie a 99 años, en lugar de la compra de un terreno. La inversión ahorrada (alrededor de 2000000 de soles), permite obtener un alto rendimiento en el negocio. El costo del terreno se encuentra licuado en las mensualidades del derecho de superficie, y se considera descontado por la tasa de costo de capital. Así mismo, se evita la adquisición de una deuda importante.

- El sector servicios, en especial los servicios de restaurantes y bares, se caracteriza por tener una alta rentabilidad. En general, la fijación de precios se da en base al costo de materiales del servicio. Un servicio cualquiera puede permitirse cobrar por lo menos tres veces el costo de sus materiales. A medida que aumenta el valor 
para el cliente, aumentará el margen bruto. Esta situación permite que la empresa tenga una rentabilidad bruta de $87 \%$. Por lo que no se generan pérdidas en ningún año del negocio.

- La "alta" inversión inicial en maquinaria de automatización de la barra, permite que se eviten los altos salarios que se pagan a los bartenders. Este personal resulta especialmente caro en negocios de esta categoría, ya que poseen un conocimiento especializado y son los que se encuentran en contacto directo con el cliente.

- Si bien el Valor Actual Neto es relativamente alto, existen motivos por los cuales suponer que este no fue más alto. Principalmente, esto se debe al costo de la construcción del local. Este monto asciende a casi 1600000 soles, por lo compone casi toda la inversión en activo fijo. Sin embargo, esta inversión permitirá poder atender a una mayor cantidad de clientes en el futuro, incrementando las ventas y los ingresos del negocio. Así mismo, el pago por el derecho de superficie es caro debido a que el local se encuentra en un área de gran demanda de terrenos comerciales.

- Los resultados financieros son más favorables que los económicos, ya que la alta inversión a realizar en activo fijo, se licúa dentro de la vida útil del proyecto. Así mismo, el costo del capital es menor, debido al escudo fiscal de los intereses pagados durante el negocio.

\subsection{Análisis de sensibilidad del proyecto}

El último paso para verificar la viabilidad del negocio, es determinar la sensibilidad frente a potenciales cambios en el mercado. Para tal efecto, se ha decidido realizar modificaciones a la demanda obtenida en el estudio de mercado, al precio fijado y a la tasa del préstamo obtenido, y analizar sus efectos sobre el valor actual neto del proyecto.

En el primer escenario, se realiza una disminución del 1\% del precio fijado para cada uno de los productos comercializados, es decir que los coctéles y piqueos disminuyen su precio a 24.75 soles, y los piqueos a 19.80. Para este escenario, se obtuvo un Valor actual neto económico de 2297553 soles, una tasa interna de retorno de 55\%, y un periodo de recupero de 3 años y 17 días. Esto quiere decir que por cada punto porcentual variado en el precio de los servicios, el VAN económico 3.6\%. 
Por otro lado, el VAN financiero se reduce a 2831528 soles, la TIR disminuye a $157 \%$ y el periodo de recupero asciende a 2 años, 1 mes y 14 días. En el caso de utilizar financiamiento, la sensibilidad del proyecto frente a un cambio en el precio es de $2.91 \%$.

Para analizar la sensibilidad a la demanda, se ha realizado una variación del 1\% sobre la intención obtenida en las encuestas. Esto se reflejó en los siguientes resultados económico-financieros:

- VAN económico: 2305102

- VAN financiero: 2839076

- TIR económica: $55 \%$

- TIR financiera: $157 \%$

- Periodo de recupero económico: 3 años y 16 días

- Periodo de recupro financiero: 2 años, 1 mes y 19 días

La sensibilidad a un cambio del $1 \%$ en la intención, es de $3.25 \%$ para una situación en la que el financiamiento es netamente por aporte propio, y de $2.65 \%$ para el VAN financiero.

Para el análisis de sensibilidad con respecto a la tasa del préstamo, no es necesario determinar las variaciones en los flujos económicos, ya que estos no se ven afectados por la el costo del financiamiento. Al aumentar la tasa del préstamo obtenido en $1 \%$, se obtuvo un Valor Actual Neto de 2889 074, una Tasa Interna de Retorno de 159\%, y un periodo de recupero de 2 años, 1 mese y 10 dias. La sensibilidad al cambio en la tasa es de $0.94 \%$.

En base a lo analizado, se ha podido determinar que las variables con mayor efecto sobre la rentabilidad del negocio, son el precio y la demanda. Esto quiere decir que se debe buscar siempre mantener en un nivel óptimo la satisfación al cliente y los estándares de calidad, con el fin de fidelizar clientes actuales, y atraer clientes nuevos. Finalmente, si bien la tasa no tiene un efecto tan significativo en los resultados de proyecto, como la demanda, igual es importante negociarla con el banco hasta un monto que sea favorable para ambos. 


\section{CAPÍTULO IX: EVALUACIÓN SOCIAL}

\subsection{Identificación de las zonas y comunidades de influencia del proyecto}

El impacto social de un proyecto se puede medir de multiples formas: el impacto que tiene en la cultura de la comunidad que va a acoger al proyecto, el impacto ambiental, el impacto económico que generará en la comunidad, etc. Todas estas formas son importantes para lograr evaluar al proyecto de manera holística y definir si su implementación aportará un beneficio no solo a los inversionistas, sino a la sociedad.

Las zonas más impactadas por el proyecto serán los distritos de Lima Moderna, previamente definidos como el segmento geográfico que alberga a la mayoría de clientes potenciales. Sin embargo, el impacto mas notorio se producirá en los distritos de Miraflores y San Isidro.

En cuanto a las comunidades, el bar automatizado tendrá repercusiones en la creación de empleo, las tendencias de consumo de bebidas alcohólicas y en el modelo de negocio de la industria de los bares.

\subsection{Impacto en la zona de influencia}

El impacto que el bar causará en Lima Moderna será mayormente económico. La implementación del bar creará 20 nuevos puestos de trabajo en el distrito de Miraflores; adicionalmente, la actividad económica generada por el consumo de los clientes beneficiará al gobierno debido a la cobranza de impuestos. Asimismo, debido a que la propuesta de negocio del bar automatizado es diferente, es probable que a lo largo del tiempo los otros bares quieran incorporar practicas similares a sus propuestas de valor.

Si bien la cantidad de empleos generados no es elevada, los trabajadores del bar automatizado recibirán conocimientos de automatización y de gestión de negocios independientes, que serán valiosos para sus desarrollos profesionales. La implementación del servicio también significará un aumento en las opciones de los consumidores; al tener más oportunidad de elección, el mercado será más justo. 


\subsection{Impacto social del proyecto}

Con el fin de cuantificar el impacto que tendrá el proyecto en la sociedad, se calcularon los principales indicadores de evaluación social. Para esto, es necesario contar con la data relacionada a ventas, costos de materiales, inversiones y cantidad de trabajadores. El primer indicador es el de valor agregado.

Tabla 9.1

Evaluación social del proyecto

\begin{tabular}{l|ccccc} 
Año & $\mathbf{2 0 1 9}$ & $\mathbf{2 0 2 0}$ & $\mathbf{2 0 2 1}$ & $\mathbf{2 0 2 2}$ & $\mathbf{2 0 2 3}$ \\
\hline Ventas & 2100765 & 3683045 & 6012420 & 6614970 & 8534390 \\
Materiales & 233383 & 408328 & 666826 & 733676 & 946548 \\
Valor Agregado & 1867382 & 3274717 & 5345594 & 5881294 & 7587842 \\
Elaboración propia & & & & &
\end{tabular}

Este indicador mide el valor que el negocio aportará a lo largo de su vida útil. Cada año se construyó restando el valor de las ventas con el costo de los materiales necesarios para la producción del servicio. Llevando todos estos valores al presente, se obtiene un valor agregado acumulado de S/ 11395 179, que es el beneficio que el negocio está aportando a la sociedad al ser implementado.

Una vez calculado el valor agregado acumulado fue posible obtener diferentes indicadores de evaluación social, como:

- Intensidad de Capital: 0.17

- Relación Producto-Capital: 6

- Densidad de Capital: 96526

La intensidad de capital y la relación producto-capital van de la mano. El primero representa el porcentaje del valor agregado que se le atribuye la inversión; mientras que el segundo, muestra el potencial que tiene la inversión para generar valor.

Estos dos ratios indican que lo que aporta valor en el Bar no es la inversión en activo fijo, sino otros factores como el concepto, los diferentes ambientes y la eficiencia del servicio. Adicionalmente, demuestran que el negocio tiene un alto potencial para generar valor, ya que el beneficio brindado es seis veces la inversión. 
En cuanto a la densidad de capital se encontró que para la instalación de este bar se requiere de S/ 96526 para la generación de cada puesto de trabajo. Con el fin de analizar mejor el resultado, se realizó un benchmark con data estadística obtenida por el INEI para empresas pequeñas. El rango de densidad de capital para una empresa de hasta 20 trabajadores, es de S/ 9000. Si bien se percibe una exorbitante diferencia, esta se debe a la fuerte inversión que existe al momento de construir el local en Miraflores.

Para verificar que los valores se encuentren dentro de los rangos, se decidió calcular una densidad de capital que no incluyese la construcción dentro de la inversión. Es así que se obtuvo un valor de S/ 16 526. Este valor también se encuentra por encima de lo promediado por el INEI, pero se explica gracias a la poca necesidad de personal debido a la automatización del servicio.

Finalmente, se calculó la productividad de la mano de obra, con el fin de evaluar el valor generado por cada trabajador, cada uno de los años del proyecto.

\section{Tabla 9.2}

Productividad de la mano de obra

\begin{tabular}{l|ccccc} 
Año & $\mathbf{2 0 1 9}$ & $\mathbf{2 0 2 0}$ & $\mathbf{2 0 2 1}$ & $\mathbf{2 0 2 2}$ & $\mathbf{2 0 2 3}$ \\
\hline $\begin{array}{l}\text { Productividad de MO } \\
\text { Elaboración propia }\end{array}$ & 93369 & 163736 & 267280 & 294065 & 379392
\end{tabular}

Conforme progrese el negocio y aumenten las ventas, es posible generar mayor valor sin aumentar la cantidad de trabajadores. Esto se debe a que este bar, al ser automatizado, solo requiere de una pequeña cantidad de personal vital para un buen funcinamiento del negocio. 


\section{CONCLUSIONES}

- Después de realizado el estudio referente a las necesidades de tecnología de automatización del negocio, se ha podido comprobar que la inversión no es demasiado grande, y los componentes son sencillos de conseguir en el mercado. Esto indica una alta viabilidad técnica del proyecto y un beneficio en cuanto al ahorro de fondos para la instalación del servicio.

- Se estableció que Miraflores es el distrito ideal para la instalación de un bar, basando la decisión en los resultados obtenidos en las encuestas, así como en su alta disponibilidad de terrenos. Dentro de este distrito, la zona óptima es la aledaña al parque Kennedy, por su alta afluencia de personas y cantidad de terrenos disponibles.

- El diseño de los ambientes físicos es crucial para la instalación de un servicio en el que el cliente participa activamente del proceso de servucción. Por ello, es necesario conocer al cliente y mantener un ambiente que sea siempre de su agrado. Con el fin de satisfacer a todos los clientes, se han diseñado cuatro ambientes diferentes que puedan ser del agrado de cada uno de los consumidores.

- Se ha podido observar que una empresa proveedora de servicios de consumo puede llegar a ser altamente rentable debido a sus estructuras de costos. El margen de contribución resulta elevado, ya que los costos variables incluyen solo la materia prima. Además, el valor añadido otorgado por la automatización, permite disminuir los gastos operativos y administrativos, generando una mayor utilidad.

- Si bien existe una alta demanda potencial para el servicio, nunca será posible alcanzar el $100 \%$ de la participación. Esto se debe a la existencia de competidores en el sector, y a la captación de cada uno de los servicios. 


\section{RECOMENDACIONES}

- Se recomienda contratar a una empresa especialista en Investigación \& Diseño para la creación, prototipado y la instalación de la tecnología de automatización de la barra. De esta forma, la empresa podrá concentrarse en su "core business", agregando más valor al servicio gracias a las sinergias que se generen entre la empresa especialista y la empresa dueña del bar.

- Es importante recordar que este estudio ha incluido análisis y proyecciones que puede que no lleguen a concretarse conforme pase el tiempo, es por eso que la empresa siempre deberá estar atenta a la situación actual en la que esté, para así tomar decisiones adecuadas y beneficiosas.

- Se recomienda a la empresa nunca escatimar en los diferentes insumos a utilizar en los procesos de servucción, sean bebidas alcohólicas, comida, o incluso juegos de mesa; todos los insumos deberán ser de calidad, sin importar que tengan mayor costo. Esto se debe a que el público objetivo de este bar es muy exigente en cuanto a la calidad, cosa que también se evidencia con los resultados del análisis de sensibilidad. 


\section{REFERENCIAS}

Istocka, S. (2015). Automated Beverage Dispenser - Honors Research Projects. (Tesis para optar el título profesional de Bachiller en Ciencias. The University of Akron, Ohio, Estados Unidos de América.) Recuperado de http://ideaexchange.uakron.edu/honors_research_projects/87

Kotler, P. and Armstrong, G. (1991). Principles of marketing. 16th ed. Pearson.

Lewandowski M., Schmidt K., Kielhorn C., Uckelmann D. (2012) The Internet of Drinks. Doi: 10.1007/978-3-642-28816-6_16.

Martínez Morán, M. d., Pedraza Armenta, V. (2004). Aplicación de métodos de localización para un restaurant-bar temático en la isla de Tenerife. (Tesis para optar la licenciatura en Administración de hoteles y restaurantes. Universidad de las Américas Puebla., Puebla, México). Recuperado de http://catarina.udlap.mx/u_dl_a/tales/documentos/lhr/martinez_m_md/

Matthew L. Meuter, Mary Jo Bitner, Amy L. Ostrom, Stephen W. Brown (2005). Choosing Among Alternative Service Delivery Modes: An Investigation of Customer Trial of Self-Service Technologies. Journal of Marketing, 69, 2, 61-83. Doi: $10.1509 /$ jmkg.69.2.61.60759 


\section{BIBLIOGRAFÍA}

A donde vivir. (2017). Se vende excelente terreno en Miraflores. Recuperado de: https://www.adondevivir.com/propiedades/se-vende-excelente-terreno-enmiraflores-53481132.html

Cooking Issues. (2017). Cocktail science in general Recuperado de http://www.cookingissues.com/index.html\%3Fp=4601.html

E1 93\% de peruanos usan las redes sociales para buscar noticias o información de interés. (18 de Setiembre de 2015). Diario Gestión.

Euromonitor. (2016). Alcoholic Drinks in Peru- Industry Overview. Recuperado de https://www.euromonitor.com\%2Falcoholic-drinks-inperu\%2Freport\&usg=AOvVaw1lV2-Rw3_CPvKoCltUMY_m

Euromonitor. (2017). Alcoholic Drinks: 4 Key Trends for 2017. Recuperado de http:// blog.euromonitor.com/2017/03/alcoholic-drinks-4-key-trends-for-2017.html

Grimaldi, P. A. (1982). EE.UU. Patente $\mathrm{N}^{\circ} 4469$ 150. Washington DC: U.S. Patent and Trademark Office. Dispenser for automatically dispensing a beverage or liquid food into take-away recipients.

Instituto Nacional de Estadística e Informática INEI. (2016). El Perú tiene una población de 31 millones 488 mil 625 habitantes. Recuperado de https://www.inei.gob.pe/prensa/noticias/el-peru-tiene-una-poblacion-de-31millones-488-mil-625-habitantes-9196/

Instituto Nacional de Estadística e Informática INEI. (2017). Sistema de Información Geográfica para Emprendedores. Recuperado de http://sige.inei.gob.pe/sige/

Kurzweil, R. (2005). On how technology will transform us. En TED 2005. [Archivo de video]. 
https://www.ted.com/talks/ray_kurzweil_on_how_technology_will_transform_u $\mathrm{S}$

Luz del Sur. (2017). Tarifas del servicio. Recuperado de https://www.luzdelsur.com.pe/media/pdf/tarifas/TARIFAS.pdf

Luz del Sur. (2017). Tarifas. Recuperado de https://www.luzdelsur.com.pe/preguntasfrecuentes/tarifas.html

Mitsubishi Electric Research Laboratories. (2002). Wireless Liquid Level Sensing for Restaurant Applications. Recuperado de http://www.merl.com/publications/docs/TR2002-21.pdf

Montar un Bar y Sobrevivir. (2017). Inversión inicial para montar un bar [mensaje en un blog]. Recuperado de https://montarunbarysobrevivir.blogspot.pe/2011/08/montar-un-bar-inversioninicial.html

Municipalidad de Miraflores (2015). Demografía de Miraflores. Recuperado de http://www.miraflores.gob.pe/_contenTempl1.php?idpadre=4951\&idhijo=4972 \&idcontenido $=5398$

Municipalidad de Miraflores. (2007). Alturas de edificación por zonas. Recuperado de: http://www.miraflores.gob.pe/Gestorw3b/files/pdf/5148-41602_alturas_edificacion_2007.pdf

Municipalidad de Miraflores. (2013). Plano de zonificación actualizado. Recuperado de: http://www.miraflores.gob.pe/Gestorw3b/files/pdf/5148-6564-planozonificacion-actualizado-ene.2013.pdf

Organismo Supervisor de la Inversión en Energía y Minería OSINERGIM. (2017). Cálculo del consumo de luz. Recuperado de http://www.osinergminorienta.gob.pe/web/ciudadano/consultasfrecuentes/calculo-consumo-luz 
Para Quitarse el Sombrero: El Portal de los Emprendedores. (2017). ¿Cuanto cuesta instalar un pos en mi negocio? Recuperado de http://www.pqs.pe/actualidad/noticias/cuanto-cuesta-instalar-pos-en-mi-negocio

Para Quitarse el Sombrero: El Portal de los Emprendedores. (2017) ¿Cuánto se invierte en un café-bar? Recuperado de http://www.pqs.pe/actualidad/noticias/cuanto-seinvierte-en-un-cafe-bar

Restaurante Lleno. (2017). Cómo reducir el gasto de energía en restaurante. Recuperado de: http://restaurantelleno.com/reducir-el-gasto-de-energia-en-restaurante.html

Swedberg, C. (2011). Wall of Beer Lets Patrons Draw Their Drinks. RFID Journal. Recuperado de http:// www.rfidjournal.com/articles/view?8651

Tarifas Gas y Luz. (2016). ¿Cuánto cuesta la luz al mes? Recuperado de https://tarifasgasluz.com/faq/cuanto-cuesta-luz-mes

The Drink Business. (Diciembre 2016). How Technology is Transforming the Drinks Trade. Recuperado de https://www.thedrinksbusiness.com/2016/12/the-internetof-drinks/

Urbania. (2017). Alquiler de local comercial en Miraflores, Lima. Recuperado de: https://urbania.pe/inmueble/alquiler-de-local-comercial-en-miraflores-lima4137009

Urbania. (2017). Alquiler de locales comerciales cerca de Larcomar. Recuperado de: http://urbania.pe/buscar/alquiler-de-locales-comerciales?freeSearch=larcomar

Urbania. (2017). Alquiler de locales comerciales cerca del Ovalo Gutiérrez. Recuperado de: $\quad$ http://urbania.pe/buscar/alquiler-de-locales comerciales?freeSearch $=$ ovalo $\% 20$ gutierrez

Urbania. (2017). Alquiler de locales comerciales cerca del Parque Kennedy. Recuperado de http://urbania.pe/buscar/alquiler-de-localescomerciales?freeSearch $=$ parque $\% 20$ kennedy

Urbania. (2017). Venta de terreno en Miraflores. Recuperado de https://urbania.pe/inmueble/venta-de-terreno-en-miraflores-lima-4102840 
Visa. (2016). Costo de alquiler del POS Recuperado de https://www.visanet.com.pe/pregunta-frecuente/costo-del-alquiler-del-pos/

Wadhwa, V. (2012). Why I Believe That This Will Be The Most Innovative Decade In History. Forbes. Recuperado de https://www.forbes.com/sites/singularity/2012/06/25/most-innovative-decadein-history/ \#7943fc30135a 
ANEXOS 


\section{Anexo 1: Modelo de encuestas}

\section{Bar Automatizado}

*Obligatorio

1. Edad*

Marca solo un óvalo.

Menor de 18 años $\quad$ Deja de rellenar este formulario.
18 a 35 años $\quad$ Pasa a la pregunta 2.
36 a 55 años $\quad$ Pasa a la pregunta 2.
56 a 80 años $\quad$ Pasa a la pregunta 2.

\section{Bar Automatizado}

\section{Género *}

Marca solo un óvalo.

Hombre

Mujer

3. ¿Asistes a bares al menos 2 veces al año? * Marca solo un óvalo.

Si

No

4. ¿Cuál es tu marca favorita de cerveza? *

Marca solo un óvalo.

\section{No tomo cerveza}

Cristal

Pilsen

Cusqueña

Miller

Corona

Heineken

Budweiser

Otro: 
5. ¿Qué atributos valoras en un bar? *

Selecciona todos los que correspondan.

Limpieza

Rapidez de la atención

Música

Piqueos

Calidad de los tragos

Otros complementos (Juegos de mesa, dardos, billar, etc.)

Otro:

6. ¿Cuáles son los bares que visitas con mayor frecuencia? * Selecciona todos los que correspondan.
Barbarian
Spa Lounge Club
La Cachina Bar
Rouge Bar
Cocodrilo Verde
La Basílica
Bar Crawl
Madbar
Huaringas
Ayahuasca
Barranco Beer Company
Superba
Nuevo Mundo Draft Bar
La Destilería
Treff
$\square$ La Emolientería
$\square$ Otro: 
7. ¿En qué distritos están ubicados? *

Selecciona todos los que correspondan.
Barranco
La Molina
Miraflores
Surco
San Isidro
Otro:

8. ¿Con qué frecuencia visitas estos bares? * Marca solo un óvalo.

Menos de 1 vez al mes

Al menos 1 vez al mes

2 - 3 veces al mes

Todos los fines de semana

Más de una vez por semana

9. ¿Cuál es el nivel de personalización que tienes en la elaboración de tus tragos? * (Grado de personalización que te permite el barman en los bares que más frecuentas) Marca solo un óvalo.

Bajo - El barman prepara el trago a su manera

Intermedio - El barman me permite elegir un coctel extra fuerte o débil

Alto - El barman me permit elegir las cantidades de todos los ingredientes

10. ¿Estás satisfecho con el nivel de personalización de la pregunta anterior? * Marca solo un óvalo.

$\int$ Sí

No

11. ¿Cuánto pagas actualmente por un coctel? *

Marca solo un óvalo.

\section{De 18 a 25 soles}

De 25 a 30 soles

De 30 a 35 soles

De 35 a 40 soles

Más de 40 soles 
12. ¿Cuánto gastas en promedio cuando visitas un bar? *

(Gasto personal)

Marca solo un óvalo.
De 20 a 40 soles
De 40 a 60 soles
De 60 a 80 soles
De 80 a 100 soles
De 100 a 120 soles
De 120 a 140 soles
De 140 a 160 soles
De 160 a 180 soles
De 180 a 200 soles
Más de 200 soles

13. ¿Estarías interesado en visitar un Bar que te permita personalizar tu bebida y te la entregue al momento? *

Marca solo un óvalo.
$\int$ Sí
No

14. Del 1 al 10, ¿Qué tan interesado estarías en visitarlo? *

Marca solo un óvalo.

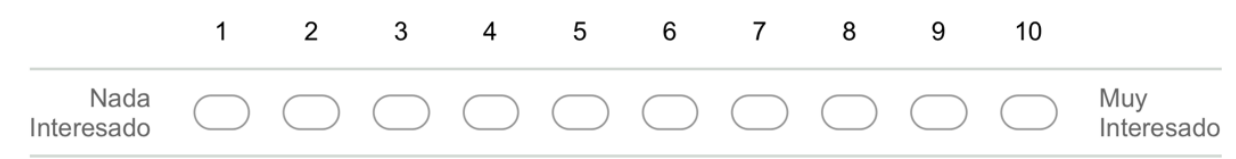

15. ¿Dónde te gustaría que estuviese ubicado el Bar? * Marca solo un óvalo.

San Isidro (Camino Real) $\quad$ Pasa a la pregunta 17.
Barranco (Plaza de Armas) Pasa a la pregunta 17.
Miraflores Pasa a la pregunta 16.
Otro:

Pasa a la pregunta 17.

\section{Localización de Bares en Miraflores}


16. ¿En qué lugar de Miraflores te gustaría encontrar el bar?* Marca solo un óvalo.

Parque Kennedy

Óvalo Gutierrez

Larcomar

\section{Bar automatizado}

17. ¿Cuánto estás dispuesto a pagar por un coctel personalizado sin tiempo de preparación? *

Marca solo un óvalo.
De 20 a 25 soles
De 25 a 30 soles
De 30 a 35 soles
De 35 a 40 soles
Más de 40 soles

18. ¿Cómo te gustaría enterarte de nuestro Bar y sus promociones? * Marca solo un óvalo.

Redes Sociales

Televisión

Radio

Correo Electrónico

Google Forms 


\section{Anexo 2: Presupuesto de requerimientos de materiales}

A continuación, se presentan los presupuestos de requerimientos para cada uno de los insumos necesarios para el funcionamiento del bar automatizado:

Presupuesto de requerimiento de bebidas.

\begin{tabular}{l|ccccc} 
Año & $\mathbf{2 0 1 9}$ & $\mathbf{2 0 2 0}$ & $\mathbf{2 0 2 1}$ & $\mathbf{2 0 2 2}$ & $\mathbf{2 0 2 3}$ \\
\hline Visitas & 29654.87 & 51990.32 & 84872.05 & 93378.01 & 120473.48 \\
Cantidad de Bebidas & 88964.62 & 155970.95 & 254616.15 & 280134.04 & 361420.44 \\
Cerveza & 61741.45 & 108243.84 & 176703.61 & 194413.02 & 250825.79 \\
Corona & 11422.17 & 20025.11 & 32690.17 & 35966.41 & 46402.77 \\
Cusqueña & 16793.67 & 29442.32 & 48063.38 & 52880.34 & 68224.61 \\
Pilsen & 15250.14 & 26736.23 & 43645.79 & 48020.02 & 61953.97 \\
Otras Cervezas & 18275.47 & 32040.18 & 52304.27 & 57546.25 & 74244.43 \\
Otros Tragos & 27223.17 & 47727.11 & 77912.54 & 85721.01 & 110594.66 \\
Pisco & 8540.60 & 14973.21 & 24443.15 & 26892.87 & 34696.36 \\
Ron & 6850.28 & 12009.76 & 19605.44 & 21570.32 & 27829.37 \\
Vodka & 5337.88 & 9358.26 & 15276.97 & 16808.04 & 21685.23 \\
Whiskey & 5337.88 & 9358.26 & 15276.97 & 16808.04 & 21685.23 \\
Tequila & 1156.54 & 2027.62 & 3310.01 & 3641.74 & 4698.47 \\
Elaboración propia & & & & &
\end{tabular}

Presupuesto de requerimiento de Corona

\begin{tabular}{l|ccccc} 
Año & $\mathbf{2 0 1 9}$ & $\mathbf{2 0 2 0}$ & $\mathbf{2 0 2 1}$ & $\mathbf{2 0 2 2}$ & $\mathbf{2 0 2 3}$ \\
\hline Corona (Vasos) & 11422.17 & 20025.11 & 32690.17 & 35966.41 & 46402.77 \\
Corona (Litros) & 2855.54 & 5006.28 & 8172.54 & 8991.60 & 11600.69 \\
Corona (Botellas) & 4326.58 & 7585.27 & 12382.64 & 13623.64 & 17576.81 \\
Botellas mensuales & 360.55 & 632.11 & 1031.89 & 1135.30 & 1464.73
\end{tabular}

Elaboración propia

Presupuesto de requerimiento de Cusqueña

\begin{tabular}{l|ccccc} 
Año & $\mathbf{2 0 1 9}$ & $\mathbf{2 0 2 0}$ & $\mathbf{2 0 2 1}$ & $\mathbf{2 0 2 2}$ & $\mathbf{2 0 2 3}$ \\
\hline Cusqueña (vasos) & 16793.67 & 29442.32 & 48063.38 & 52880.34 & 68224.61 \\
Cusqueña (litros) & 4198.42 & 7360.58 & 12015.85 & 13220.09 & 17056.15 \\
Cusqueña (Botellas) & 6459.11 & 11323.97 & 18485.92 & 20338.59 & 26240.24 \\
Botellas mensuales & 538.26 & 943.66 & 1540.49 & 1694.88 & 2186.69
\end{tabular}

Elaboración propia 
Presupuesto de requerimiento de Pilsen

\begin{tabular}{l|ccccc} 
Año & $\mathbf{2 0 1 9}$ & $\mathbf{2 0 2 0}$ & $\mathbf{2 0 2 1}$ & $\mathbf{2 0 2 2}$ & $\mathbf{2 0 2 3}$ \\
\hline Pilsen (vasos) & 15250.14 & 26736.23 & 43645.79 & 48020.02 & 61953.97 \\
Pilsen (litros) & 3812.53 & 6684.06 & 10911.45 & 12005.00 & 15488.49 \\
Pilsen (Botellas) & 6051.64 & 10609.61 & 17319.76 & 19055.56 & 24584.91 \\
Botellas mensuales & 504.30 & 884.13 & 1443.31 & 1587.96 & 2048.74
\end{tabular}

Elaboración propia

Presupuesto de requerimiento de Pisco

\begin{tabular}{l|ccccc} 
Año & $\mathbf{2 0 1 9}$ & $\mathbf{2 0 2 0}$ & $\mathbf{2 0 2 1}$ & $\mathbf{2 0 2 2}$ & $\mathbf{2 0 2 3}$ \\
\hline Pisco (bebidas) & 8540.60 & 14973.21 & 24443.15 & 26892.87 & 34696.36 \\
Maracuyá sour (vasos) & 4270.30 & 7486.61 & 12221.58 & 13446.43 & 17348.18 \\
Pisco (Onzas) & 17081.21 & 29946.42 & 48886.30 & 53785.73 & 69392.73 \\
Pisco Sour (vasos) & 4270.30 & 7486.61 & 12221.58 & 13446.43 & 17348.18 \\
Pisco (onzas) & 12810.91 & 22459.82 & 36664.73 & 40339.30 & 52044.54 \\
Pisco total (onzas) & 29892.11 & 52406.24 & 85551.03 & 94125.04 & 121437.27 \\
Pisco (mililitros) & 836979.14 & 1467374.66 & 2395428.71 & 2635501.00 & 3400243.54 \\
Pisco (damajuanas) & 209.24 & 366.84 & 598.86 & 658.88 & 850.06 \\
Elaboración propia & & & & &
\end{tabular}

Elaboración propia

Presupuesto de requerimiento de Ron

\begin{tabular}{l|ccccc} 
Año & $\mathbf{2 0 1 9}$ & $\mathbf{2 0 2 0}$ & $\mathbf{2 0 2 1}$ & $\mathbf{2 0 2 2}$ & $\mathbf{2 0 2 3}$ \\
\hline Ron (bebidas) & 6850.28 & 12009.76 & 19605.44 & 21570.32 & 27829.37 \\
Mojito (vasos) & 3425.14 & 6004.88 & 9802.72 & 10785.16 & 13914.69 \\
Ron (Mililitros) & 154131.20 & 270219.66 & 441122.47 & 485332.22 & 626160.92 \\
Cuba Libre (vasos) & 3425.14 & 6004.88 & 9802.72 & 10785.16 & 13914.69 \\
Ron (onzas) & 6850.28 & 12009.76 & 19605.44 & 21570.32 & 27829.37 \\
Ron (mililitros) & 191807.72 & 336273.36 & 548952.41 & 603968.98 & 779222.48 \\
Ron total (mililitros) & 345938.92 & 606493.02 & 990074.89 & 1089301.20 & 1405383.40 \\
Ron (Botellas) & 461.25 & 808.66 & 1320.10 & 1452.40 & 1873.84
\end{tabular}

Elaboración propia 
Presupuesto de requerimiento de Tequila

\begin{tabular}{l|ccccc} 
Año & $\mathbf{2 0 1 9}$ & $\mathbf{2 0 2 0}$ & $\mathbf{2 0 2 1}$ & $\mathbf{2 0 2 2}$ & $\mathbf{2 0 2 3}$ \\
\hline Tequila (Bebidas) & 1156.54 & 2027.62 & 3310.01 & 3641.74 & 4698.47 \\
Margarita (vasos) & 1156.54 & 2027.62 & 3310.01 & 3641.74 & 4698.47 \\
Tequila (Onzas) & 1734.81 & 3041.43 & 4965.01 & 5462.61 & 7047.70 \\
Tequila (mililitros) & 48574.68 & 85160.14 & 139020.42 & 152953.18 & 197335.56 \\
Tequila (Botellas) & 64.77 & 113.55 & 185.36 & 203.94 & 263.11
\end{tabular}

Elaboración propia

Presupuesto de requerimiento de Vodka

\begin{tabular}{l|ccccc} 
Año & $\mathbf{2 0 1 9}$ & $\mathbf{2 0 2 0}$ & $\mathbf{2 0 2 1}$ & $\mathbf{2 0 2 2}$ & $\mathbf{2 0 2 3}$ \\
\hline Vodka (bebidas) & 5337.88 & 9358.26 & 15276.97 & 16808.04 & 21685.23 \\
Martini (vasos) & 5337.88 & 9358.26 & 15276.97 & 16808.04 & 21685.23 \\
Vodka (Onzas) & 8896.46 & 15597.09 & 25461.61 & 28013.40 & 36142.04 \\
Vodka (mililitros) & 249100.93 & 436718.65 & 712925.21 & 784375.30 & 1011977.24 \\
Vodka (Botellas) & 332.13 & 582.29 & 950.57 & 1045.83 & 1349.30
\end{tabular}

Elaboración propia

Presupuesto de requerimiento de Whiskey

\begin{tabular}{l|ccccc} 
Año & $\mathbf{2 0 1 9}$ & $\mathbf{2 0 2 0}$ & $\mathbf{2 0 2 1}$ & $\mathbf{2 0 2 2}$ & $\mathbf{2 0 2 3}$ \\
\hline Whiskey (bebidas) & 5337.88 & 9358.26 & 15276.97 & 16808.04 & 21685.23 \\
Whiskey (Mililitros) & 224190.84 & 393046.78 & 641632.69 & 705937.77 & 910779.52 \\
Whiskey (Botellas) & 298.92 & 524.06 & 855.51 & 941.25 & 1214.37
\end{tabular}

Elaboración propia

Presupuesto de requerimiento de Limón

\begin{tabular}{l|ccccc} 
Año & $\mathbf{2 0 1 9}$ & $\mathbf{2 0 2 0}$ & $\mathbf{2 0 2 1}$ & $\mathbf{2 0 2 2}$ & $\mathbf{2 0 2 3}$ \\
\hline Pisco Sour (vasos) & 4270.30 & 7486.61 & 12221.58 & 13446.43 & 17348.18 \\
Jugo de Limón (Onzas) & 4270.30 & 7486.61 & 12221.58 & 13446.43 & 17348.18 \\
Maracuya Sour (vasos) & 4270.30 & 7486.61 & 12221.58 & 13446.43 & 17348.18 \\
Jugo de Limón (Onzas) & 1517.08 & 2659.72 & 4341.88 & 4777.02 & 6163.17 \\
Cuba Libre (vasos) & 3425.14 & 6004.88 & 9802.72 & 10785.16 & 13914.69 \\
Jugo de Limón (Onzas) & 3425.14 & 6004.88 & 9802.72 & 10785.16 & 13914.69 \\
Maragarita (vasos) & 1156.54 & 2027.62 & 3310.01 & 3641.74 & 4698.47 \\
Jugo de Limón (Onzas) & 433.70 & 760.36 & 1241.25 & 1365.65 & 1761.92 \\
Jugo de Limón (Total) & 9646.22 & 16911.56 & 27607.43 & 30374.27 & 39187.96 \\
Jugo total (mililitros) & 270094.24 & 473523.69 & 773007.92 & 850479.56 & 1097262.96 \\
Limones (Kilogramos) & 714.54 & 1252.71 & 2044.99 & 2249.95 & 2902.81 \\
Elaboración propia & & & & &
\end{tabular}


Presupuesto de requerimiento de Jarabe de Goma

\begin{tabular}{l|ccccc} 
Año & $\mathbf{2 0 1 9}$ & $\mathbf{2 0 2 0}$ & $\mathbf{2 0 2 1}$ & $\mathbf{2 0 2 2}$ & $\mathbf{2 0 2 3}$ \\
\hline Pisco Sour (vasos) & 4270.30 & 7486.61 & 12221.58 & 13446.43 & 17348.18 \\
Jarabe de Goma (Onzas) & 4270.30 & 7486.61 & 12221.58 & 13446.43 & 17348.18 \\
Maracuyá Sour (Vasos) & 4270.30 & 7486.61 & 12221.58 & 13446.43 & 17348.18 \\
Jarabe de Goma (Onzas) & 8540.60 & 14973.21 & 24443.15 & 26892.87 & 34696.36 \\
Jarabe de Goma (Total) & 12810.91 & 22459.82 & 36664.73 & 40339.30 & 52044.54 \\
Jarabe de Goma (Botellas) & 478.27 & 838.50 & 1368.82 & 1506.00 & 1943.00 \\
Elaboración propia & & & & &
\end{tabular}

Elaboración propia

Presupuesto de requerimiento de Maracuyá

\begin{tabular}{l|ccccc} 
Año & $\mathbf{2 0 1 9}$ & $\mathbf{2 0 2 0}$ & $\mathbf{2 0 2 1}$ & $\mathbf{2 0 2 2}$ & $\mathbf{2 0 2 3}$ \\
\hline Maracuyá Sour (Vasos) & 4270.30 & 7486.61 & 12221.58 & 13446.43 & 17348.18 \\
Jugo de Maracuyá (Onzas) & 8540.60 & 14973.21 & 24443.15 & 26892.87 & 34696.36 \\
Maracuyá (Kilogramos) & 478.27 & 838.50 & 1368.82 & 1506.00 & 1943.00
\end{tabular}

Elaboración propia

Presupuesto de requerimiento de Cointreau

\begin{tabular}{l|ccccc} 
Año & $\mathbf{2 0 1 9}$ & $\mathbf{2 0 2 0}$ & $\mathbf{2 0 2 1}$ & $\mathbf{2 0 2 2}$ & $\mathbf{2 0 2 3}$ \\
\hline Margaritas (Vasos) & 1156.54 & 2027.62 & 3310.01 & 3641.74 & 4698.47 \\
Cointreau (Onzas) & 1156.54 & 2027.62 & 3310.01 & 3641.74 & 4698.47 \\
Cointreau (Botellas) & 43.18 & 75.70 & 123.57 & 135.96 & 175.41
\end{tabular}

Elaboración propia

Presupuesto de requerimiento de Vermú

\begin{tabular}{l|ccccc} 
Año & $\mathbf{2 0 1 9}$ & $\mathbf{2 0 2 0}$ & $\mathbf{2 0 2 1}$ & $\mathbf{2 0 2 2}$ & $\mathbf{2 0 2 3}$ \\
\hline Martinis (Vasos) & 5337.88 & 9358.26 & 15276.97 & 16808.04 & 21685.23 \\
Vermú (Onzas) & 1779.29 & 3119.42 & 5092.32 & 5602.68 & 7228.41 \\
Vermú (Botellas) & 66.43 & 116.46 & 190.11 & 209.17 & 269.86
\end{tabular}

Elaboración propia 
Presupuesto de requerimientos de insumos para piqueos

\begin{tabular}{l|ccccc} 
Año & $\mathbf{2 0 1 9}$ & $\mathbf{2 0 2 0}$ & $\mathbf{2 0 2 1}$ & $\mathbf{2 0 2 2}$ & $\mathbf{2 0 2 3}$ \\
\hline Visitas & 29654.87 & 51990.32 & 84872.05 & 93378.01 & 120473.48 \\
Piqueos & 7413.72 & 12997.58 & 21218.01 & 23344.50 & 30118.37 \\
Tequeños & 2471.24 & 4332.53 & 7072.67 & 7781.50 & 10039.46 \\
Langostinos & 2471.24 & 4332.53 & 7072.67 & 7781.50 & 10039.46 \\
Yucas Fritas & 2471.24 & 4332.53 & 7072.67 & 7781.50 & 10039.46 \\
Tequeños (Unidades) & 19769.92 & 34660.21 & 56581.37 & 62252.01 & 80315.65 \\
Langostinos (Unidades) & 19769.92 & 34660.21 & 56581.37 & 62252.01 & 80315.65 \\
Yucas (Unidades) & 19769.92 & 34660.21 & 56581.37 & 62252.01 & 80315.65 \\
Tequeños (Cajas) & 197.70 & 346.60 & 565.81 & 622.52 & 803.16 \\
Langostinos (Kilos) & 439.33 & 770.23 & 1257.36 & 1383.38 & 1784.79 \\
Yucas (Kilos) & 395.40 & 693.20 & 1131.63 & 1245.04 & 1606.31
\end{tabular}

Elaboración propia 


\section{Anexo 3: Diagrama del Servicio}

Plano del primer piso del servicio

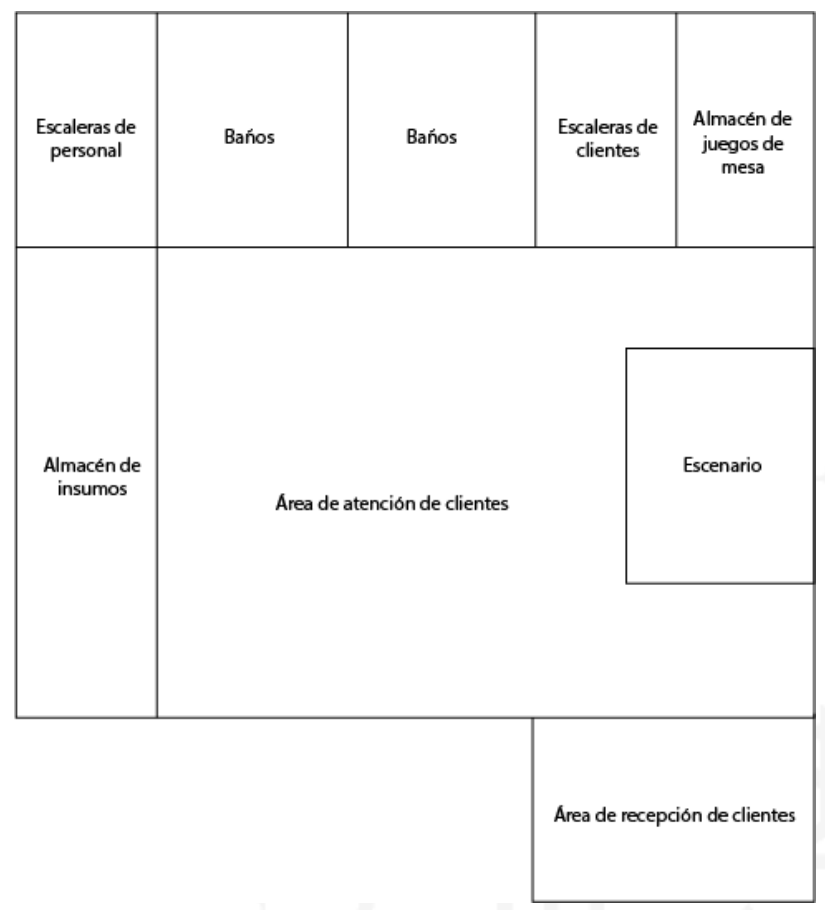

Elaboración propia

Plano del segundo piso del servicio

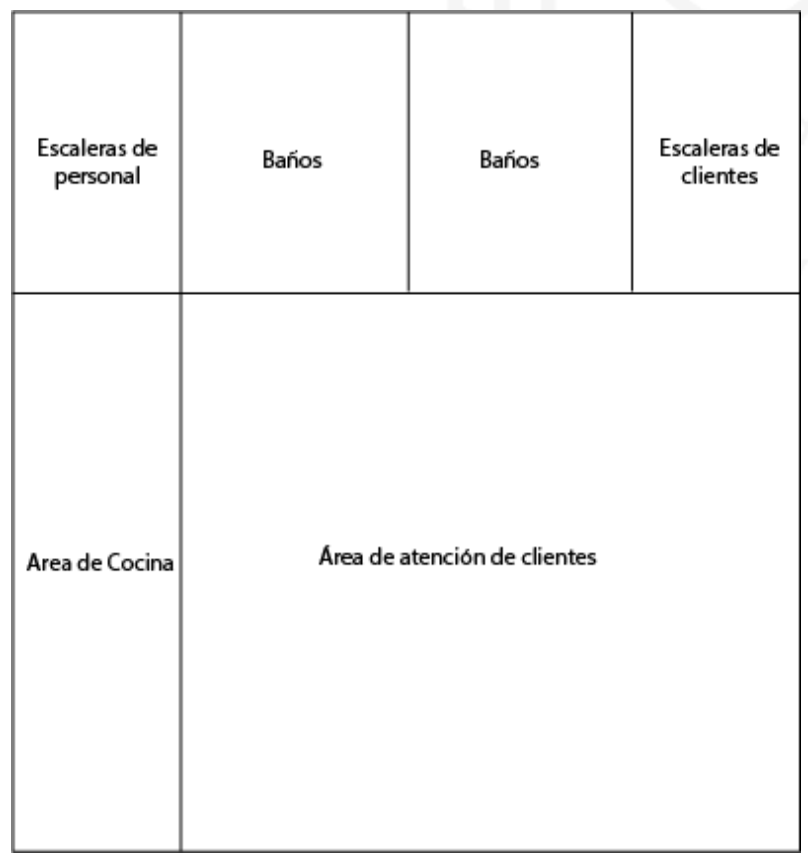

Elaboración propia 
Plano del tercer piso del servicio

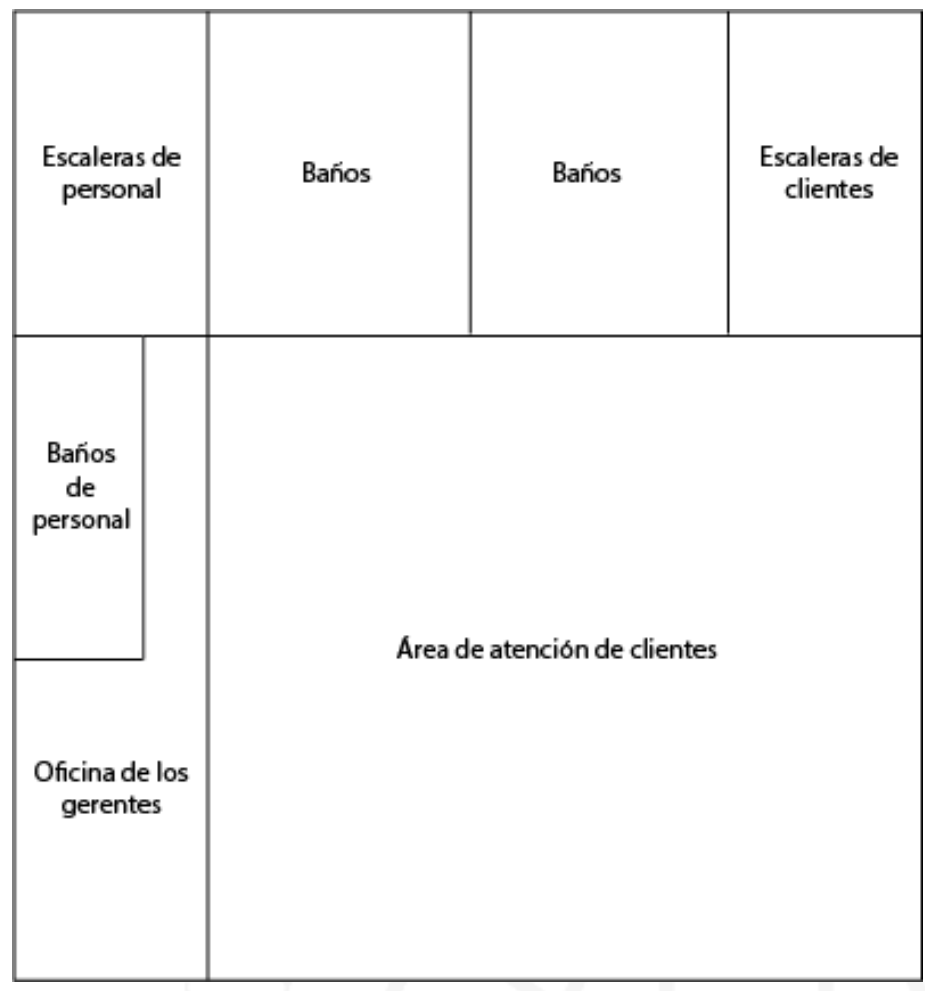

Elaboración propia

Plano del cuarto piso del servicio

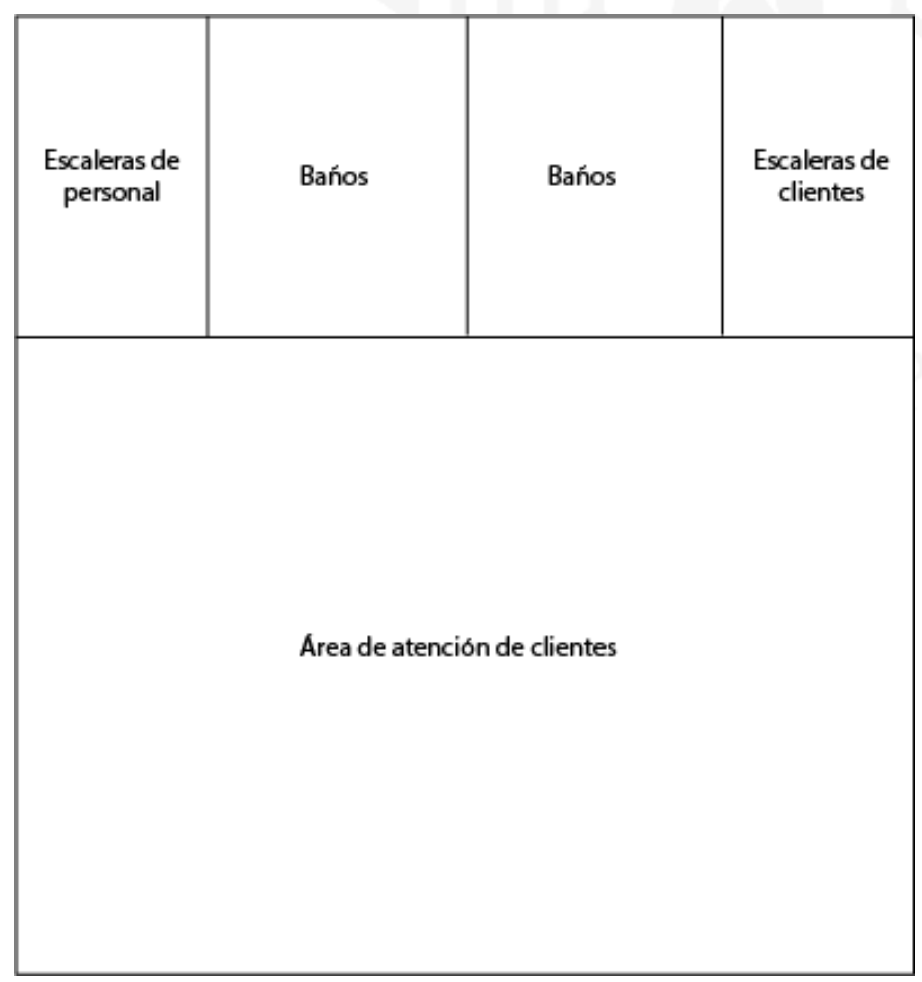

Elaboración propia 


\section{Anexo 4: Presupuesto de Inventarios}

Presupuesto de inventario de materiales para bebidas

\begin{tabular}{|c|c|c|c|c|c|}
\hline Año & 2019 & 2020 & 2021 & 2022 & 2023 \\
\hline \multicolumn{6}{|l|}{ Pisco } \\
\hline Inventario Inicial & 0 & 0.76 & 0.91 & 0.05 & 0.18 \\
\hline Compras & 210.00 & 367.00 & 598.00 & 659.00 & 850.00 \\
\hline Requerimiento & 209.24 & 366.84 & 598.86 & 658.88 & 850.06 \\
\hline Inventario final & 0.76 & 0.91 & 0.05 & 0.18 & 0.12 \\
\hline \multicolumn{6}{|l|}{ Ron } \\
\hline Inventario Inicial & 0 & 0.75 & 0.09 & 0.99 & 0.59 \\
\hline Compras & 462.00 & 808.00 & 1321.00 & 1452.00 & 1874.00 \\
\hline Requerimiento & 461.25 & 808.66 & 1320.10 & 1452.40 & 1873.84 \\
\hline Inventario final & 0.75 & 0.09 & 0.99 & 0.59 & 0.74 \\
\hline \multicolumn{6}{|l|}{ Tequila } \\
\hline Inventario Inicial & 0 & 0.23 & 0.69 & 0.33 & 0.39 \\
\hline Compras & 65.00 & 114.00 & 185.00 & 204.00 & 263.00 \\
\hline Requerimiento & 64.77 & 113.55 & 185.36 & 203.94 & 263.11 \\
\hline Inventario final & 0.23 & 0.69 & 0.33 & 0.39 & 0.27 \\
\hline \multicolumn{6}{|l|}{ Vodka } \\
\hline Inventario Inicial & 0 & 0.87 & 0.57 & 0.01 & 0.17 \\
\hline Compras & 333.00 & 582.00 & 950.00 & 1046.00 & 1350.00 \\
\hline Requerimiento & 332.13 & 582.29 & 950.57 & 1045.83 & 1349.30 \\
\hline Inventario final & 0.87 & 0.57 & 0.01 & 0.17 & 0.87 \\
\hline \multicolumn{6}{|l|}{ Whiskey } \\
\hline Inventario Inicial & 0 & 0.08 & 0.02 & 0.51 & 0.26 \\
\hline Compras & 299.00 & 524.00 & 856.00 & 941.00 & 1215.00 \\
\hline Requerimiento & 298.92 & 524.06 & 855.51 & 941.25 & 1214.37 \\
\hline Inventario final & 0.08 & 0.02 & 0.51 & 0.26 & 0.88 \\
\hline \multicolumn{6}{|l|}{ Corona } \\
\hline Inventario Inicial & 0 & 0.42 & 0.15 & 0.51 & 0.87 \\
\hline Compras & 4327.00 & 7585.00 & 12383.00 & 13624.00 & 17576.00 \\
\hline Requerimiento & 4326.58 & 7585.27 & 12382.64 & 13623.64 & 17576.81 \\
\hline Inventario final & 0.42 & 0.15 & 0.51 & 0.87 & 0.07 \\
\hline
\end{tabular}

Elaboración propia 
Presupuesto de inventario de materiales para bebidas (continuación)

\begin{tabular}{|c|c|c|c|c|c|}
\hline Año & 2019 & 2020 & 2021 & 2022 & 2023 \\
\hline \multicolumn{6}{|l|}{ Cusqueña } \\
\hline Inventario Inicial & 0 & 0.89 & 0.92 & 0.01 & 0.42 \\
\hline Compras & 6460.00 & 11324.00 & 18485.00 & 20339.00 & 26240.00 \\
\hline Requerimiento & 6459.11 & 11323.97 & 18485.92 & 20338.59 & 26240.24 \\
\hline Inventario final & 0.89 & 0.92 & 0.01 & 0.42 & 0.18 \\
\hline \multicolumn{6}{|l|}{ Pilsen } \\
\hline Inventario Inicial & 0 & 0.36 & 0.74 & 0.99 & 0.42 \\
\hline Compras & 6052.00 & 10610.00 & 17320.00 & 19055.00 & 24585.00 \\
\hline Requerimiento & 6051.64 & 10609.61 & 17319.76 & 19055.56 & 24584.91 \\
\hline Inventario final & 0.36 & 0.74 & 0.99 & 0.42 & 0.52 \\
\hline \multicolumn{6}{|l|}{ Limón } \\
\hline Inventario Inicial & 0 & 0.46 & 0.76 & 0.76 & 0.82 \\
\hline Compras & 715.00 & 1253.00 & 2045.00 & 2250.00 & 2902.00 \\
\hline Requerimiento & 714.54 & 1252.71 & 2044.99 & 2249.95 & 2902.81 \\
\hline Inventario final & 0.46 & 0.76 & 0.76 & 0.82 & 0.00 \\
\hline \multicolumn{6}{|l|}{ Jarabe de Goma } \\
\hline Inventario Inicial & 0 & 0.73 & 0.23 & 0.41 & 0.41 \\
\hline Compras & 479.00 & 838.00 & 1369.00 & 1506.00 & 1943.00 \\
\hline Requerimiento & 478.27 & 838.50 & 1368.82 & 1506.00 & 1943.00 \\
\hline Inventario final & 0.73 & 0.23 & 0.41 & 0.41 & 0.41 \\
\hline \multicolumn{6}{|l|}{ Maracuyá } \\
\hline Inventario Inicial & 0 & 0.73 & 0.23 & 0.41 & 0.41 \\
\hline Compras & 479.00 & 838.00 & 1369.00 & 1506.00 & 1943.00 \\
\hline Requerimiento & 478.27 & 838.50 & 1368.82 & 1506.00 & 1943.00 \\
\hline Inventario final & 0.73 & 0.23 & 0.41 & 0.41 & 0.41 \\
\hline \multicolumn{6}{|l|}{ Cointreau } \\
\hline Inventario Inicial & 0 & 0.82 & 0.12 & 0.55 & 0.59 \\
\hline Compras & 44.00 & 75.00 & 124.00 & 136.00 & 175.00 \\
\hline Requerimiento & 43.18 & 75.70 & 123.57 & 135.96 & 175.41 \\
\hline Inventario final & 0.82 & 0.12 & 0.55 & 0.59 & 0.18 \\
\hline \multicolumn{6}{|l|}{ Vermú } \\
\hline Inventario Inicial & 0 & 0.57 & 0.11 & 0.00 & 0.83 \\
\hline Compras & 67.00 & 116.00 & 190.00 & 210.00 & 270.00 \\
\hline Requerimiento & 66.43 & 116.46 & 190.11 & 209.17 & 269.86 \\
\hline Inventario final & 0.57 & 0.11 & 0.00 & 0.83 & 0.97 \\
\hline
\end{tabular}

Elaboración propia 
Presupuesto de inventarios de materiales para piqueos

\begin{tabular}{|c|c|c|c|c|c|}
\hline Año & 2019 & 2020 & 2021 & 2022 & 2023 \\
\hline \multicolumn{6}{|l|}{ Tequeños } \\
\hline Inventario Inicial & 0 & 0.30 & 0.70 & 0.89 & 0.37 \\
\hline Compras & 198.00 & 347.00 & 566.00 & 622.00 & 803.00 \\
\hline Requerimiento & 197.70 & 346.60 & 565.81 & 622.52 & 803.16 \\
\hline Inventario final & 0.30 & 0.70 & 0.89 & 0.37 & 0.21 \\
\hline \multicolumn{6}{|l|}{ Langostinos } \\
\hline Inventario Inicial & 0 & 0.67 & 0.44 & 0.08 & 0.70 \\
\hline Compras & 440.00 & 770.00 & 1257.00 & 1384.00 & 1785.00 \\
\hline Requerimiento & 439.33 & 770.23 & 1257.36 & 1383.38 & 1784.79 \\
\hline Inventario final & 0.67 & 0.44 & 0.08 & 0.70 & 0.91 \\
\hline \multicolumn{6}{|l|}{ Yucas } \\
\hline Inventario Inicial & 0 & 0.60 & 0.40 & 0.77 & 0.73 \\
\hline Compras & 396.00 & 693.00 & 1132.00 & 1245.00 & 1606.00 \\
\hline Requerimiento & 395.40 & 693.20 & 1131.63 & 1245.04 & 1606.31 \\
\hline Inventario final & 0.60 & 0.40 & 0.77 & 0.73 & 0.42 \\
\hline
\end{tabular}

Elaboración propia 


\section{Anexo 5: Resultados de Encuestas}

\section{Edad}

81 respuestas

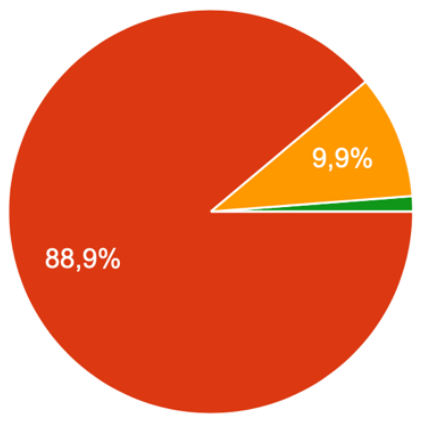

Menor de 18 años

18 a 35 años

36 a 55 años

56 a 80 años

\section{Género}

81 respuestas

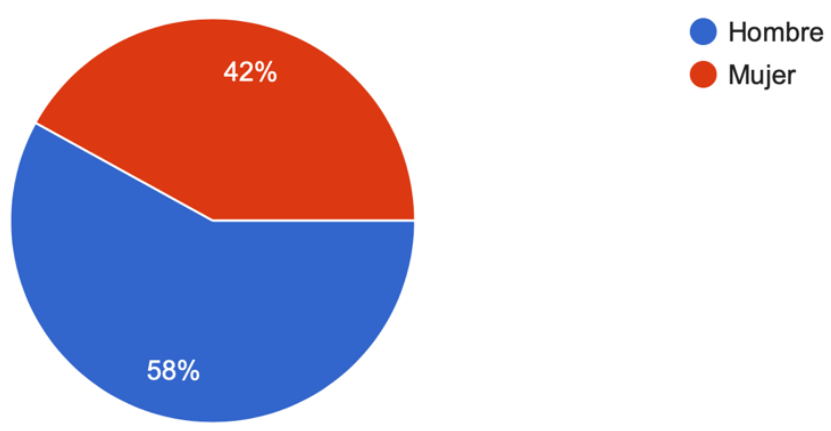

¿Asistes a bares al menos 2 veces al año?

81 respuestas

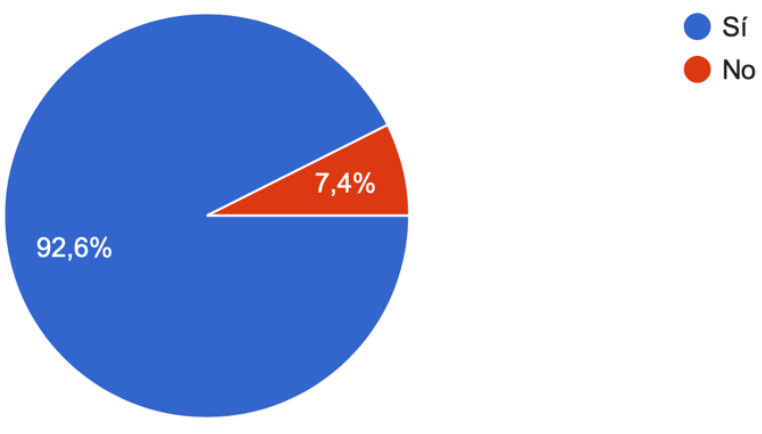


¿Cuál es tu marca favorita de cerveza?

81 respuestas

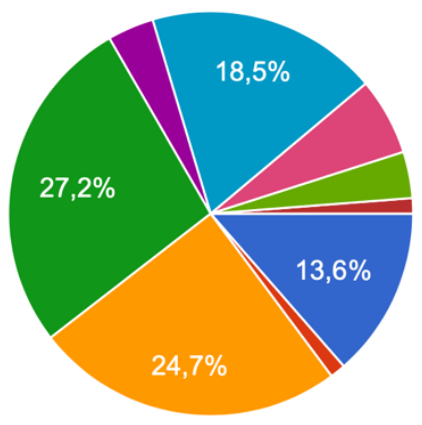

No tomo cerveza
Cristal
Pilsen
Cusqueña
Miller
Corona
Heineken
Budweiser
No tomo cerveza.

¿Qué atributos valoras en un bar?

81 respuestas

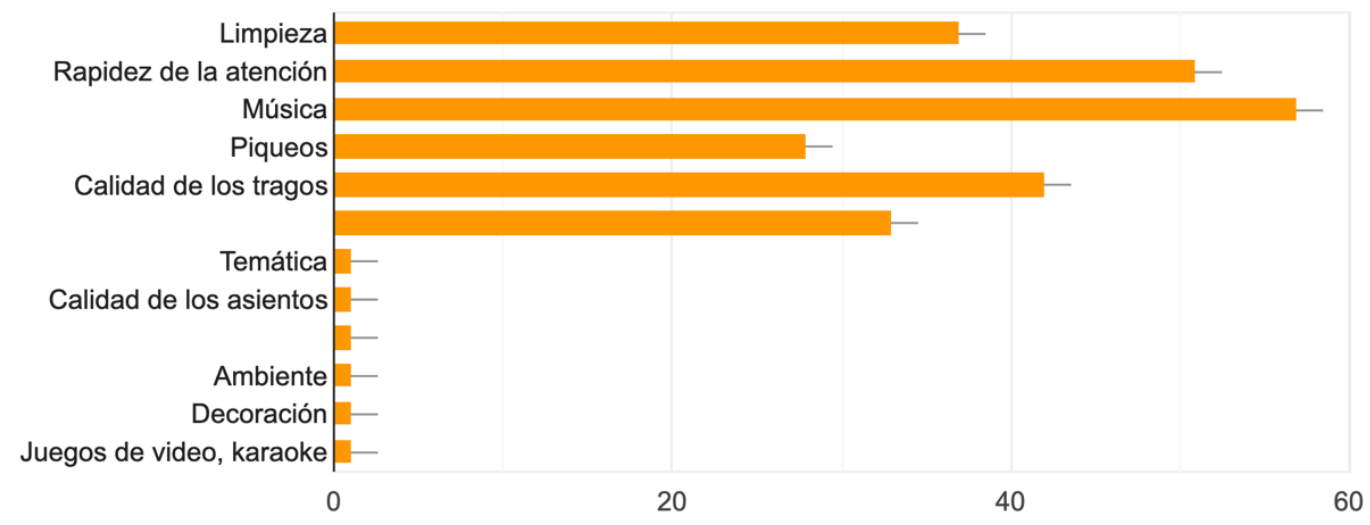


¿Cuáles son los bares que visitas con mayor frecuencia?

81 respuestas

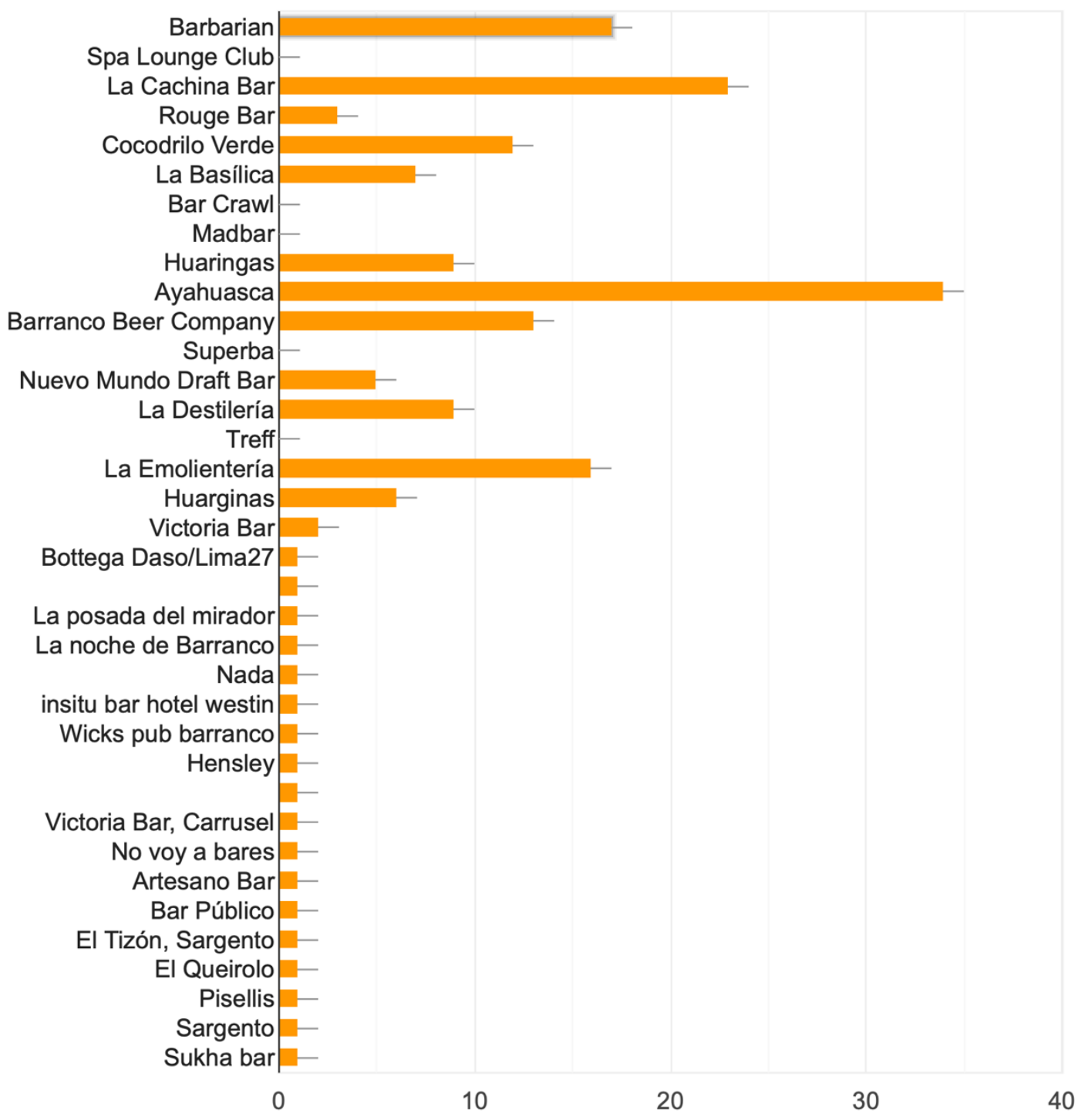




\section{¿En qué distritos están ubicados?}

81 respuestas

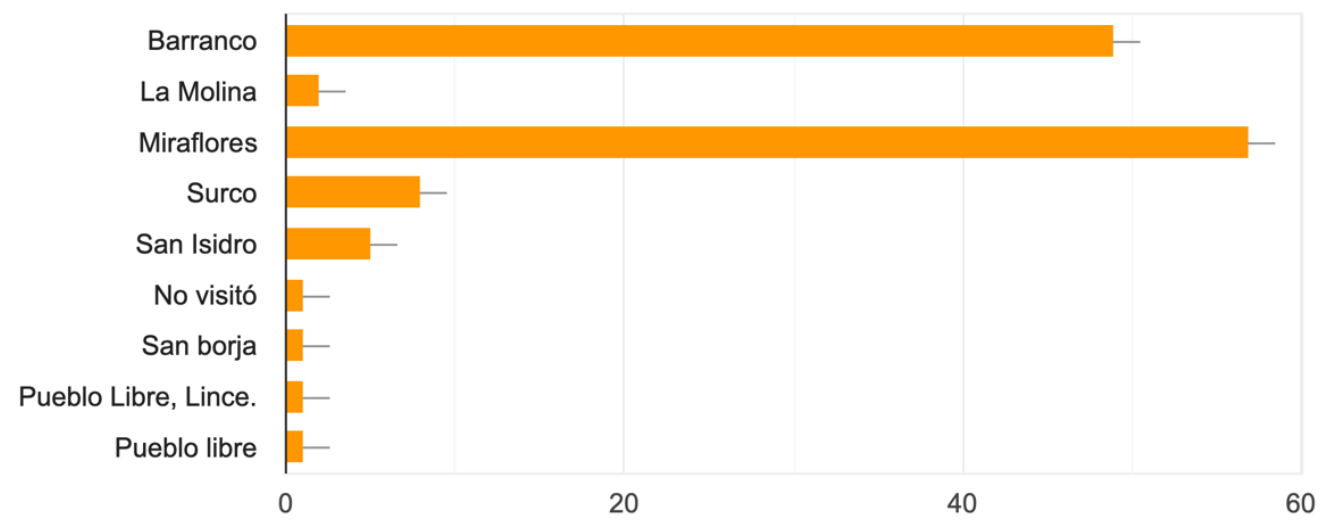

¿Con qué frecuencia visitas estos bares?

81 respuestas

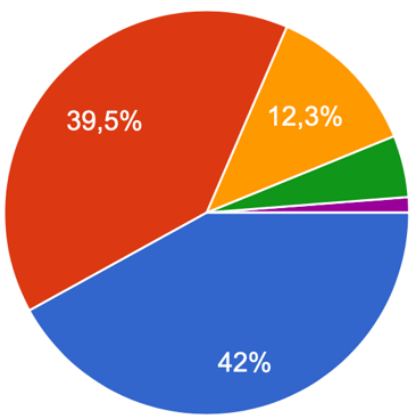

Menos de 1 vez al mes

Al menos 1 vez al mes

2 - 3 veces al mes

Todos los fines de semana

Más de una vez por semana

¿Cuál es el nivel de personalización que tienes en la elaboración de tus tragos?

81 respuestas

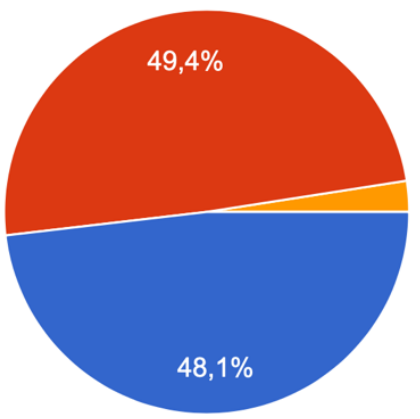

Bajo - El barman prepara el trago a su manera

Intermedio - El barman me permite elegir un coctel extra fuerte o débil

Alto - El barman me permit elegir las cantidades de todos los ingredientes 
¿Estás satisfecho con el nivel de personalización de la pregunta anterior? 81 respuestas

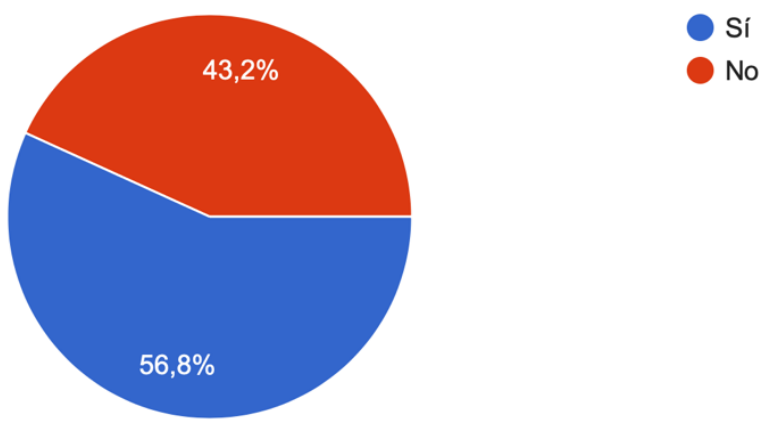

¿Cuánto pagas actualmente por un coctel?

81 respuestas

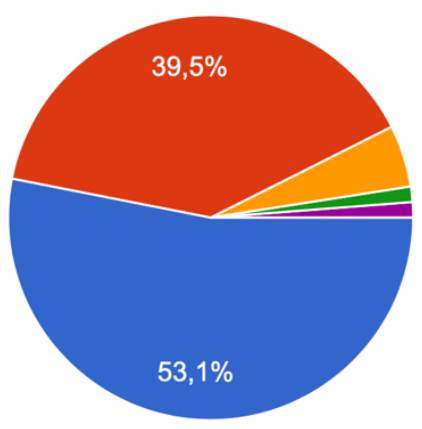

De 18 a 25 soles
De 25 a 30 soles
De 30 a 35 soles
De 35 a 40 soles
Más de 40 soles

¿Cuánto gastas en promedio cuando visitas un bar?

81 respuestas

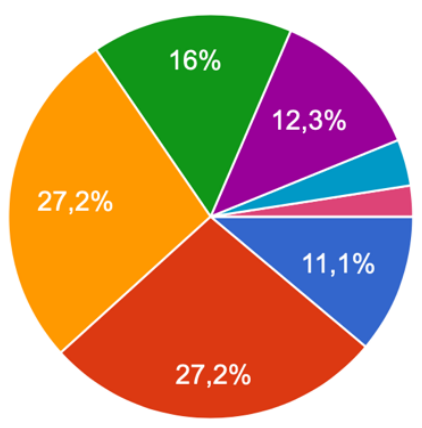

De 20 a 40 soles

De 40 a 60 soles

De 60 a 80 soles

De 80 a 100 soles

De 100 a 120 soles

De 120 a 140 soles

De 140 a 160 soles

De 160 a 180 soles

$\Delta 1 / 2 \nabla$ 
¿Estarías interesado en visitar un Bar que te permita personalizar tu bebida $y$ te la entregue al momento?

81 respuestas

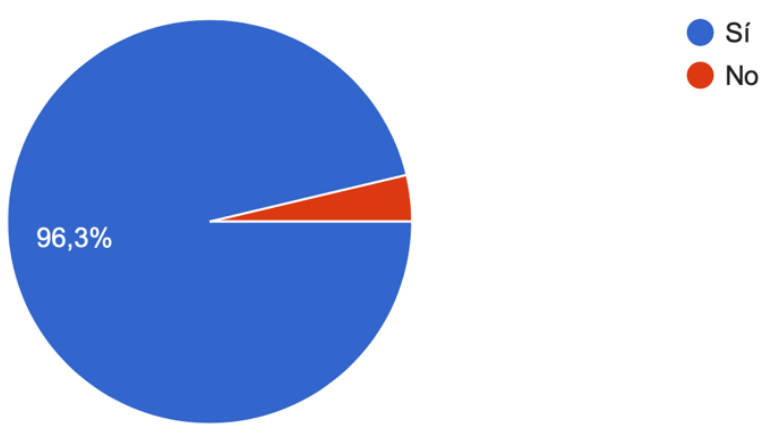

Del 1 al 10, ¿Qué tan interesado estarías en visitarlo?

81 respuestas

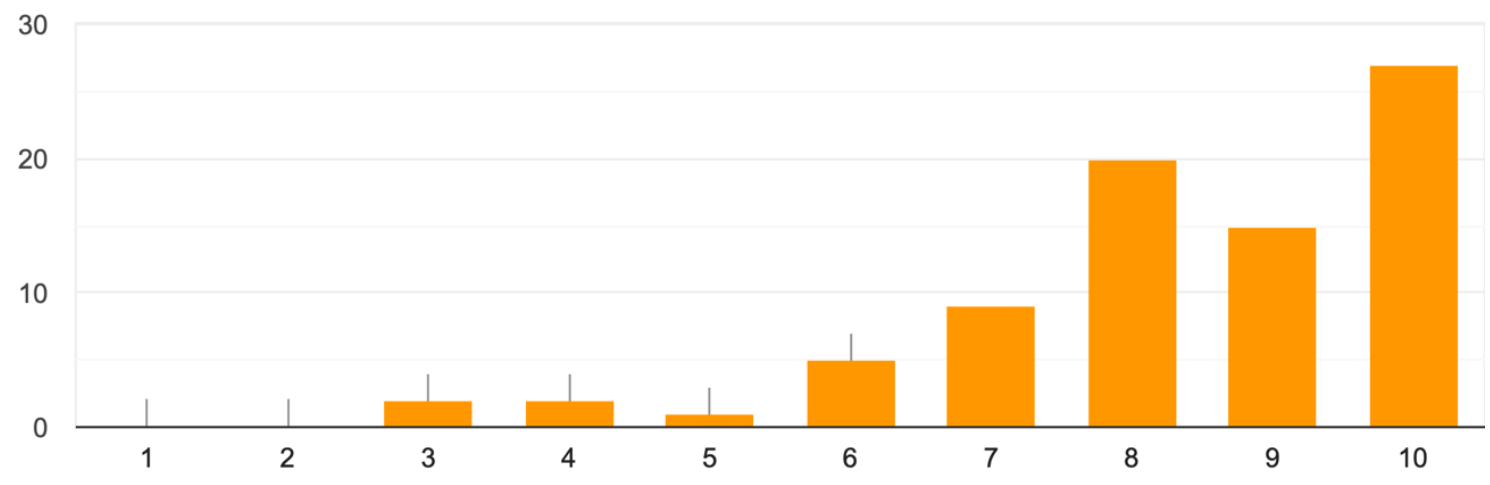

¿Dónde te gustaría que estuviese ubicado el Bar?

81 respuestas

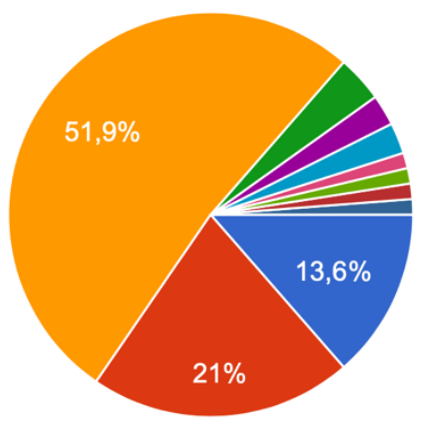

San Isidro (Camino Real)

- Barranco (Plaza de Armas)

Miraflores

La Molina

Surco

Chacarilla

San Isidro pero no Camino Real.

surco

A $1 / 2 \nabla$ 
¿En qué lugar de Miraflores te gustaría encontrar el bar?

42 respuestas

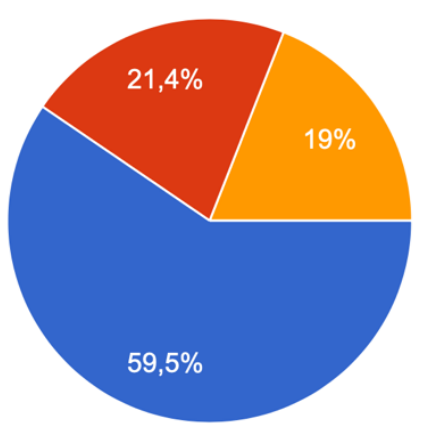

Parque Kennedy

Óvalo Gutierrez

Larcomar

¿Cuánto estás dispuesto a pagar por un coctel personalizado sin tiempo de preparación?

81 respuestas

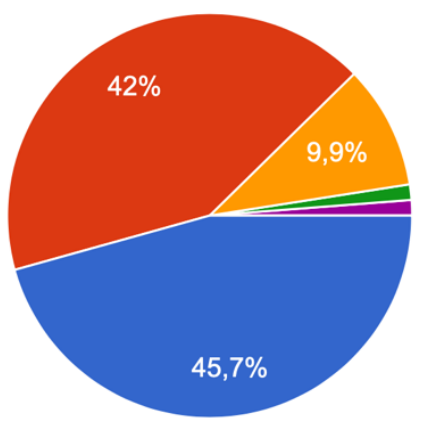

De 20 a 25 soles

De 25 a 30 soles

De 30 a 35 soles

De 35 a 40 soles

- Más de 40 soles

¿Cómo te gustaría enterarte de nuestro Bar y sus promociones?

81 respuestas

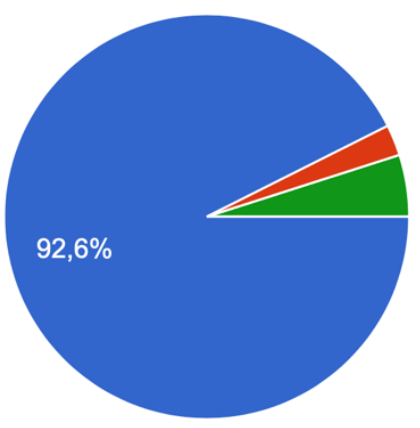

Redes Sociales

Televisión

Radio

Correo Electrónico 


\section{Anexo 6: Herramientas de planeamiento y control de operaciones}

La tabla presentada se refiere al plan agregado para los primeros 6 meses del 2023, considerando la mitad de la demanda proyectada para el año. Este plan considera la familia de productos de piqueos, ya que es la única que requiere mano de obra. Así mismo, por tratarse de un servicio, no se ha considerado la posibilidad de contar con inventarios. El plan agregado sigue una estrategia de nivelación de la fuerza de trabajo.

\begin{tabular}{|c|c|c|c|c|c|c|c|}
\hline & \multicolumn{7}{|c|}{ Plan Agregado 2023} \\
\hline & Enero & Febrero & Marzo & Abril & Mayo & Junio & Total \\
\hline Días Laborales & 18 & 17 & 17 & 17 & 19 & 16 & 104 \\
\hline Clientes por trabajador-dia & 274 & 274 & 274 & 274 & 274 & 274 & 274 \\
\hline Demanda (Clientes) & 9500 & 9430 & 10000 & 11300 & 10000 & 10007 & 60237 \\
\hline Trabajadores Requeridos & 2 & 3 & 3 & 3 & 2 & 3 & 3 \\
\hline Trabajadores Actuales & 3 & 3 & 3 & 3 & 3 & 3 & 3 \\
\hline Contratados & ----- & ----- & ----- & ----- & ----- & ----- & \\
\hline Costo de contratar & 0 & 0 & 0 & 0 & 0 & 0 & 0 \\
\hline Despedidos & --- & ---- & ---- & --- & - & ---- & \\
\hline Costo de despedir & 0 & 0 & 0 & 0 & 0 & 0 & 0 \\
\hline Trabajadores utilizados & 3 & 3 & 3 & 3 & 3 & 3 & 3 \\
\hline Mano de Obra & 21000 & 21000 & 21000 & 21000 & 21000 & 21000 & 21000 \\
\hline Inventarios & ---- & ---- & ----- & ----- & ----- & ----- & \\
\hline Costo de Inventarios & 0 & 0 & 0 & 0 & 0 & 0 & 0 \\
\hline Faltantes & ----- & ----- & ---- & ----- & ----- & ----- & \\
\hline Costo de Faltantes & 0 & 0 & 0 & 0 & 0 & 0 & 0 \\
\hline Unidades producidas & 9500 & 9430 & 10000 & 11300 & 10000 & 10007 & 60237 \\
\hline Costo Total & 21000 & 21000 & 21000 & 21000 & 21000 & 21000 & 21000 \\
\hline
\end{tabular}

En la siguiente página se muestran 2 diagramas de Gozinto como ejemplo de herramientas que se utilizarán para el planeamiento de la servucción. 

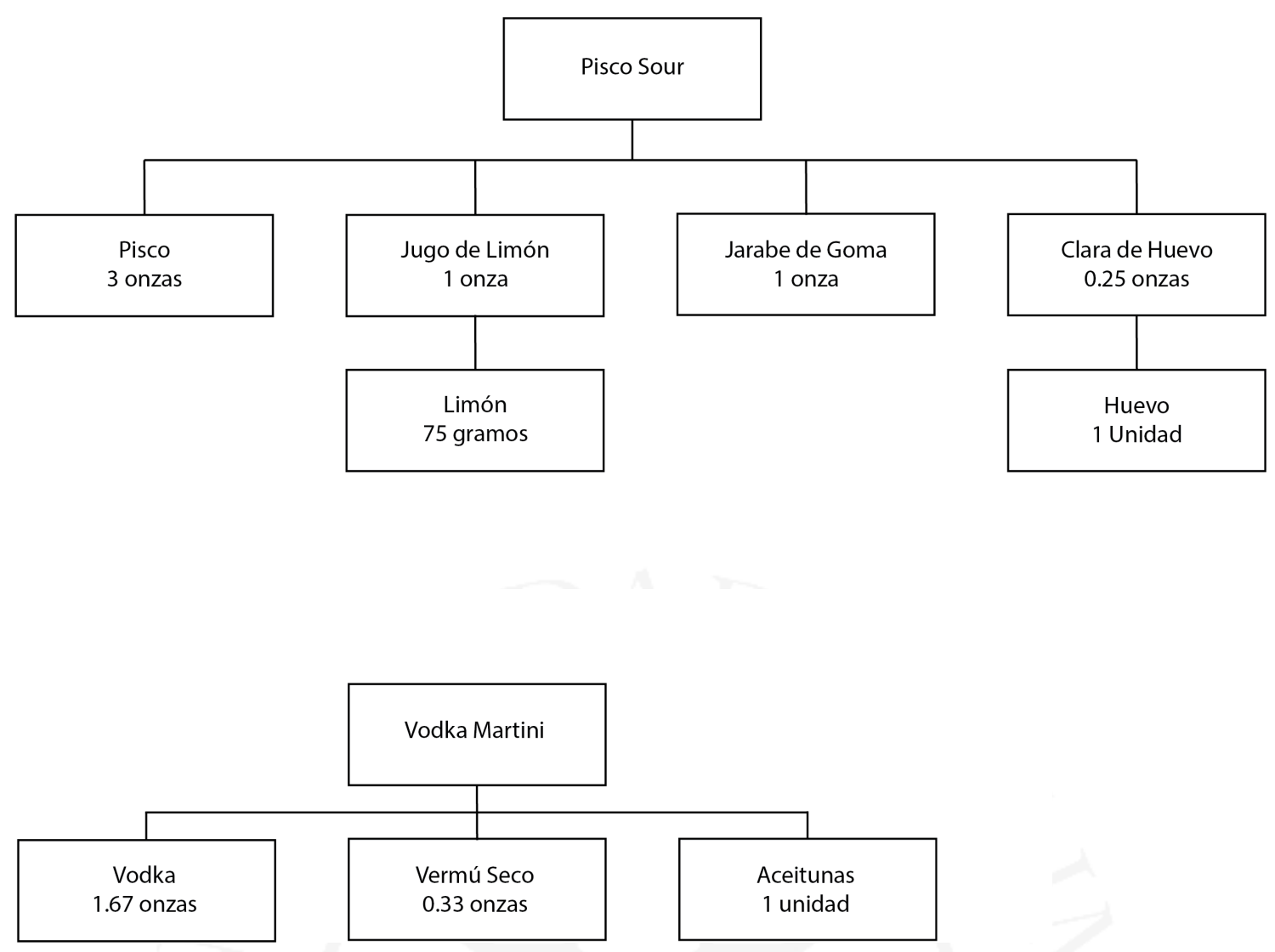